\title{
Evaluating Work-Related Risk Factors Associated with Low Back Disorders in the Roofing Industry
}

Di Wang

Follow this and additional works at: https://researchrepository.wvu.edu/etd

\section{Recommended Citation}

Wang, Di, "Evaluating Work-Related Risk Factors Associated with Low Back Disorders in the Roofing Industry" (2015). Graduate Theses, Dissertations, and Problem Reports. 6903.

https://researchrepository.wvu.edu/etd/6903

This Thesis is protected by copyright and/or related rights. It has been brought to you by the The Research Repository @ WVU with permission from the rights-holder(s). You are free to use this Thesis in any way that is permitted by the copyright and related rights legislation that applies to your use. For other uses you must obtain permission from the rights-holder(s) directly, unless additional rights are indicated by a Creative Commons license in the record and/ or on the work itself. This Thesis has been accepted for inclusion in WVU Graduate Theses, Dissertations, and Problem Reports collection by an authorized administrator of The Research Repository @ WVU. For more information, please contact researchrepository@mail.wvu.edu. 


\title{
Evaluating Work-Related Risk Factors Associated with Low Back Disorders in the Roofing Industry
}

\section{Di Wang}

Thesis submitted

to the Benjamin M. Statler College of Engineering and Mineral Resources at West Virginia University

in partial fulfillment of the requirements for the degree of

\author{
Master of Science in Engineering
}

Fei Dai, Ph. D., Chair

Radhey Sharma, Ph. D.

Roger Chen, Ph.D.

Xiaopeng Ning, Ph.D.

Department of Civil and Environmental Engineering

Morgantown, West Virginia

2015

Keywords: Factorial Experiment, Roofing Activities, Risk Assessment, Low Back Pain, Trunk Flexion 


\section{ABSTRACT \\ Evaluating Work-Related Risk Factors Associated with Low Back Disorders in the Roofing Industry}

\section{Di Wang}

Roofers have long suffered from low back disorders (LBDs), which is a primary non-fatal injury in construction. The harsh work environment exposes the roofers to a diversity of physical exposures which may cause severe LBD injuries. Until now, most of research on roofing safety has been mainly focused on fatal injury risks, such as falls from height, leaving much to be desired in the risk assessment of non-fatal, cumulative musculoskeletal disorders among this population. Existing ergonomics studies have identified several physical risk factors associated with LBDs in workplaces and developed predictive models for general LBD risk assessments. However, these models cannot be directly used for assessments in roof workplaces because they are designed for general tasks without considering the variance of roofer working postures and the effects of working on slanted ground surfaces (i.e., rooftops).

The objective of this thesis study is to understand the relationship between the roofing work-related risk factors and the LBD risks during the performance of roof shingle installation. The roofing work-related risk factors comprise slope angles, postures, facing directions, and working pace. An in-lab factorial experiment is conducted with the aid of Vicon and Electromyography (EMG) sensors. The trunk flexion angle and muscle activities in the low back are measured as indicators, which are then analyzed to implicate the LBD risk.

The experiment results revealed the risk factors with significant effects on the LBD development. Also, this study uncovered the relationships between trunk flexion angles, muscle activities and combinations of different risk factors. This knowledge will be useful for better understanding and education of roofing non-fatal LBD development in the industry and the research community. This knowledge may also have the potential for development of detailed safety guidelines and interventions for the LBD injury prevention among the roofer population. 


\section{ACKNOWLEDGEMENTS}

Firstly, I would like to thank my advisor, Prof. Fei Dai, for his encouragement, guidance, and continuous support to my Master's study and related research. His advices helped me through the entire process of research and writing of this thesis.

I would also like to thank the rest of my thesis committee: Prof. Radhey Sharma, Prof. Roger Chen, and Prof. Xiaopeng Ning, not only for their encouragement, but also for the hard questions which inspired me to widen my research and think out of the box.

My research work on construction safety is in interdisciplinary nature, which involves knowledge of construction management, ergonomics, and sensing technologies. I especially thank Prof. Xiaopeng Ning, who granted me access to the Industrial Ergonomics Laboratory. He and Prof. Dai have been continuously providing their valuable comments and guidance throughout my thesis study. In addition, I appreciate the help of Mr. Boyi Hu in improving the quality of my thesis study.

I thank all the participants of the experiment for their precious time and cooperation. I thank my office mates for their thought-provoking discussions, for the sleepless nights we had at school, and for the happiness and unhappiness we shared. I thank my parents for giving birth to me. In particular, I am grateful to Ye Tao, who has been always in the company and reshaping my life since we met. 


\section{TABLE OF CONTENTS}

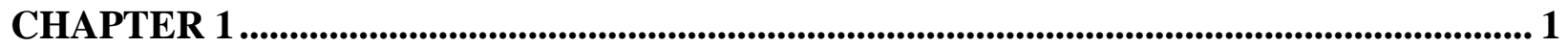

INTRODUCTION

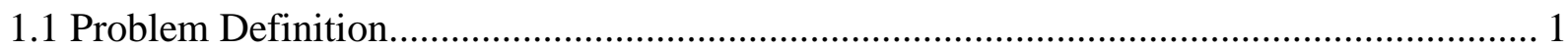

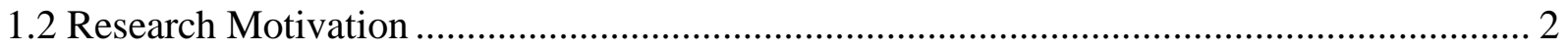

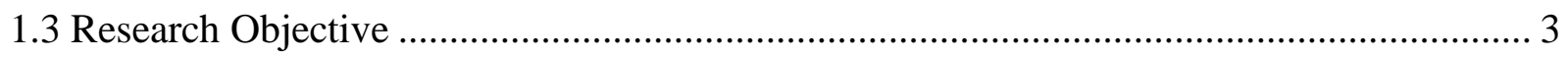

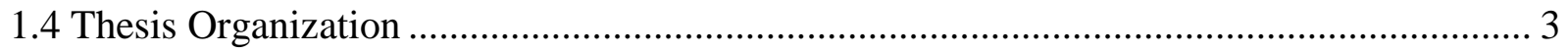

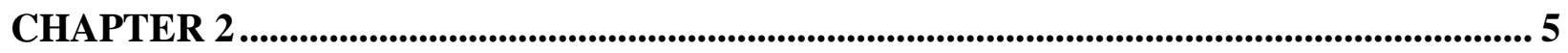

SEVERITY OF LOW BACK DISORDERS IN THE ROOFING INDUSTRY .................... 5

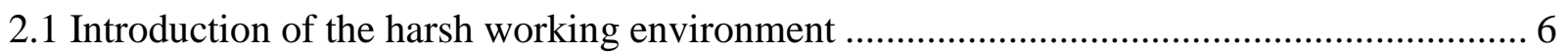

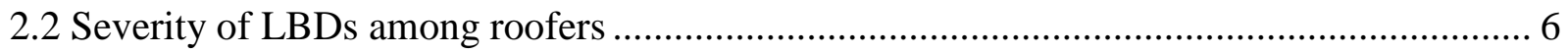

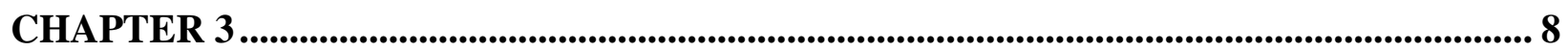

STATE OF PRACTICE AND RESEARCH ................................................................................... 8

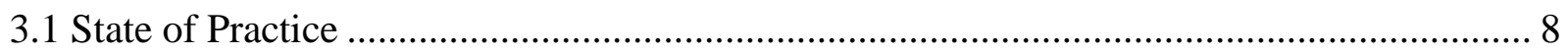

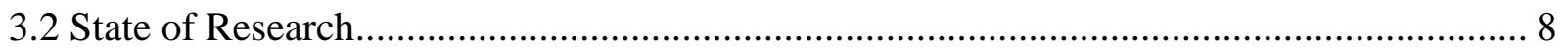

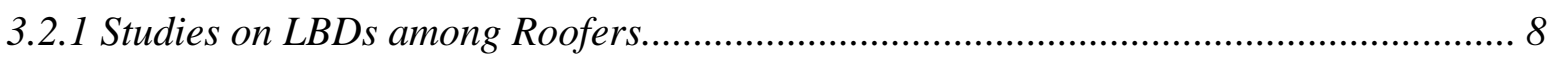

3.2.2 Work Related LBD Risk Factors in Roofing Activities ............................................. 10

CHAPTER 4 ...................................................................................................................................... 14

LBD RISK ASSESSMENT METHODS........................................................................................ 14

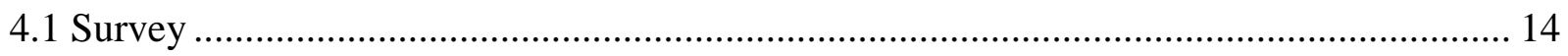

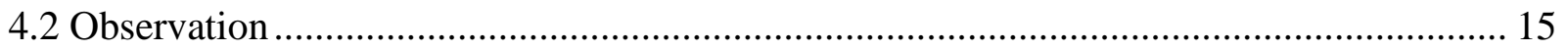

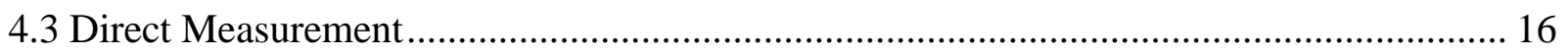

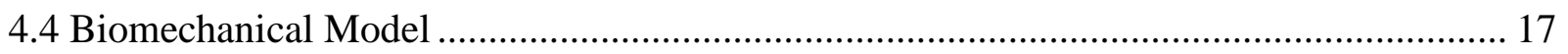

4.5 Selection of Risk Assessment Methods .......................................................................... 18

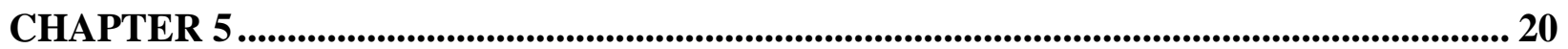

EXPERIMENT DESIGN AND IMPLEMENTATION ........................................................... 20

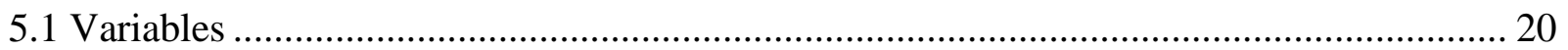

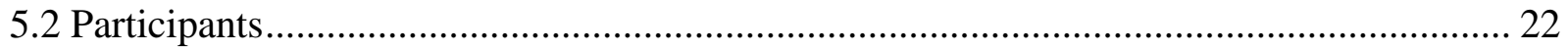

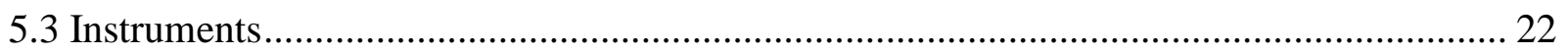

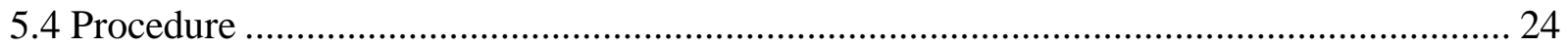

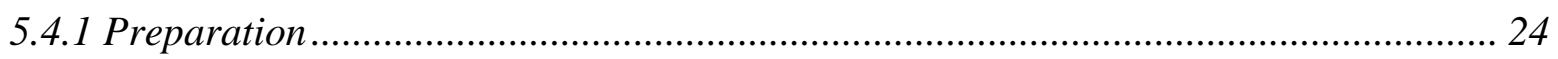

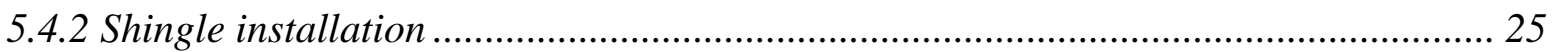




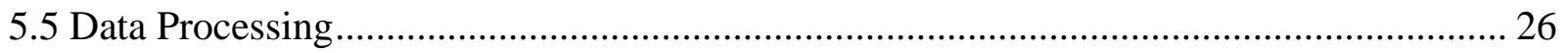

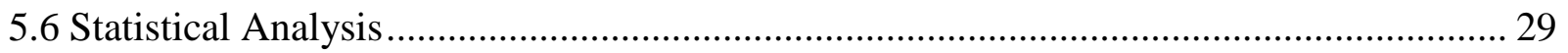

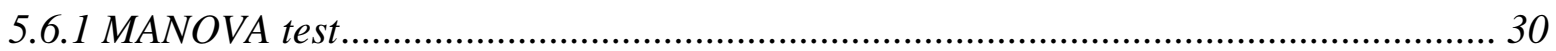

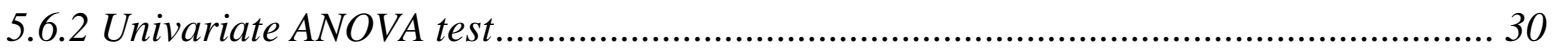

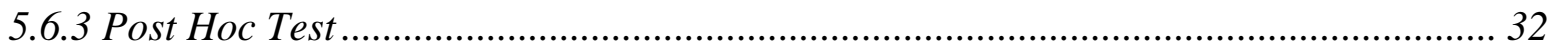

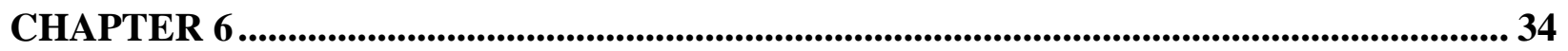

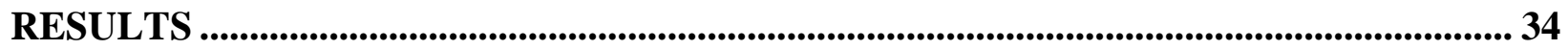

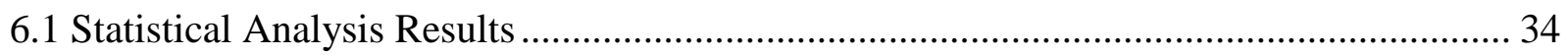

6.2 Stooped Postures................................................................................................... 37

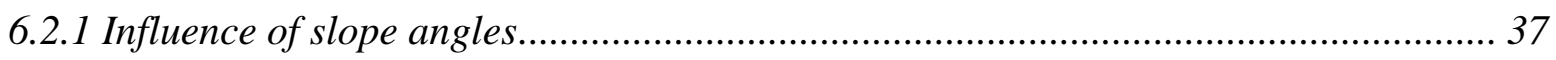

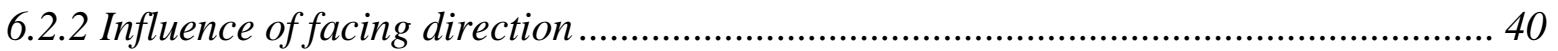

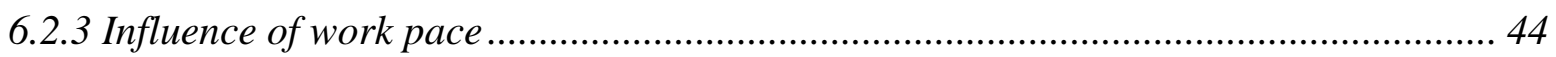

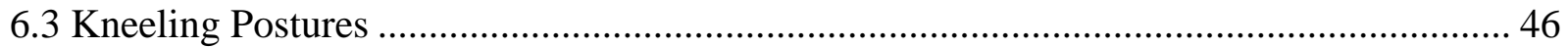

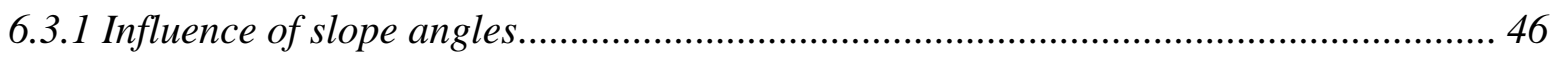

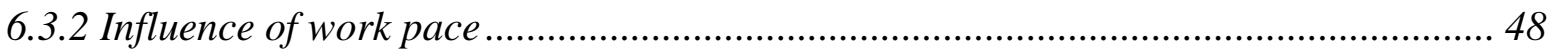

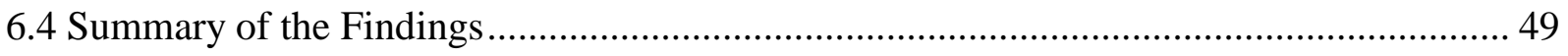

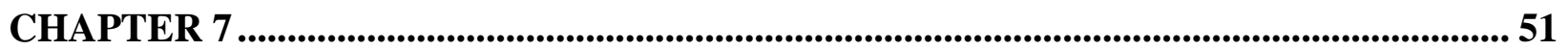

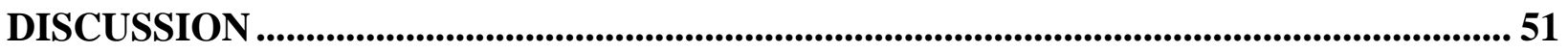

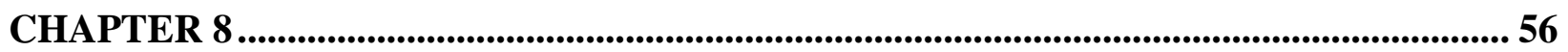

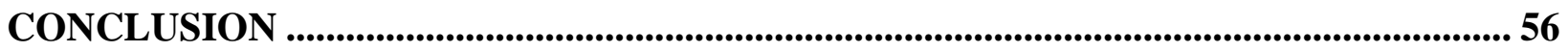

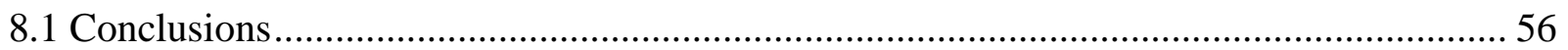

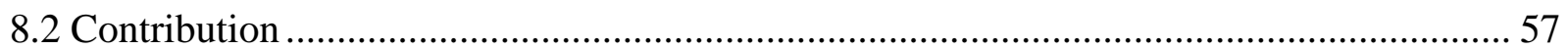

APPENDIX I: EMG and VICON Data Processing Code (MATLAB R2013a)....................... 75

APPENDIX II: Survey Form of LBD Study on Roofing Activities ........................................ 79

APPENDIX III: Trunk Flexion Angle and Normalized EMG data (15 Subjects) .................... 80 


\section{LIST OF TABLES}

Table 1: An overview of LBD risk assessment methods (adapted from [Wang et al. 2015a])

Table 2: MANOVA and ANOVA results for trunk flexion angle and EMG (stooped): statistical significance and interactions of the factors (left and right sides combined)

Table 3: MANOVA and ANOVA results for trunk flexion angle and EMG (kneeling): statistical significance and interactions of the factors (left and right sides combined)

Table 4: The mean (SD) values of dependent variables at different independent variable levels (ESl, ESr, MUl and MUr refer to left erector spinae, right erector spinae, left multifidus and right multifidus respectively) (Stooped)

Table 5: The mean (SD) values of dependent variables at different independent variable levels (ESl, ESr, MUl and MUr refer to left erector spinae, right erector spinae, left multifidus and right multifidus respectively) (Kneeling) 


\section{LIST OF FIGURES}

Figure 1: a) Stooped posture in roofing; b) Kneeling posture in roofing $\quad$...................11

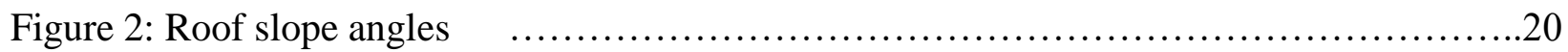

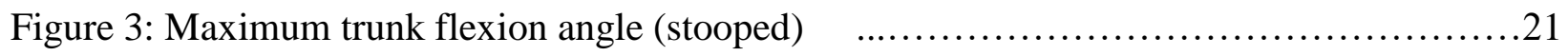

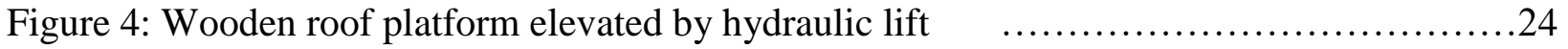

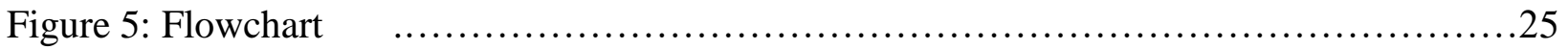

Figure 6: A time series trunk-angle plot of shingle installation process (stooped) …........27

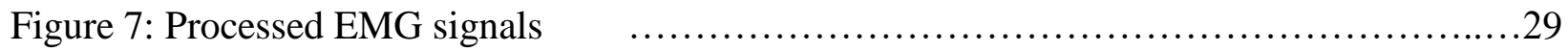

Figure 8: Effects of slope angles on maximum trunk flexion angle (Stooped) $\quad$...............38

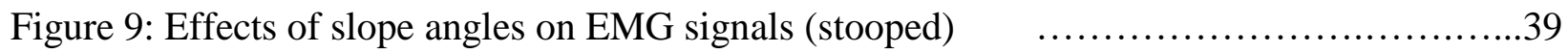

Figure 10: Effects of facing directions on maximum trunk flexion angle (stooped) $\quad$..........40

Figure 11: Effects of facing directions at each slope level (Stooped) $\quad$...................41

Figure 12: Time series plot of maximum trunk flexion angle for facing sideways $\quad$............42

Figure 13: Time series plot of maximum trunk flexion angle for facing uphill $\quad$.............42

Figure 14: Effects of work pace on EMG signals (Stooped) $\quad$...........................45

Figure 15: Effects of slope angle on maximum trunk flexion angle (Kneeling) $\quad$............47

Figure 16: Effects of slope angles on EMG signals (Kneeling) $\quad$...........................

Figure 17: Effects of work pace on EMG signals (Kneeling) $\quad$...........................49 


\section{CHAPTER 1}

\section{INTRODUCTION}

\subsection{Problem Definition}

Low back disorders (LBDs) is a primary non-fatal injury in roofing industry. $31 \%$ (i.e., 3,300 of 10,815) cases of injuries and illnesses for roofers were reported to occur in the trunk (Fredericks et al. 2005). Prolonged bending of the back while installing tile or shingles can cause injuries to muscles, nerves, discs, and ligaments of the low back (Wang et al. 2015a; Choi et al. 2014).

Roofing work has high physical demands. The harsh working environment and task requirements expose the roofers to high LBD risks. It is reported that roofers spend over $60 \%$ of their working hours on rooftops (BLS 2015b; Fredericks et al. 2005). The time roofing workers spent on crawling, squatting, stooping and kneeling is among top 7 of all industrial activities (O*NET 2013). In roofing, shingles are widely used as roof covering materials. Shingle installation, a daily task for roofers, is a time-consuming activity during which lots of injury cases can take place (OSHA 2015; CPWR 2015). Workers who install shingle roofs face LBD hazards from lifting, carrying, stooped postures, and kneeling postures, etc. However, it is difficult to associate a specific event with the LBD injury. LBD is not typically the result of a fall or acute injury, but is a cumulative trauma injury which can be caused by high repetition and overuse of the back (Theodore 1992). Roofers risk developing LBDs due to a diversity of risk factors from the work itself and the work environment. However, without enough knowledge and 
education on the pathology of LBDs, roofers are prone to adapt themselves to the harsh workplace environments (e.g., steep rooftops) and fast work pace at the sacrifice of their own health.

\subsection{Research Motivation}

LBD among roofers are complex due to a number of risk factors involved in the work and working environment. Several main research gaps were identified that need to be bridged before major advances in roofing LBD studies. Firstly, until now, in the roofing industry, it has not been systematically investigated which factors are prone to cause LBDs, let alone the interventions. Secondly, although there are LBD protection guidelines available, they are designed for general industrial tasks (e.g., manual material handling) (Cheung 2007), ignoring the differences of environmental settings, working procedures, job rotations, and alternative postures. Thirdly, the established LBD predictive models, for example, NIOSH lifting equation, are designed for general industrial use. Those models fail to take into account the effects of different roofer working postures (e.g., stooped, kneeling) and working on slanted rooftops. Lastly, the research on roofing safety mainly focuses on fatal injuries, while existing efforts in non-fatal studies focus on the pathology studies.

This thesis study is built on my previous researches during the master study. The manuscript is significantly influenced by Wang et al. 2015a, which revealed the severity of musculoskeletal disorders in construction and reviewed the existing risk assessment methods, and by Wang et al. 2015b, which is a preliminary study on effects of selected roofing activities on LBD incidence by analyzing the muscle activations and trunk motion data. If you want to reuse the figures, tables, and data or so which has been published in the above papers, please refer to UBC (University of British Columbia) library copyright or request permission from 
ASCE JCEM (Journal of Construction Management and Engineering) and put appropriate citations.

\subsection{Research Objective}

The objective of this thesis study is to understand the relationship between the roofing related risk factors (i.e., slope, posture, facing direction, and work pace) and the LBD risks during the performance of roofing tasks. To achieve this, the main risk factors in the roofing shingle installation are first identified. Then, a factorial experiment is designed to study their effects on LBDs, in which advanced motion capture system Vicon and skeletal muscle signal recording system Electromyography (EMG) are utilized to conduct the LBD risk measurements. The experiment is expected to result in findings with respect to how the risk factors affect the LBDs and the risk levels given different work conditions.

The scope of the thesis study is to identify the work-related risk factors with a significant effect on the low back disorder development. The other body parts, such as arms, shoulders and lower extremities, are not included in the analysis.

\subsection{Thesis Organization}

This thesis is organized as follows: First, it reviews the severity of LBDs in the roofing industry. Then, a comprehensive state of practice and research is synthesized in understanding, reducing and preventing LBDs among the roofers. Thirdly, the main existing ergonomic injury risk assessment methods are reviewed with a discussion on their advantages, disadvantages, and applicability. The suitable methods are selected for this experiment. Fourth, the thesis introduces the experiment design and implementation with the aid of Vicon and surface EMG sensors, followed by data analysis and result interpretation. Finally, the findings and limitations of the 
studied are discussed. The conclusion and contribution to the body of knowledge in the roofing industry are also stated. 


\section{CHAPTER 2}

\section{SEVERITY OF LOW BACK DISORDERS IN THE ROOFING INDUSTRY}

Low back disorders (LBDs) are one type of work-related musculoskeletal disorders (WMSDs), which refers to a group of painful disorders of soft tissues developed usually over from highly physical tasks (CCOHS 2013). WMSDs have long been a primary cause of non-fatal injuries in construction. The main causes of most WMSDs are from the everyday work itself and working environment (UWYO 2015, Wang et al. 2015a), either caused by high force during a single event such as lifting, lowering, pulling, and carrying, etc., or resulting from repetitively performing a task (HSE 2014). WMSDs can bring about a large number of injury cases and economic losses to the contractors and the society (WCRC 2012).

The back is the primary body part affected by WMSDs in construction with a significant proportion of 58\% in 2003 and 45\% in 2010 (CPWR 2013b). Concluding from statistics of all private industries in the state of West Virginia, the incidence rate of pain in the trunk (mostly in the back) is much higher than that in other body parts (i.e., 5 times that of the second - shoulder) (BLS 2013d; Wang et al. 2015a). Roofers are a primary construction workforce and it is reported that this population suffers from the $2^{\text {nd }}$ highest WMSD incidence rate along with a high back injury rate. Then, the harsh roofing working environment involved with severe LBD exposures is introduced, followed by the highlighting of the severity of LBD in the roofing industry. 


\subsection{Introduction of the harsh working environment}

In the United States, there was a total of approximately 132,700 workers employed in 2012 as roofers whose main jobs included repair and installation of roofs using shingles, asphalt, metal, and solar panels, etc. (BLS 2015a). Roofing work can be categorized into commercial roofing on low-pitch roofs (below $\left.10^{\circ}\right)$ and residential roofing on a relatively steep roof $\left(10^{\circ} \sim 45^{\circ}\right)$ (NCINC 2015).

The roofing contractors' job is strenuous and physically demanding, which requires longtime stooping, kneeling, lifting, twisting, and drilling (BLS 2015a). Shingles are the typical roof covering material, which can be made of wood, slate, flagstone, fiber cement, metal, plastic, and composite material such as asphalt shingles (Kang et al. 2008). According to a survey conducted among roofers (Fredericks et al. 2005), roofers spent $61 \%$ of their time on roofs and typically spend 3-4 hours daily on manual lifting/carrying. The time roofing workers spent crawling, squatting, stooping and kneeling is among top 7 of all industrial activities $(\mathrm{O} * \mathrm{NET}$ 2013). The cumulative effects of stooping, kneeling, or squatting may lead to lower back pains, and also can increase forces in the knee (CPWR 2015).

\subsection{Severity of LBDs among roofers}

Roofers engage in many activities that may expose them to not only fatal hazards, such as falling from rooftops, unguarded machinery, being struck by heavy construction equipment, but also non-fatal occupational hazards, including LBD risks.

Roofers are at a greater risk of slipping or falling from scaffolds, ladders, or roofs (Choi and Fredericks 2008). The number of fatalities was increasing during construction in the United States with roofers between 1992 and 2001. Roofers are six times more likely to get fatal injuries than average workers (BLS 2004). In addition, typical injuries caused by roof work are 
extremely severe, which requires long periods of treatment and recovery and resulting in substantial medical costs and lost work time (Gillen et al. 1997).

Occupational non-fatal injuries take place more often and are extremely difficult to prevent (CPWR 2015). Although the daily physical demanding operations, such as manual material handling and lifting, would not cause acute pain shortly, high repetition could cause the stresses to accumulate on the musculoskeletal system in the back and expose workers to nonfatal occupational injury like LBDs (David 2005).

Low back disorder occurs in the lumbar spine and its surrounding structures, which are commonly referred as the low back region (NINDS 2014). LBD can be either acute or chronic. It is reported that about $80 \%$ of adults have experienced low back pain during their lifetimes (NIH 2015). Low back pain is reported to a main cause of job-related disability, missed work days and an inability to stand upright (PHC4 2015). LBD causes up to 240 million days away from work per year (Gilkey et al. 2007). Back injuries account for half of WMSDs in all body parts that result in days away from work (CPWR 2013b). Occupational LBDs account for 34\% of all workrelated injury and illness cost (Meyers et al. 2004). Its estimated costs were US $\$ 49$ billion annually in 1992 (Leigh et al. 1997).

LBDs in roofing are causing tremendous economic loss and productivity loss. Wang et al. (2015a) reported that, among all construction activities, roofing workers have one of the highest WMSD incidence rate (i.e., 50.7 per 10,000 full worker year) (BLS 2013a), and it is only second to flooring workers. The rate of nonfatal injuries and illnesses involving days away from work of roofers is 209.4 per 10,000 FTEs which is above the average level of all construction (CPWR 2015). 


\section{CHAPTER 3}

\section{STATE OF PRACTICE AND RESEARCH}

\subsection{State of Practice}

Ergonomics studies the human working efficiency and safety issues in their working environment (Wang et al. 2015; UMLHE 2000). Construction ergonomics practices include general guidelines promoted by NIOSH and OSHA which are designed to bring under the overall occupational injury rate in the industry. In addition, generic causes of LBD hazards are documented.

In terms of specified practices for LBD prevention among roofers, ISHA suggests that when stripping and removing materials from roofs, use upright scraping tools whenever possible, to provide mechanical leverage and reduce the need to bend (IHSA 2013). ISHA (2010) also recommend avoiding working on the floor, which can result in injuries to the back, hips, and knees. Instead, it suggests to increase the work height by using a workbench.

\subsection{State of Research}

\subsubsection{Studies on LBDs among Roofers}

The implemented roofing fatal injury studies (e.g., fall, slips) covered a diversity of aspects including risk assessment, communication, and prevention (Hisao 2014). In 
contrast, the studies of non-fatal injuries in roofing activities mainly focus on surveillance and pathology at present.

The existing LBD studies in roofing industry are conducted with an emphasis on the nature, severity and causes of LBD, with the aid of surveys and observations. Hunting et al. (2004) have conducted a survey study on injuries among construction workers. It is found that half of non-fatal injuries among the roofers are in the back and most non-fatal cases are caused by overexertion, strenuous movement and high repetition. Fredericks et al. (2005) has analyzed the U.S. Bureau of Labor Statistics (BLS) data in roofing and has revealed the primary source of injuries among roofers is motion/position, which is associated with body postures and repetitive motions (Wang et al. $2015 \mathrm{a}, \mathrm{b}$ ).

Another study reported that WMSD are the most common injuries and health problems in roofing activities that force roofers into early retirement. Sixty percent of roofers who exited the trade within one year left their jobs due to chronic pain, workrelated musculoskeletal disorders, and poor health (Welch et al. 2010).

A survey study among Latino residential roofing workers showed that they value productivity over safety and reduce their use of personal protective equipment (PPE) when they feel that it reduces productivity and when it is uncomfortable (Arcury et al., 2013). The weak safety belief can have a negative influence on injury risk. It is reported that Hispanic roofers have both a higher non-fatal injury rate and a higher fatal injury incidence rate than white and non-Hispanic (Dong et al. 2010a, b).

There are also some recommended exercises to help prevent LBD injury. A study done by Hayden et al (2015) showed that a supervised stretching (and exercise) program 
may reduce lower back pain. The exercise therapies in chronic low back pain were also reviewed in their study.

\subsubsection{Work Related LBD Risk Factors in Roofing Activities}

Decades of research have identified a potential link between certain physical workplace factors and LBD risk. A review by the National Institute for Occupational Safety and Health (NIOSH) of epidemiological (Putz-Anderson 1997) found evidence for an association between LBDs and heavy physical work, lifting and forceful movements, bending and twisting (awkward postures), and whole-body vibration (Wang et al. $2015 \mathrm{a}$, b).

The potential LBD risk factors are identified through roofing site visits, online video observations and the literature review. The typical work-related risk factors in the roofing shingle installation can be summarized as: slope angle, work pace, facing direction, and posture. Existing literature indicates a potential relationship between these factors and the LBD risk. For example, it is found that a reduced postural balance is observed as the slopes increase (Choi et al. 2008). Details about these factors are discussed below.

\section{I) Stooped vs. Kneeling Postures}

Stooped postures are put into common use at workplaces in agriculture, construction, mining, and other industries (Parekh and Phatak 2014). It is found that in agricultural activities, work requiring stooped postures has a strong association with high LBD incidence. For working at low levels, kneeling and squatting are often adopted to avoid severe bending (Fathallah et al. 2004). Studies demonstrate that there are good biomechanical reasons to view these postures as significant contributors to low back 
pains (Jin et al. 2009). During a one-year low back pain study among 1773 construction workers, a dose-response relationship was found between severe low back pain and either stooping or kneeling (Holmström et al. 1992).

Through the review of literature, survey and on-site observations, roofers are typically involved with two main postures in shingle installation: stooped and kneeling. Roofers can use different working postures due to personal preference. Stooped posture,

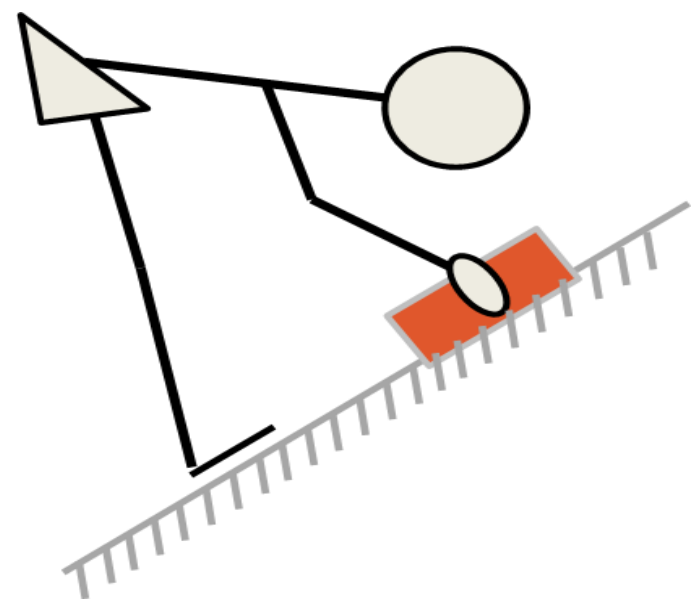

Figure 1 (a): Stooped posture in roofing

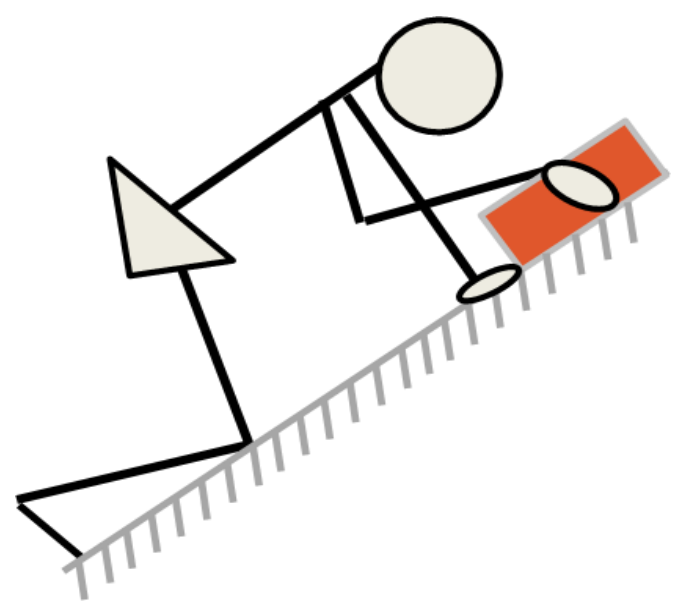

which requires the roofers to bend forward while holding their legs straight, is illustrated in Figure 1(a). In contrast, kneeling typically requires the workers to kneel on the roof and maintain trunk in parallel to the roof (Figure 1(b)). However, the existing risk assessment methods do not include any information regarding the relationship between injuries and stooping or/and kneeling. The LBD risk of each posture in the roofers' working environment is not well studied. Therefore, reducing the incidence of LBDs among roofers requires a new focus on identifying and describing stooped and kneeling postures as specific LBD risk factors in the workplace (Fathallah et al. 2004).

\section{II) Roof Slope}


The residential slope can vary from $12^{\circ} \sim 40^{\circ}$ (NCINC 2015). There is a study on fall from the roof with slope degree and maximum frequency (Choi et al. 2008). The purpose of this study was to investigate the influence of surface slopes $\left(18^{\circ}, 26^{\circ}, 34^{\circ}\right)$ on the shingling frequency and postural balance of males performing a simulated roofshingling task. Maximum Acceptable Roof Shingling Frequency (MARSF) was recorded during the experiment. It was reported that the average MARSF at $18^{\circ}$ slope was 206 shingles per hour, while that at the $26^{\circ}$ and $34^{\circ}$ slopes were 195 and 168 shingles $/ \mathrm{h}$, respectively. This finding indicates a reduced postural balance at steep slopes (Wang et al. $2015 \mathrm{a}, \mathrm{b})$.

\section{III) Facing Direction}

Based on the online video search and on-site observation, it is noted that different roofing materials can have different installation methods on rooftops (NINDS 2014). For three- or four-tab residential shingles, roofers often install them parallel to the ridge, which requires the roofers to stand facing uphill. For solar panels, it is found through video observation that the roofers often stand perpendicularly to the ridge while installing them in order to avoid stepping on these panels.

In addition, in the recent ergonomics study, it is found that manual handling of sudden loading on uneven surface can have a significant difference from on the ground in terms of LBD risk (Zhou et al. 2015), which provokes the needs for studies on jobs conducted on uneven surfaces such as roofs. Moreover, the symmetry was detected during bending on uneven slopes (Hu et al. 2013; Ning et al. 2011). A displacement of the $\mathrm{C} 7$ joint (in the neck area) to the upper edge of the slope was found when bending on uneven slopes than on the flat ground. It showed that people tend to incline to upper edge 
when standing and bending on uneven slopes. Also, the left-sided and right-sided lumbar muscles were reported to have different tensions and non-simultaneous cessation of muscle activities. These findings indicate that different facing directions can have different bending motions which can bring about different trunk flexions and muscle activities (Wang et al. $2015 \mathrm{a}, \mathrm{b}$ ).

\section{IV) Work Pace}

Dai et al. (2010) have reported that the horizontal load speed can have a significant on the spinal loadings. A deeper flexion and higher muscle activations were found in fast manual materials handling and lifting. Whether this finding applies to roofing shingle installation process is unknown. The reported frequencies in (Choi et al. 2008) will be used as benchmark for the design of frequency levels in this study. 


\section{CHAPTER 4}

\section{LBD RISK ASSESSMENT METHODS}

Epidemiological studies have identified certain physical risk factors for LBDs in workplaces and some predictive models are developed based on the selected factors. However, the models cannot be directly used for roofing activities due to dissimilarity in the survey sample that determines the coefficients and also, these selected risk factors need modification before applying to roofing tasks. To be specific, these models do not take into account roofer working postures (e.g., stooped, kneeling) and slanted rooftops. Through the literature review and the site observation, the main risk factors in roofing tasks are identified and summarized as work pace, facing direction, posture, and slope angle (Wang et al. $2015 \mathrm{a}, \mathrm{b}$ ).

However, in order to evaluate these risk factors, an appropriate risk assessment method needs to be selected. The existing WMSD assessment tools are reviewed and evaluated based on the needs of the planned LBD study. Table 1 (adapted from [Wang et al. 2015a]) provides a summary of the risk assessment methods in terms of their principle, applicability, pros, and cons, etc. Appropriate methods are selected after a follow-up discussion in terms of their suitability.

\subsection{Survey}

Self-report is widely applied in studies because it is inexpensive, easy to conduct, applicable to the large population. However, self-report requires the workers to stop the 
ongoing works and spend time to answer the questions or fill in the questionnaires. Wang et al. (2015) reviewed a number of wide-used non-fatal injury survey tools, the Nordic Musculoskeletal Questionnaire (Kuorinka et al. 1987; Aarås et al. 1998; Kucera et al. 2009; Reme et al. 2012), Task Analysis (Silverstein 1985), internet survey, recorded videos and video conferences (HSE 2014) (Wang et al. $2015 \mathrm{a}, \mathrm{b}$ ).

There is a series of survey work on roofers' nonfatal injury for diagnosis of LBD nature and injury formation (GMU 2015; IN 2008). The advantage of the self - report method is that a large number of workers can report issues and problems that are difficult to observe (e.g., pain and perceived workload), and this method is cost-effective and applicable to a wide range of occupations. The downside of the self-report method is that the results are based on subjective assessment and thus can vary significantly among individuals. Also, the survey responses can be biased due to personal implications, undermining the reliability of these methods in comparison to other methods such as direct measurement and advanced sensing techniques (Spielholz et al. 2001; Jones and Kumar 2010).

This study has conducted surveys (APPENDIX II) among the participants to rate and report discomfort on lower back and other body parts on different working conditions.

\subsection{Observation}

Observation is a systematic recording of postures at workplace (i.e., region, frequency, severity, duration) (David 2005). There are a large number of observational tools developed for industrial use featuring postural loading assessment tools. The OWAS, PATH evaluated the WMSD risk level of different body segments (back, arms, and legs) by assessing postures of workers during their task performance. A whole body 
postural analysis tool called Rapid Entire Body Assessment (REBA) was developed to mainly analyze unpredictable working postures detected in the health care and service industries (Hignett and McAtamney 2000). These observational tools have less interference with worker task performance and are cost effective as minimal instrumentation is required. Therefore, observations are widely used in field studies. However, observational tools rely on experts' visit and sometimes the evaluation is subjective and has large inter-rater differences. Besides, the limitation is that the assessment cannot be performed continuously and only a limited number of jobs can be assessed during the experts' visit.

In this experiment, the observational study is conducted to assess the postural loading of lower extremities (i.e., legs, ankles) of two postures to reveal the difference.

\subsection{Direct Measurement}

Direct measurement is often used to assist or replace expert observation as it provides higher accuracy and repeatable measurements. When conducting direct measurement, markers or sensors are directly attached onto the human body (skin or clothes) to record human location, body segment 3D motions, muscle activities, and heart beat etc. Electromyography (EMG), optical markers, goniometers, inclinometers, optical scanners, and sonic sensors which are frequently used in direct measurement to analyze biomechanics and tissue and joint loading (CPWR 2013a). Among them, EMG is mainly applied in studying muscle exertions by attaching a group of sensors on the skin over the sampling muscles (Ning and Mirka 2010, Ning et al. 2014; Marras and Granata 1997a,b). It records myoelectric signals, and is widely used to evaluate muscle tension and muscle fatigue (Ning 2011; Nimbarte et al. 2014; David 2005). 
Various optical-marker-based direct measurement methods are commercially available such as Vicon, APAS (2014), CODA, Motion Analysis, and Qualisys. Threedimensional (3D) coordinates of all body markers can be recorded in real time using dedicated computing algorithms to track the position and angular movement of different body segments ( $\mathrm{Li}$ and Buckle 1999). The kinematics data will then be combined with muscle EMG data to estimate muscle and joint loadings using biomechanical models (Lloyd and Besier 2003; Wang et al. 2015 a, b).

\subsection{Biomechanical Model}

Those models are prototypes that model reality activities and assignment weights to different risk factors. Below are several examples of the well-known tools associated with trunk loadings. The NIOSH Lifting Equation is designed assess the manual material handling risks during lifting and lowering tasks in the workplace by occupational health professionals. This equation records certain job task variables to evaluate the risk of the lifting practices. It can be used to estimate the recommended weight to be lifted. Besides, 4D WATBAK is a biomechanical modelling tool which can be used to estimate both acute and cumulative loads at main body joints (4D WATBAK). It can be used to estimate the risk of injury associated with a variety of occupational actions, including pushing, pulling, lifting, lowering, holding, carrying, etc. The development of biomechanical modeling to the back has made it possible to assess spine loading using remote sensing method (Ning and Guo 2013). Nowadays, biomechanical models are usually applied for post-processing of human motion data collected by direct measurement or remote sensing methods. But it highly relies on the accuracy and processing efficiency of the captured sensing data (Wang et al. $2015 \mathrm{a}, \mathrm{b}$ ). 


\subsection{Selection of Risk Assessment Methods}

In the thesis study, LBD risk assessment methods are selected for data collection and analysis. Vicon is reported to have an accurate localization and tracking of the multiple joints and segments, which can be used accurately and continuously to calculate the joint angles. EMG is a well-established muscle sensor which can be used to measure the muscle activity, fatigue, and muscle utilization patterns. Specifically for our LBD study, the Vicon system is utilized to record trunk angle data, and EMG can be used to accurately and reliably record the muscle signals of the back muscles. Also, the video observation is applied to measure the postural loading of the lower extremities in kneeling and stooped postures. The survey is conducted to record the perceived discomfort in the back and other body parts (Wang et al. $2015 \mathrm{a}, \mathrm{b}$ ). 
Table 1: An overview of LBD risk assessment methods (adapted from [Wang et al.

2015a])

\begin{tabular}{|c|c|c|c|c|c|}
\hline Methods & Principle & Example & Pros & Cons & Applicability \\
\hline Survey & $\begin{array}{l}\text { Self-reported } \\
\text { approach to help } \\
\text { diagnose pain }\end{array}$ & $\begin{array}{l}\text { Questionnaire } \\
\text { (Spielholz et al. } \\
\text { 2001); interview } \\
\text { (Dane et al. } \\
\text { 2002); }\end{array}$ & $\begin{array}{l}\text { Efficient and } \\
\text { cost-effective }\end{array}$ & $\begin{array}{l}\text { Imprecise } \\
\text { perceptions; } \\
\text { personal } \\
\text { implications }\end{array}$ & $\begin{array}{l}\text { Easy to } \\
\text { implement }\end{array}$ \\
\hline $\begin{array}{l}\text { Observati } \\
\text { on }\end{array}$ & $\begin{array}{l}\text { Systematically } \\
\text { records awkward } \\
\text { postures and } \\
\text { evaluate risk }\end{array}$ & PATH, REBA & $\begin{array}{l}\text { Inexpensive; } \\
\text { minimal } \\
\text { disturbance }\end{array}$ & $\begin{array}{l}\text { Expert required, } \\
\text { inter-rater } \\
\text { difference }\end{array}$ & Site visit \\
\hline $\begin{array}{l}\text { Direct } \\
\text { measurem } \\
\text { ent }\end{array}$ & $\begin{array}{l}\text { Directly attach } \\
\text { sensors on the } \\
\text { human body to } \\
\text { capture movement or } \\
\text { muscle activities }\end{array}$ & EMG, Vicon & $\begin{array}{l}\text { Accurate and } \\
\text { various } \\
\text { exposure data } \\
\text { collection }\end{array}$ & $\begin{array}{l}\text { Markers attached } \\
\text { directly and } \\
\text { tightly on the skin }\end{array}$ & $\begin{array}{l}\text { Short and } \\
\text { repetitive } \\
\text { movements }\end{array}$ \\
\hline $\begin{array}{l}\text { Predictive/ } \\
\text { Biomecha } \\
\text { nical } \\
\text { model }\end{array}$ & $\begin{array}{l}\text { Measure the risk as a } \\
\text { weighted sum or } \\
\text { formula of selected } \\
\text { risk factors, e.g., } \\
\text { load, posture, } \\
\text { distance, etc. }\end{array}$ & $\begin{array}{l}\text { Utah lifting } \\
\text { index, NIOSH } \\
\text { lifting equation, } \\
\text { Open-Sim, } \\
\text { 4D Watbak }\end{array}$ & $\begin{array}{l}\text { Flexibility, can } \\
\text { be used to } \\
\text { simulate } \\
\text { extreme } \\
\text { conditions }\end{array}$ & $\begin{array}{l}\text { Rely on accurate } \\
\text { and complex } \\
\text { measurement of } \\
\text { parameters } \\
\text { defined by the } \\
\text { model }\end{array}$ & $\begin{array}{l}\text { Manual } \\
\text { handling and } \\
\text { lifting; large } \\
\text { data collection }\end{array}$ \\
\hline
\end{tabular}




\section{CHAPTER 5}

\section{EXPERIMENT DESIGN AND IMPLEMENTATION}

The shingle installation process was selected as the task to be simulated in lab considering that it is a primary roofing task and requires constant bending. The purpose was to understand the relationship between the selected risk factors (i.e., roof slope, posture, facing direction, and work pace) and LBDs among roofers. To this end, a factorial experiment was conducted, in which the selected ergonomic risk assessment techniques were utilized to capture the dependent variables for estimating the LBD risk in different work conditions (Wang et al. 2015b).

\subsection{Variables}

Four risk factors (independent variables) are evaluated in the experiment: 1) Slope: $0^{\circ}, 15^{\circ}, 30^{\circ}$, as denoted in Figure 2; 2) Posture: stooped and kneeling, as denoted in

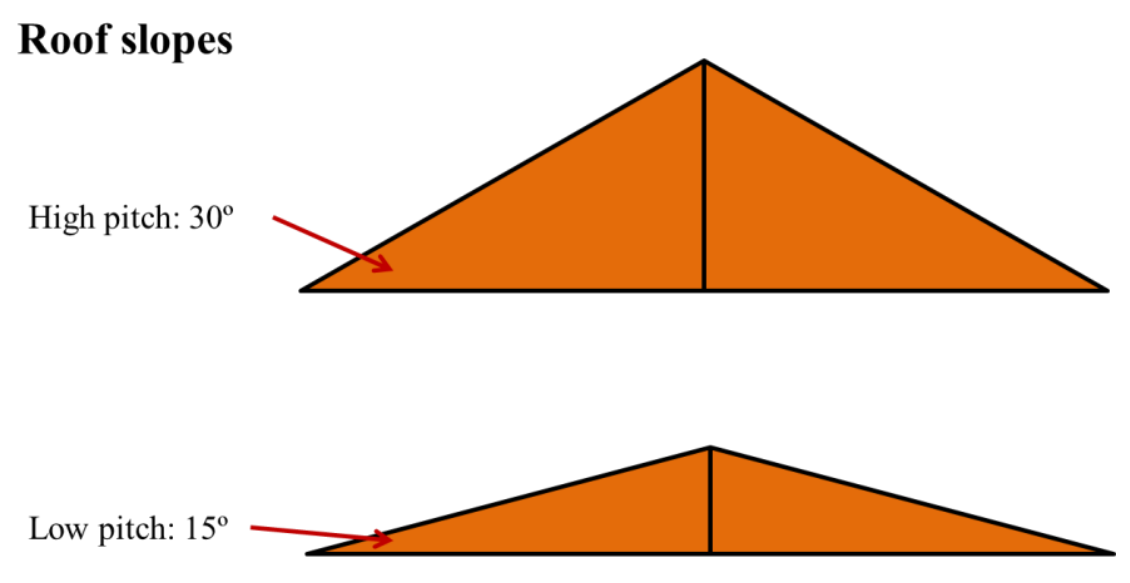

Flat: $0^{\circ}$ 
Figure 1; 3) Facing direction: uphill and sideways; 4) Frequency: slow (12 seconds/shingle), fast (6 seconds/shingle). The frequency is set according to site observations and studies on maximum acceptable working frequency on roof slopes (Choi et al. 2008).

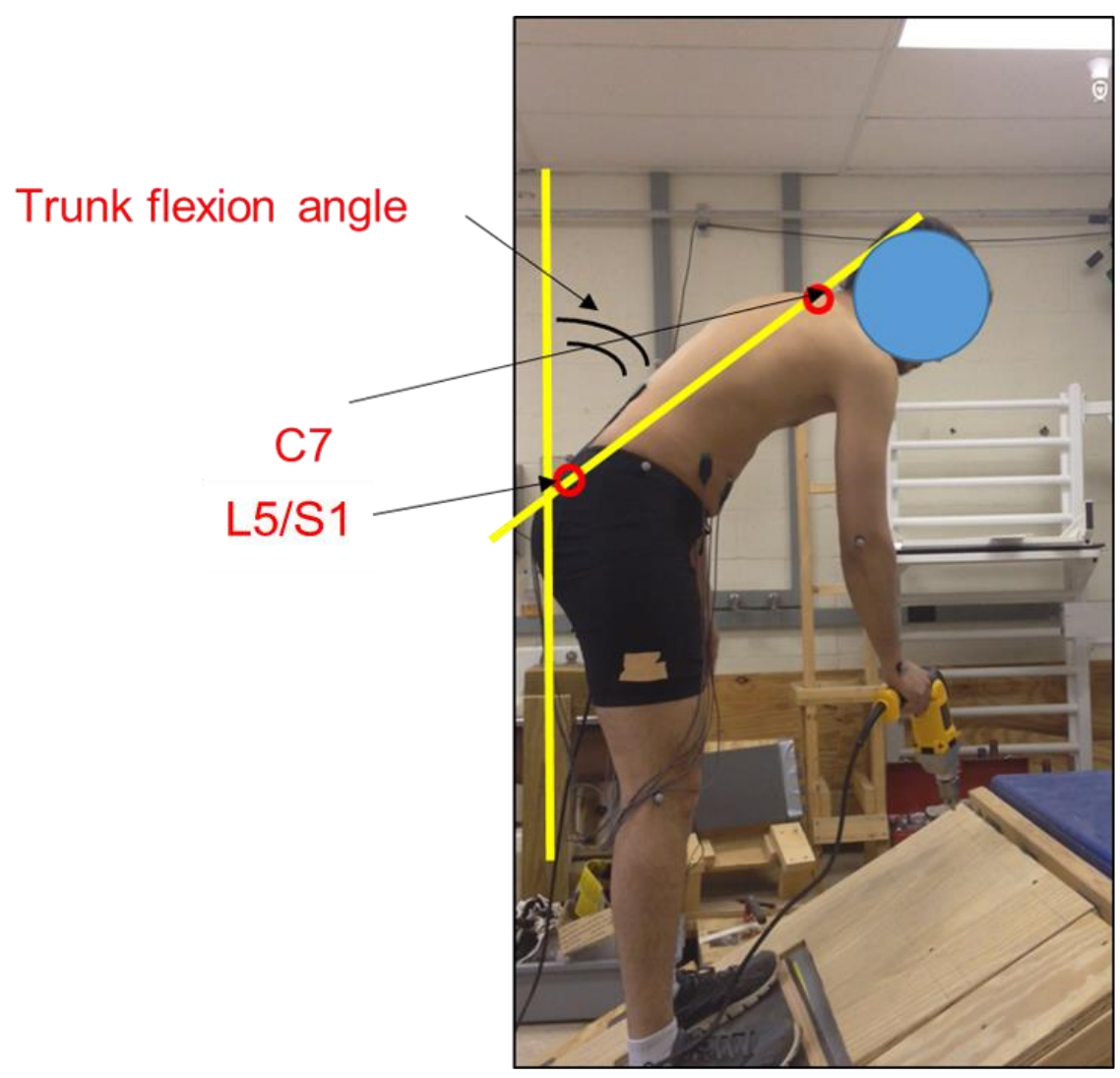

Figure 3: Maximum trunk flexion angle (stooped)

Two types of response variables (dependent variables), i.e., maximum trunk flexion angle and normalized EMG signals, were measured to reflect the effects of the risk factors and indicate the LBD risk. The maximum trunk flexion angle (or maximum trunk inclination angle) was the maximum of the trunk flexion angles during a whole shingle installation cycle. The trunk flexion angle was defined as the angle between the vertical line and the line between the $\mathrm{C} 7$ and L5/S1 joints (Hu et al. 2013; Ning et al. 
2011), as shown in Figure 3. A natural upright posture generates an approximate zero trunk inclination. The lumbar joint moment, which is directly associated with spinal loading, increases as the trunk inclination increases from $0^{\circ}$ to $90^{\circ}$ (Ning and Guo 2013). Larger trunk flexion angle indicates higher spinal moment and the higher associated spinal injury risks. The normalized EMG measures the activation levels of two pairs of lumbar extensor muscles (Erector spinae and multifidus), with one sensor on each side. These two independent variables were used to help establish LBD risks (Wang et al. 2015b).

\subsection{Participants}

There were 15 participants in this study. The subjects for the experiment are voluntary researchers and students. The age, stature and whole body mass (with standard deviation) of this study population were 25.2 years (3.3), $176.4 \mathrm{~cm}(3.4)$, and $70.6 \mathrm{~kg}$ (8.4). Female participants were excluded from the study as $99.5 \%$ of roofers are male (BLS 2015d). All subjects had no history of chronic low back injury. The research involving human experiments was approved by the Institutional Review Board of West Virginia University (Hu et al. 2014; Wang et. Al 2015).

\subsection{Instruments}

The participants' trunk kinematics data were collected using an optical motion analysis system - Vicon (T-Series Camera System, Oxford, 2002). Two retroflective Vicon markers were placed on the participant's trunk: one at the $\mathrm{C} 7$ joint (around the neck) and the other at the L5/S1 joint. Real-time 3D coordinates of the two joints can therefore be obtained. These data were used to calculate joint locations, joint angles, and movement velocities, etc. Additional markers were placed on the shoulders, arms, and 
legs for the convenience of the recognition of postures and facing direction. Vicon data were recorded at a frequency of $100 \mathrm{~Hz}$.

Muscular activities of the lumbar paraspinal muscles (erector spinae and multifidus muscles) were recorded using a surface electromyography (EMG) system (Bagnoli, Delsys, Boston, MA, USA). Bipolar surfaced EMG electrodes were placed 4 $\mathrm{cm}$ lateral from the L3 spinous process measuring the erector spinae (ES) muscles and 2 $\mathrm{cm}$ lateral from the L4 spinous process measuring multifidus muscles (MUL) (Hu et al. 2013). These muscles were selected to estimate the muscle tension and the activation of the lumbar muscles (Hu et al. 2013; Hu et al. 2014). The EMG data was collected at a rate of $1000 \mathrm{~Hz}$ and was synchronized with Vicon data on the software platform of Vicon Nexus (Vicon, Oxford, 2002). Participants' maximum voluntary contraction data of the lumbar muscles was collected using a dynamometer (HUMAC Norm, Computational Medicine, Stoughton, MA, USA).

A $1.2 \mathrm{~m}$ by $1.6 \mathrm{~m}$ custom-made wooden platform was built to mimic the rooftop on which the simulated shingle installation was conducted (Figure 4). The platform was connected to a hydraulic lift. By elevating the lift, the connected wooden structure could form a slope angle ranging from $0^{\circ}$ to over $60^{\circ}$. Anti-skidding tape was attached to the platform surface to increase the friction and avoid slips or falls. Video streams of the experimental trials were recorded by the Canon video camera (Canon, VIXIA HF R500, 2005), which is used for the observation study. 


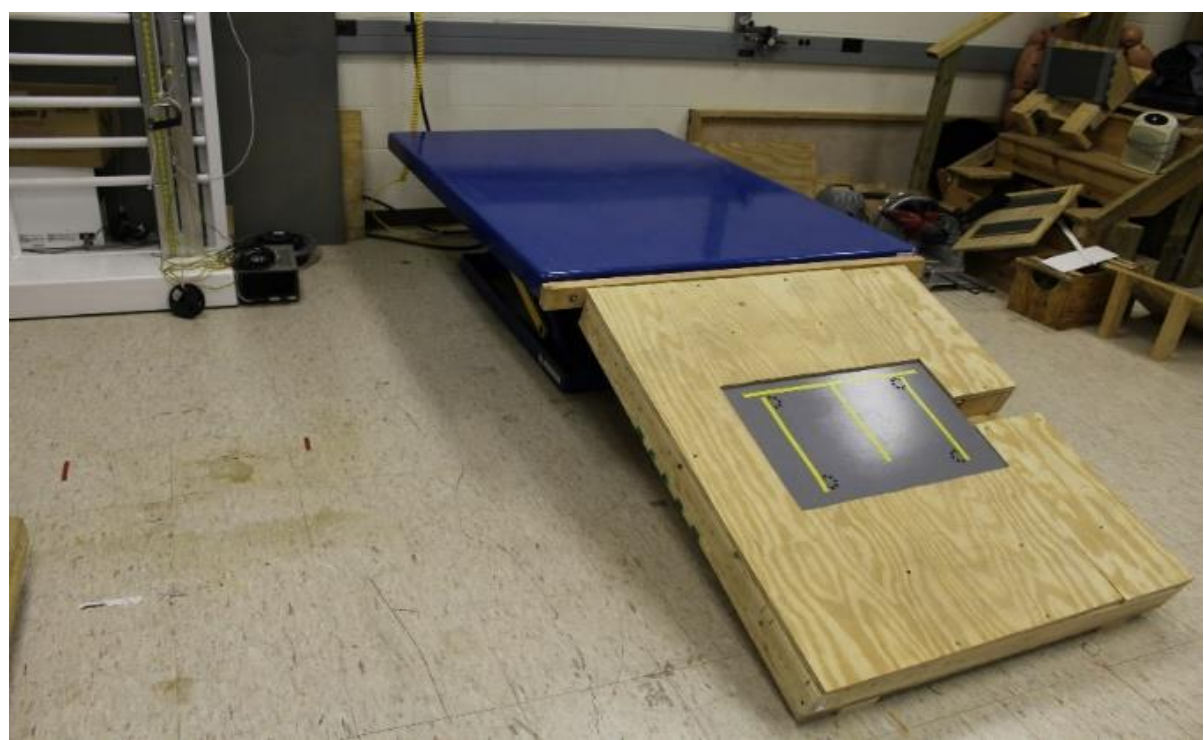

Figure 4: Wooden roof platform elevated by hydraulic lift

\subsection{Procedure}

Figure 5 shows the procedure of the experiment. It is divided into two parts: preparation and shingle installation. The preparation work includes the platform set-up and initialization of the Vicon and EMG system. The main part of the work is to simulate the shingle installation task with the combinations of different risk factors.

\subsubsection{Preparation}

1) The wooden platform was adjusted to three slope levels. 2) Before the shingle installation trials, the maximum voluntary contraction (MVC) was collected using a dynamometer (HUMAC Norm, Computer Medicine, Stoughton, MA, USA). MVC is the greatest amount of tension a muscle can generate and hold (Dic 2015). Each muscle' MVC was saved and used to normalize the EMG signals recorded during the shingle installation process. The details are introduced in Section 5.5. 3) Vicon camera system was calibrated, including: a) static calibration, which calculates the center of the capture 
volume, and determines the orientation of the 3D workplace; b) dynamic calibration, which is to calculate the relative positions and orientation of the camera by moving a calibration wand throughout the whole capture area.
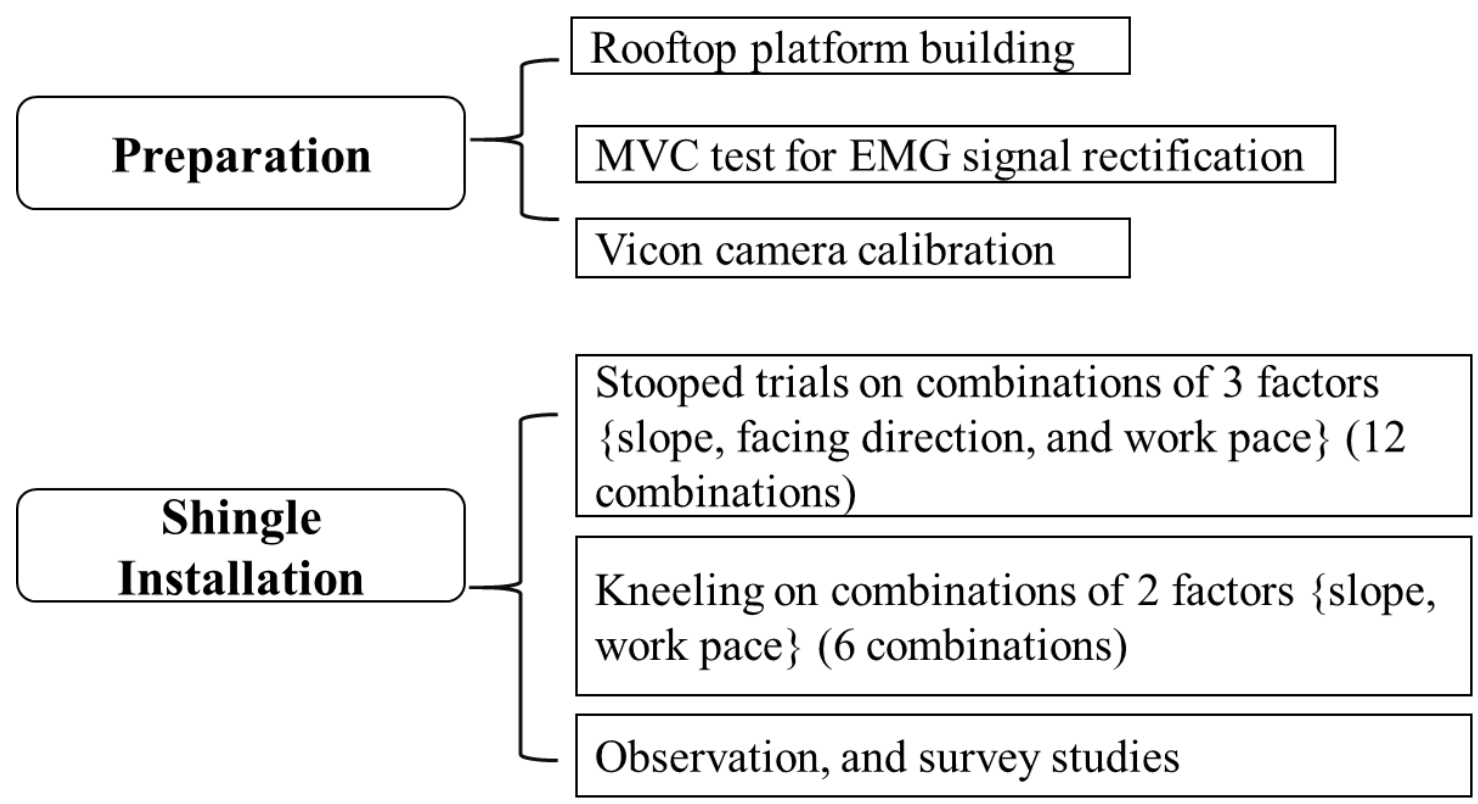

Figure 5: Procedure

\subsubsection{Shingle installation}

The shingle installation process is the main part of the experiment. The protocol is described as below. The experimental procedure was introduced to the participants upon their arrival to the lab. After a warm-up session (5 min), surface EMG electrodes and Vicon markers are secured to the designated locations on the back using double-sided tape. During the data collection, each participant performed the shingle installation simulations on different working conditions, which are the combinations of the four independent variables, such as stooping facing uphill on $15^{\circ}$ slope at slow work pace. The protocol defined that a complete shingle installation trial includes three steps: trunk flexion, nailing, and trunk extension. Specifically, it required the participant to use $1 / 6$ of 
a given time (slow cycle: 12 seconds; fast cycle: 6 seconds) to flex the trunk from an upright standing to reach the first nailing, 2/3 time to nail at four spots which are evenly distributed from the left edge to the right edge of an asphalt shingle (shingle length: 36 inches), 1/6 time to come back to upright standing position. This study particularly focuses on the nailing process during which the roofers constantly bend their trunk. The participants were required to hold a nail gun and use it to touch the nailing spots during the shingle installation process.

The stooped postures and kneeling postures were separately simulated due to their dissimilarity in working motions, body movement, and muscle utilizations. Firstly, the stooped postures were simulated on combinations of 3 factors, that is, the slope, the facing direction, and the work pace. For each participant, stooped postures were conducted on 12 combinations of factors and had 24 trials. Secondly, for kneeling, no facing sideways working mode is found through the literature review or site visits. Therefore, kneeling postures were performed on combinations of 2 factors, slope and work pace. In total, kneeling postures were conducted on 6 combinations of factors and had 12 trials. Lastly, the survey study was conducted among the participants to collect the perceived discomfort in the back and other body parts on different working condition. Video streams of the shingle installation processes were also recorded and used for observational study. The observation data can be used to validate the Vicon data and capture the flexion of other body parts.

\subsection{Data Processing}

Trunk flexion angle: The trunk kinematic data collected from the Vicon during the trials were used to compute the trunk flexion angle. The two markers placed on the 
trunk returned 3D coordinates of $\mathrm{C} 7$ joint denoted as $\left(\mathrm{x}_{1}, \mathrm{y}_{1}, \mathrm{z}_{1}\right)$ and $\mathrm{L} 5 / \mathrm{S} 1$ joint $\left(\mathrm{x}_{2}, \mathrm{y}_{2}\right.$, $\left.\mathrm{z}_{2}\right)$. The trunk flexion angle, is calculated as, Angle $=90-(360 / 2 *$ pi $) *$ atan $\left\{\left(z_{2}-z_{1}\right) /\right.$ sqrt $\left.\left[\left(y_{2}-y_{1}\right)^{\wedge^{2}}+\left(x_{2}-x_{1}\right)^{\wedge^{2}}\right]\right\}$. Provided the continuously recorded location of C7 and L5/S1, the trunk flexion angles of a complete shingle installation process were computed and the maximum was used as the response variable. As an example, one stooped trial was plotted in Figure 6. The maximum angle $85.36^{\circ}$ was marked. From the plot, the trunk bending pattern for each phase can be recognized. In the trunk flexion phase, a fast increased trunk flexion angle was detected. In the nailing process, a constant severe bending was detected, and the maximum flexion angle was also detected during the process. The trunk extension is a reversed flexion with a decreased trunk flexion angle.

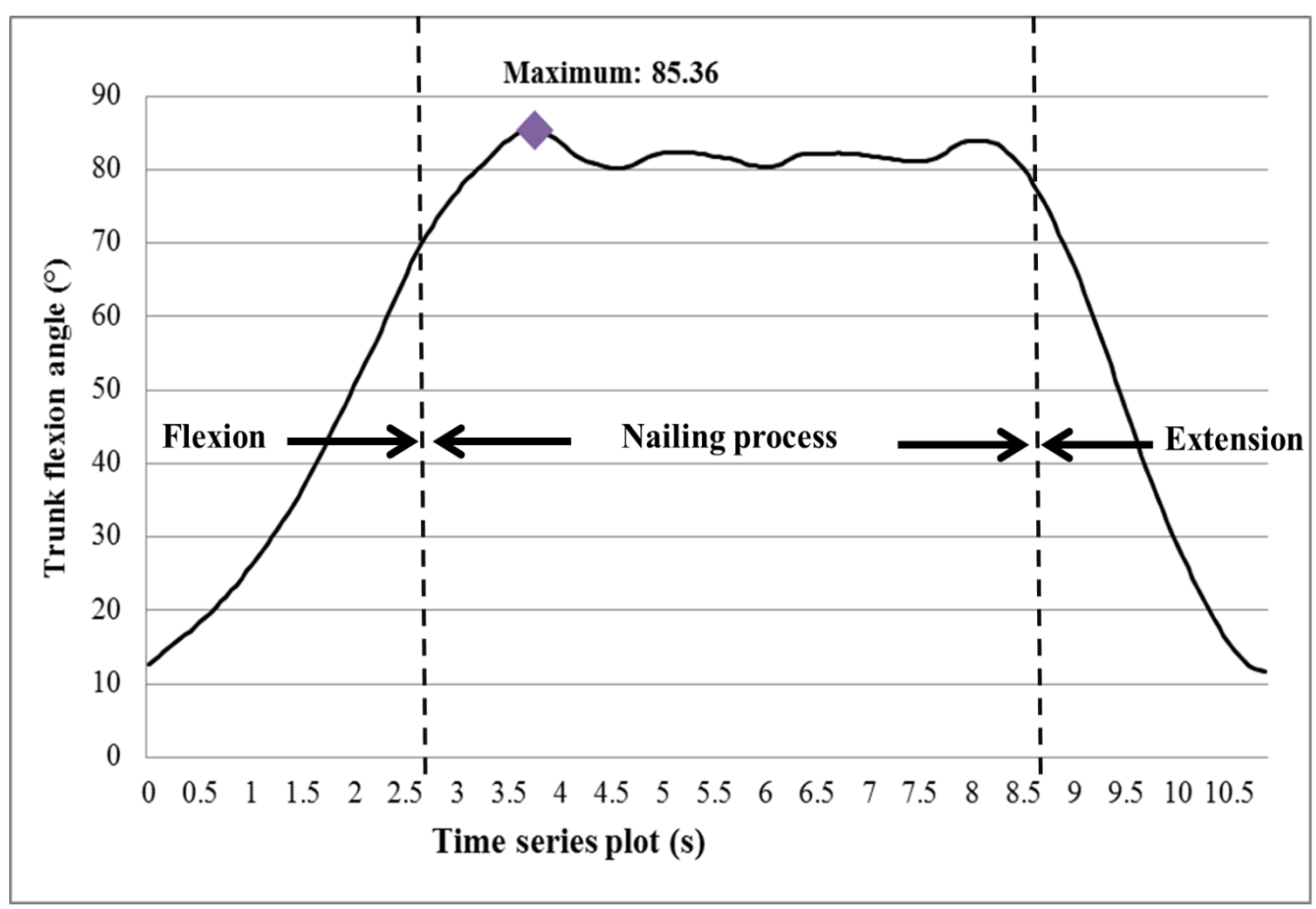

Figure 6: A time series plot of trunk angle during shingle installation process

Muscle activity: The EMG data collected during a shingle installation trial were rectified, filtered, normalized, and averaged over the nailing period. The full wave 
rectification took the absolute value of the signals and the nonnegative rectified EMG signals are plotted in Figure 7. Then, the EMG signals were filtered using $4^{\text {th }}$ order Butterworth filter, a band-pass filter (Math Works, 2013). After filtering, the data is smoothed and the outliers can be reduced. The profile of the EMG data after filtering is plotted in Figure 7. Thirdly, this filtered data was normalized in order to compare different individuals. There are many factors (e.g., electrode configuration, electrode placement, temperature, and perspiration, etc.) and individual differences that can influence the raw EMG data, making the direct comparison of raw data error-prone (Mark and Karen, 2005; Sousa and Tavares 2012). In order to compare EMG activities of different individuals and different muscles, the EMG needs to be normalized. For each muscle, the MVC is collected as a reference value which is to be divided by EMG signals during a task. The normalized EMG data is the relative measure of the muscle activation divided by the MVC. Lastly, to compute average normalized EMG signals over the nailing process. Nailing process, accounting for $2 / 3$ of the total cycle, was extracted by defining a uniform starting and ending time point in the whole cycle. As denoted in Figure 7, two peaks were captured during a single shingle installation cycle. The first peak of EMG signal represents the trunk flexion process, and the second peak represents the trunk extension process. The flat curve between the peaks represents the nailing process. The averaged normalized EMG signal during the nailing process is used as the response variable in this experiment to estimate the muscle activation and spinal loadings. A computational MATLAB program is developed to process and analyze Vicon and EMG data. The source code is attached in APPENDIX I. The processed data, including 
the computed trunk flexion angle and normalized EMG data, are attached in APPENDIX III.
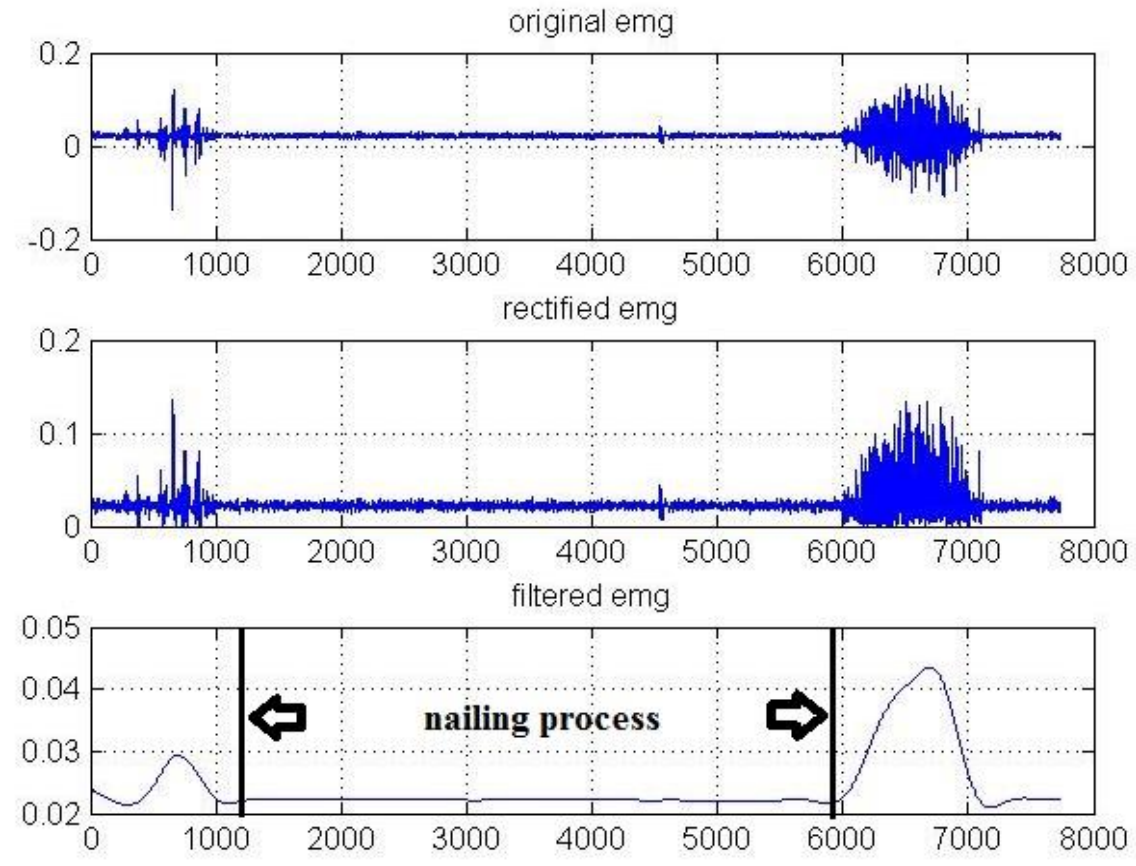

Figure 7: Processed EMG signals

\subsection{Statistical Analysis}

Due to the multivariate nature of the data collected in this study, both MANOVA and univariate ANOVA techniques were used. Prior to conducting statistical analysis, the assumptions of the ANOVA technique (normality of residuals, homogeneity of variances and independence of observations) were evaluated using the graphical approach advocated by Montgomery (2005). Multivariate analyses of variance (MANOVA, $\mathrm{p}<0.05$ for Wilks' Lambda statistic) were conducted. And for those independent variables and interactions that were found to be significant in MANOVA, univariate ANOVA ( $\mathrm{p}<0.05$ for $\mathrm{F}$ statistic) were conducted for their effects on each dependent variable. In the analysis, each repetition was treated as a single observation. The effect of each 
independent variable on each dependent variable was then investigated using repeated measures ANOVA with 'subject' considered as a random factor. The statistical analysis is performed in the Minitab ${ }^{\circledR}$ 17.1.0 software environment.

\subsubsection{MANOVA test}

Multivariate analysis of variance (MANOVA) can been viewed as ANOVA with several dependent variables. The factorial design includes two types of dependent variables, that is, trunk flexion angle (1 vector) and EMG signals (4 vectors). As such, MANOVA tests are applied to study the difference in 5 vectors of means. In addition, every two independent variables could have interaction effects on the dependent variables. An interaction effect is a change in the simple main effect of one variable over the levels of the second (Gelman and Hill 2005). In other words, the effect of one independent variable on the dependent variable may not be the same at all levels of the other independent variable. The interaction effects between different independent variables were also studied using MANOVA analysis. The null hypothesis is that the two factors have no interaction between each other. If the p-value returned from MANOVA analysis is less than 0.05 , the null hypothesis is rejected. Hence, an interaction is found in this case. After MANOVA tests find an independent variable or interaction to be significant, subsequent ANOVA tests are conducted on each dependent variable.

\subsubsection{Univariate ANOVA test}

Analysis of variance (ANOVA) is a popular statistics technique which is used to investigate the relationship between the independent variable(s) and the response variable(s) (Miller 1997). ANOVA is utilized as the tool for the factorial analysis in that 
t-test only compares 2 different levels of one IV (independent variables) whereas ANOVA compares multiple levels of one IV. In this study, the slope has three angles.

ANOVA analysis was conducted to find out the factors with significant influence on the response variables (i.e., maximum trunk flexion angle and normalized EMG data). In ANOVA analysis, the F ratio is an output which tests whether the means of different factor levels are significantly different from one another. The $F$ ratio is computed by dividing mean square between groups by mean square within groups, denoted as $\boldsymbol{F}$ ratio $=\boldsymbol{M} \boldsymbol{S}_{\text {bet }} / \boldsymbol{M} \boldsymbol{S}_{\boldsymbol{w} / \boldsymbol{i n}}$ (Montgomery 2005). Mean square between groups is computed as $\boldsymbol{M} \boldsymbol{S}_{\boldsymbol{b} / \boldsymbol{t}}$ $=\sum n(\text { cell means }- \text { grand mean })^{2}, \mathrm{n}$ denotes the total number of observations, cell means denotes the mean of each factor level, and grand mean denotes the mean of the cell means. The mean square within groups is computed by the equation: $\boldsymbol{M} \boldsymbol{S}_{w / i n}=\sum(\mathrm{X}-$ respective cell means) ${ }^{2}$. X denotes an observation value, and respective cell means represents the means of the corresponding factor level. A large F ratio demonstrates that the variation among group means is not by chance, therefore, different groups have a significant difference (SPSS, 2015). The $p$ value is determined from the F ratio and degrees of freedom. All the factors are hypothesized to have a significant effect on the response variables (Fathallah 2004; Zhou et al. 2015). ANOVA tests the null hypothesis that there is no significant difference between means of the factor levels. The null hypothesis is rejected when the returned P-value is less than a pre-defined significant level (i.e., 0.05), denoting a significant difference between different factor levels. A small $p$ value means that the factor has a significant influence on the response variable.

As described in the experiment procedures, the stooped observations and kneeling observations were separated due to their dissimilarity in body movement and muscle 
utilization, and ANOVA analysis was respectively conducted on each posture category. When conducting ANOVA analysis on a certain independent variable, the total stooped or kneeling observations were divided into groups by the factor level. A confidence interval defines an estimated range of values which an unknown population mean has a high chance to fall into. The $95 \%$ confidence interval was used in the study, which has $95 \%$ likelihood to include the population mean (George 1997). For each independent variable tested to have a significant effect on the response variables, the confidence interval plots of its different factor levels were drawn to show the sample's tendency and variability.

\subsubsection{Post Hoc Test}

For an independent variable of three or more factor levels (e.g., slope angle has three levels), the observations were divided into three or more groups by the factor level and ANOVA analysis was conducted. However, ANOVA analysis only concludes whether at least two groups are significantly different, but does not show which specific groups are significantly different (Montgomery 2005). In this study, given that ANOVA analysis has determined that the three slope groups were significantly different in terms of the maximum trunk flexion angle, we can still not conclude whether $0^{\circ}$ group is significantly different from $15^{\circ}$, or $15^{\circ}$ group is significantly different from $30^{\circ}$, or $0^{\circ}$ group is significantly different $30^{\circ}$. Therefore, post hoc test is required to determine which specific groups are significantly different from one another when the factor has three or more factor levels.

In this study, the Tukey's HSD test, a post hoc test was used on trunk flexion angles to further investigate the differences between three slope groups (Lowry 2008). Tukey's test is essentially multiple pairwise t-test. Tukey's test compares the means of 
every angle group to the means of every other group and identifies any difference between two means that is greater than the expected standard error. $t=\left(\boldsymbol{M}_{\boldsymbol{I}^{-}}\right.$ $\left.M_{2}\right) / \operatorname{sqrt}\left(M S_{w}(1 / n)\right)$ 


\section{CHAPTER 6}

\section{RESULTS}

\subsection{Statistical Analysis Results}

In this study, MANOVA and ANOVAs were conducted to study the effects of each factor and investigate the interaction between independent variables. For all statistical analysis in this study, the criteria p-value is set to be 0.05. The MANOVA and subsequent ANOVA results are presented in Table 2 for stooped postures and Table 3 for kneeling postures. In this study, two pairs of surface EMG sensors were used to measure the activities of two pair of lumbar spinal muscles: erector spinae (ES) and multifidus (MUL), as described in Section 5.3. Each pair consisted of a left-sided one and a rightsided one. Throughout the entire analysis, the left-sided and right-sided EMG signals were consistent with each other. Therefore, the statistical analysis and the following figures report the average of EMG signals on two sides.

The ANOVA analysis revealed that: 1) the maximum trunk flexion angle was significantly affected by slope angles, both for stooped and kneeling postures; 2) the maximum trunk flexion angle was significantly affected by facing directions in stooped trials; 3) EMG data demonstrated that the erector spinae and multifidus muscles are significantly affected by frequency on stooped trials; 4) EMG data also demonstrated that the multifidus EMG signals are significantly affected by task frequency on kneeling trials. 
From Table 2 and Table 3, the slope is found to have a significant effect on the trunk flexion angle. As described in 5.6.3, ANOVA analysis does not show which specific groups are different from one another given an independent variable of three more factor levels. As such, the Tukey's HSD test, a post hoc test was used on trunk flexion angle to further investigate the differences between three slope angles. For 3 slope angles, all the pairwise comparisons are performed using Tukey's Test and an overall risk level of 5\%. The detailed results are presented in the Section 6.2.1 and 6.3.1.

In addition, the interaction between every two factors was tested for both stooped postures with 3 combinations and kneeling postures with 1 combination in the format of "A*B". The results are presented in Table 2 and Table 3. A strong interaction between Slope and Facing direction on trunk flexion angle is found, which will be discussed in details in Section 6.2.2. Besides this, no other interactions are found in trunk flexion angle either in stooped postures or kneeling postures.

In the following section, the results of stooped and kneeling postures are respectively presented. For each posture, ANOVA analysis is conducted to study the effects of each factor on the response variables and $95 \%$ confidence interval is plotted for each factor level. Detailed results are reported in the following. 
Table 2: MANOVA and ANOVA results for trunk flexion angle and EMG (stooped): statistical significance and interactions of the factors (left and right sides combined)

\begin{tabular}{ccccc}
\hline \multirow{2}{*}{ Factors } & MANOVA & \multicolumn{3}{c}{ ANOVA } \\
\cline { 3 - 5 } & & Trunk Angle & ES (EMG) & MU (EMG) \\
\hline Slope & +++ & +++ & $/$ & $/$ \\
\hline Frequency & + & $/$ & ++ & ++ \\
\hline Direction & ++ & +++ & $/$ & $/$ \\
\hline Slope*Direction & ++ & +++ & $/$ & $/$ \\
\hline Slope*Frequency & $/$ & $/$ & $/$ & $/$ \\
\hline Direction*Frequency & $/$ & $/$ & $/$ &
\end{tabular}

(Note: $+++: \mathrm{p}<0.001 ;++: \mathrm{p}<0.01 ;+: \mathrm{p}<0.05 ; / \mathrm{p}>=0.05)$

Table 3: MANOVA and ANOVA results for trunk flexion angle and EMG (kneeling): statistical significance and interactions of the factors (left and right sides combined)

\section{ANOVA}

Factors MANOVA

Trunk Angle ES (EMG) MU (EMG)

\begin{tabular}{ccccc} 
Slope & +++ & ++ & $/$ & + \\
\hline Frequency & ++ & $/$ & $/$ & ++ \\
\hline Slope*Frequency & $/$ & $/$ & $/$ & $/$
\end{tabular}

(Note: $+++: \mathrm{p}<0.001 ;++: \mathrm{p}<0.01 ;+: \mathrm{p}<0.05 ; /: \mathrm{p}>=0.05)$ 


\subsection{Stooped Postures}

Table 4: The mean (SD) values of dependent variables at different independent variable levels (ESl, ESr, MUl and MUr refer to left erector spinae, right erector spinae, left multifidus and right multifidus respectively) (Stooped)

\begin{tabular}{cllllll}
\hline Factors & Conditions & Trunk angle $\left.{ }^{\circ}\right)$ & ESI (\%) & ESr (\%) & MUI (\%) & MUr (\%) \\
\hline \multirow{3}{*}{ Slope Angle } & $0^{\circ}$ & $92.23(2.89)$ & $10.90(5.42)$ & $13.00(5.55)$ & $15.31(6.50)$ & $14.12(9.86)$ \\
\cline { 2 - 7 } & $15^{\circ}$ & $88.40(7.16)$ & $9.70(5.93)$ & $12.6(7.59)$ & $15.79(8.38)$ & $12.43(8.55)$ \\
\cline { 2 - 7 } Facing & $30^{\circ}$ & $82.21(12.50)$ & $9.32(5.84)$ & $11.55(7.30)$ & $14.9(7.61)$ & $11.76(8.50)$ \\
\cline { 2 - 7 } direction & side & $93.75(4.12)$ & $9.33(5.91)$ & $11.91(7.37)$ & $15.86(8.71)$ & $12.97(8.71)$ \\
\hline \multirow{2}{*}{ Frequency } & fast & $81.98(9.85)$ & $10.17(5.70)$ & $12.70(6.88)$ & $15.05(7.09)$ & $13.68(8.73)$ \\
\cline { 2 - 7 } & slow & $86.16(10.35)$ & $11.00(6.08)$ & $13.4(7.00)$ & $16.67(7.99)$ & $14.37(8.66)$ \\
\hline
\end{tabular}

Table 4 summarizes the effects of all the three independent variables on all the dependent variables for stooped postures. Significant effects of slope, facing direction and frequency were found per the results of MANOVA (Table 2). The follow-up univariate ANOVAs revealed the interactions and effects of the independent variables on each dependent variable.

\subsubsection{Influence of slope angles}

a) Trunk flexion angle: The statistical analysis (Table 2) determines that the slope to have a significant impact on the maximum trunk flexion angle. All the stooped observations were divided into 3 groups by the slope angle level. The $95 \%$ confidence intervals were constructed for each slope level. The Tukey's test was performed and identified that $0^{\circ}$ and $15^{\circ}$ can be grouped as Group A, whereas $30^{\circ}$ is grouped as Group B. It means that mean of trunk flexion in Group A is significantly different from that in Group B. Within the group, each level has no significant difference from the other.

The maximum flexion angle calculated from Vicon data shows the trend that the maximum flexion angle is decreasing as the slope angle increases, shown in Figure 8. This result 
is demonstrated by observations on recorded video streams. It is worth noting that, all the stooped trials simulated on the roof slope are observed to have a maximum bending angle of larger than $70^{\circ}$ during the nailing process, which is categorized as high degree of trunk bending by ergonomic observational tools, e.g., PATH, OWAS, REBA.

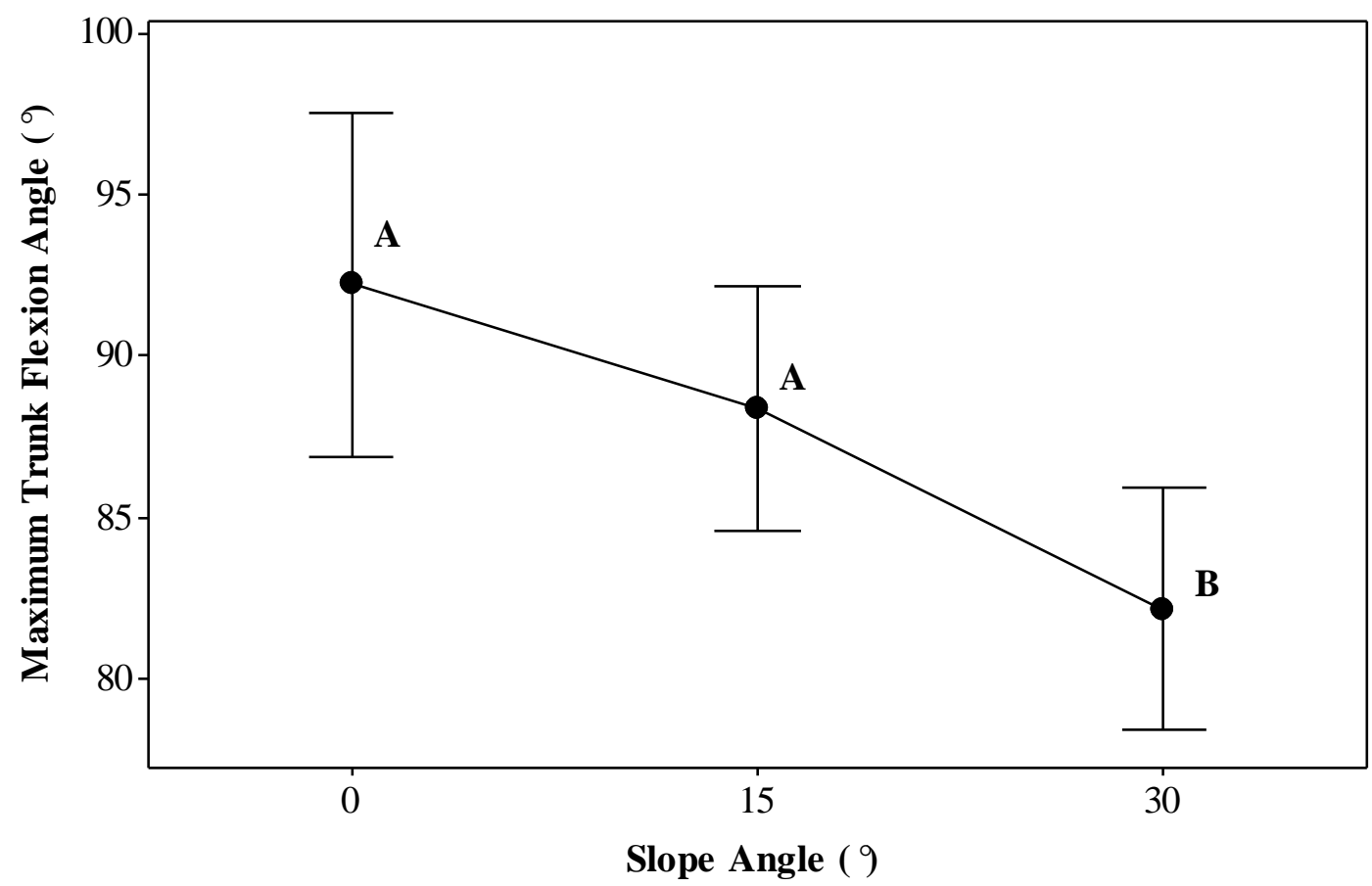

Figure 8: Effects of slope angles on maximum trunk flexion angle (Stooped)

(Note: $\mathrm{X}$-axis denotes three slope angles, and $\mathrm{Y}$-axis denotes the corresponding maximum trunk flexion angle; the mean of each factor level is marked by a dot. 95\% confidence interval for the mean plotted.)

b) EMG signals: The trend revealed by Vicon is consistent with EMG data as the same trend is detected both in erector spinae and multifidus (Figure 9) muscles. However, the EMG signal difference between different slope levels is almost negligible (within 3\%). Statistical analysis as shown in Table 2 states that the slope angle does not show a statistical significance on 
muscle activation in this study. In addition, the survey conducted among the participant does not show a significant difference of discomfort in back on different slopes.

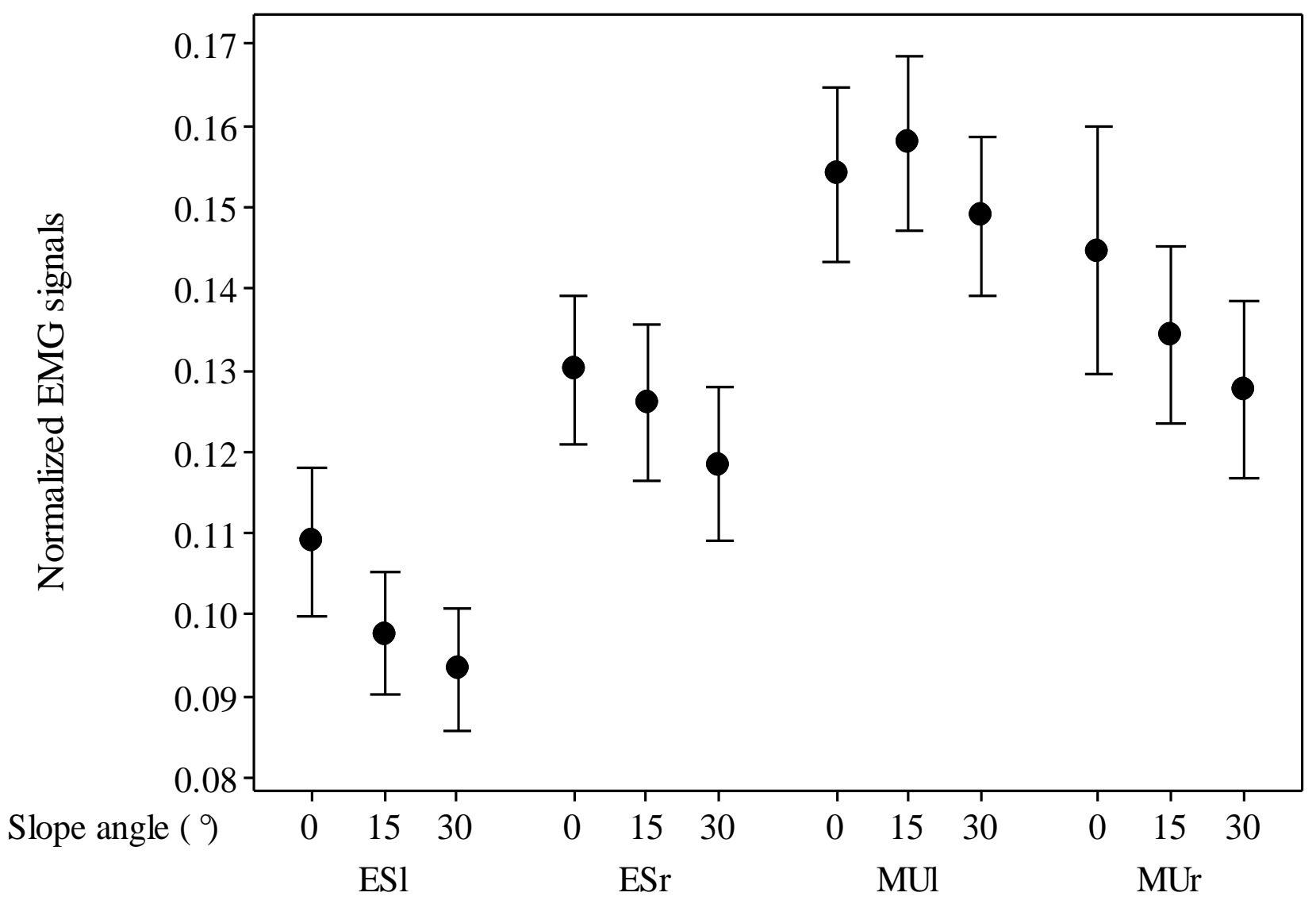

Figure 9: Effects of slope angles on EMG signals (stooped) 


\subsubsection{Influence of facing direction}

a) Trunk flexion angle: The statistical analysis (Table 2) shows that facing direction has a significant effect on the maximum trunk flexion angle. Figure 10 shows that, the maximum trunk flexion angle in trials facing sideways (denoted as A) is significantly higher than that of facing uphill (denoted as B), which indicates that the peak spinal loading in facing sideways working is higher than the peak in facing uphill.

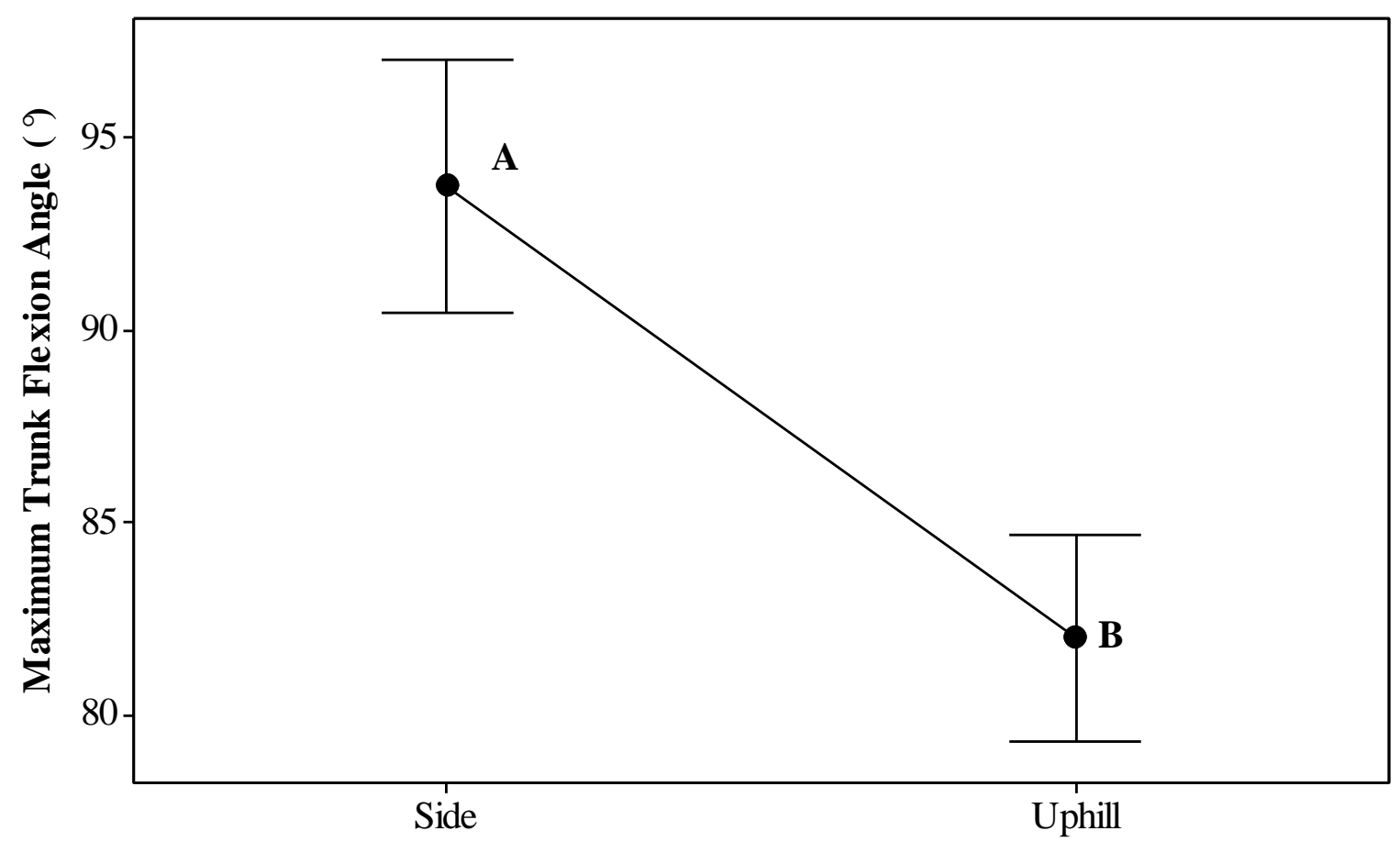

Facing Direction

Figure 10: Effects of facing directions on maximum trunk flexion angle (stooped) 


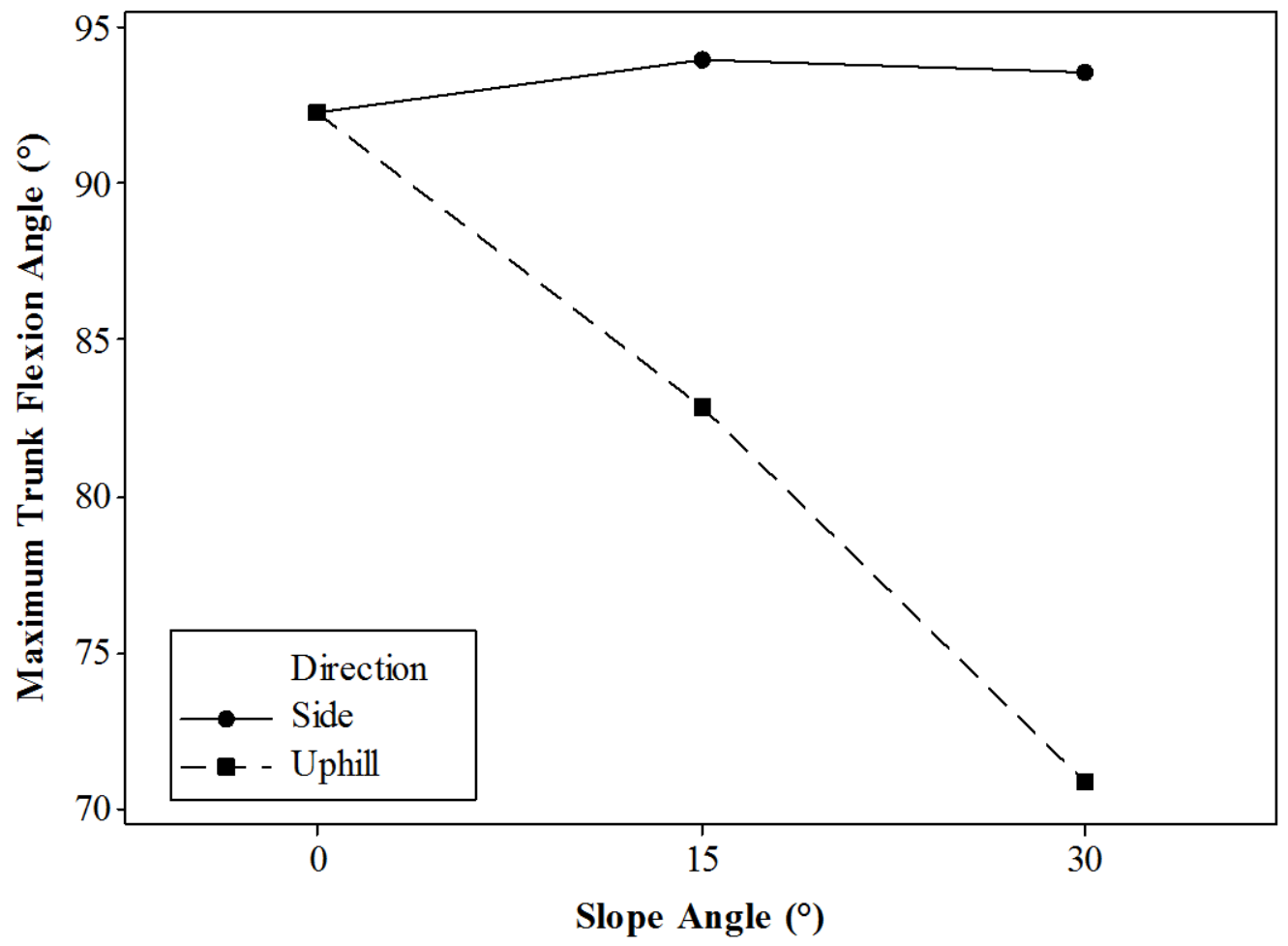

Figure 11: Interaction plot of Slope and Facing directions (Stooped)

MANOVA and subsequent ANOVA analysis found that the facing direction and slope angle have interactions on the maximum trunk flexion angle. The interaction effect is plotted in Figure 11. At each slope level, the maximum trunk flexion angles of two facing directions were compared. It is found that, on $15^{\circ}$ and $30^{\circ}$ slopes, the maximum trunk flexion angle of facing sideways is significantly higher than that of facing uphill. Besides, it is worth noting that: 1) For facing uphill, as slope's slant angle increases, the trunk flexion angle decreases, which echoes the finding of $6.2 .1 ; 2$ ) For sideways, the maximum flexion angle maintains approximately the same for all three slope levels. 


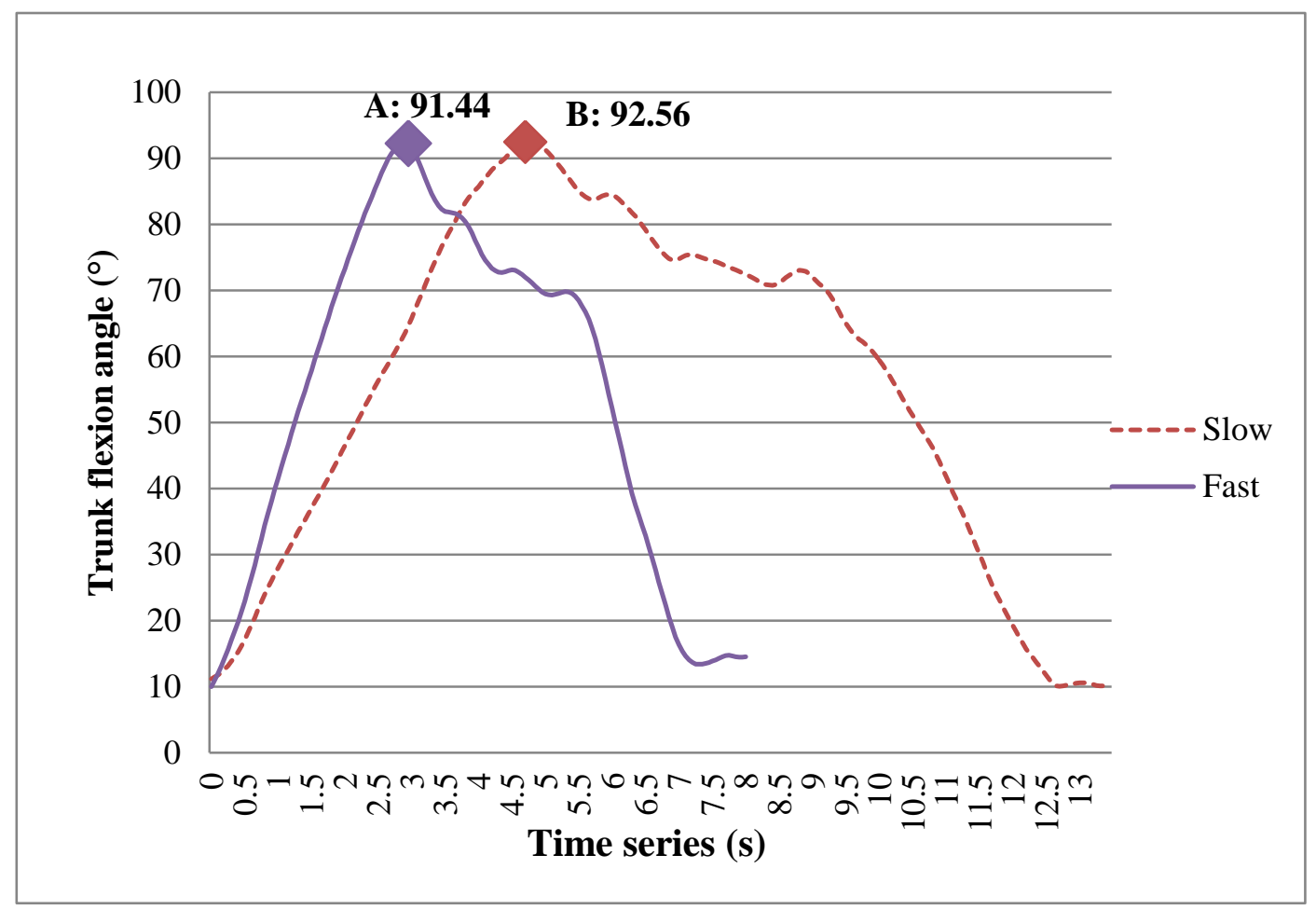

Figure 12: Time series plot of max trunk flexion angle for facing sideways

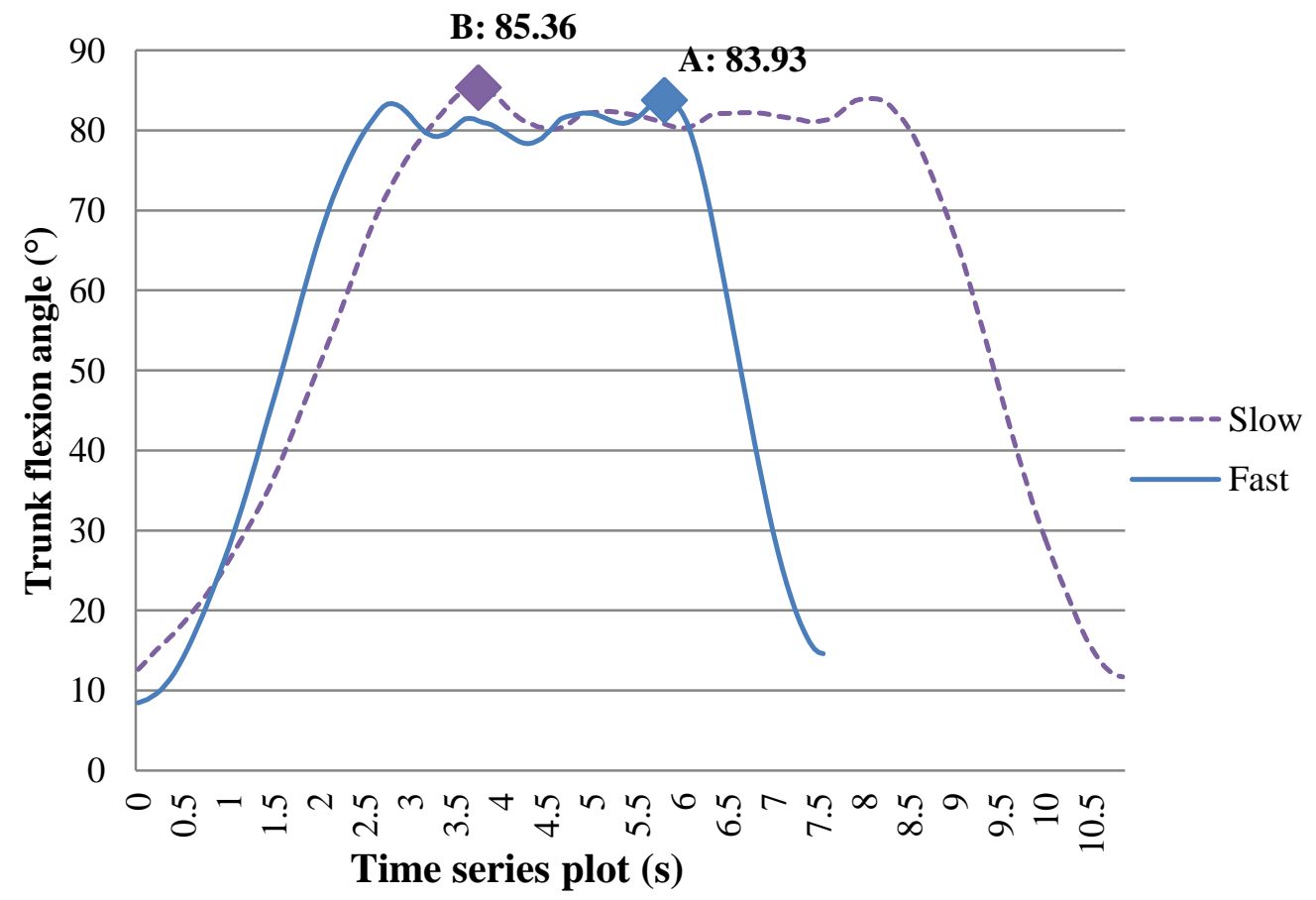

Figure 13: Time series plot of max trunk flexion angle for facing uphill 
The possible mechanism of finding is that, when bending on the laterally slanted surface (or facing sideways), the participant needs to stretch towards left to reach the leftmost nailing spot, which is at a lower position. In this study, all the participants are right handed and their right foot is placed at a higher position than left when standing on uneven slopes. When installing shingles on uneven slopes, a deeper flexion is required at the left-sided nailing spots than at the right-sided. In order to validate the above mechanism, the trunk flexion angle for one shingle installation cycle was plotted. Figure 12 shows the profile of trunk flexion angle during shingle installation when facing sideways. Figure 13 shows the trunk flexion during shingle installation when facing uphill. In both figures, fast and slow trials were plotted and observed to have the similar trend. The maximum trunk flexion angle was marked in the figures. Through comparison, distinct facts for facing sideways from facing uphill were discovered: 1) during the nailing process (denoted in Figure 6), a higher variance is discovered in facing sideways mode (SD: $11.4^{\circ}$ ) than that in facing uphill $\left(\mathrm{SD}: 4.2^{\circ}\right.$ ) on a slanted surface (i.e., $15^{\circ}$ and $30^{\circ}$ ). The computed variance is the average of variances on $15^{\circ}$ and $30^{\circ}$ slopes, and $0^{\circ}$ is excluded as facing direction and facing uphill have no difference on flat ground; 2) The maximum trunk flexion angle in facing sideways trials was detected at the beginning of the nailing process; 3) The trunk flexion angle throughout the nailing process in facing uphill trials maintains almost the same. 4) The average nailing-phase trunk flexion angle of all participants is computed, and the sample mean is summarized as below: sideways: $82.1^{\circ}$; uphill: $79.1^{\circ}$.

It is revealed that the average trunk flexion angle for facing sideways is still higher than that of facing uphill, which indicates a higher cumulative spinal loading. But this difference is significantly less than that of the maximum trunk flexion angle in Figure 10. (i.e., sideways: 93.3; uphill: $\left.82.0^{\circ}\right)$ 
b) EMG signals: The EMG data does not show significant difference between two facing directions. Hu et al. (2014) conducted a LBD study comparing bending on a slanted surface $\left(15^{\circ}\right.$ and $\left.30^{\circ}\right)$ against on flat ground $\left(0^{\circ}\right)$ and states that EMG data of left side paraspinals demonstrated significantly lower values on a slanted surface. Further study of left and right side back muscles comparison on different facing directions is needed.

\subsubsection{Influence of work pace}

a) EMG signals: The shingle installation consists of a series of different operations: flexion, nailing, and extension. The participants are required to conduct a complete shingle installation process at a different work pace. The nailing process was extracted and average normalized EMG data for nailing phase is used for the factorial analysis. The frequency was demonstrated to have a significant impact by EMG data as shown in Table 2. Erector spinae and multifidus EMG signals showed a consistent trend in both erector spinae and multifidus muscles that fast work pace generates significantly higher normalized EMG data (Figure 14). The EMG signals of the fast group (denoted as A) are significantly higher that of the slow group (denoted as B). Those findings indicated relatively strong muscle activation at fast work pace and have implications for higher LBD risk. 


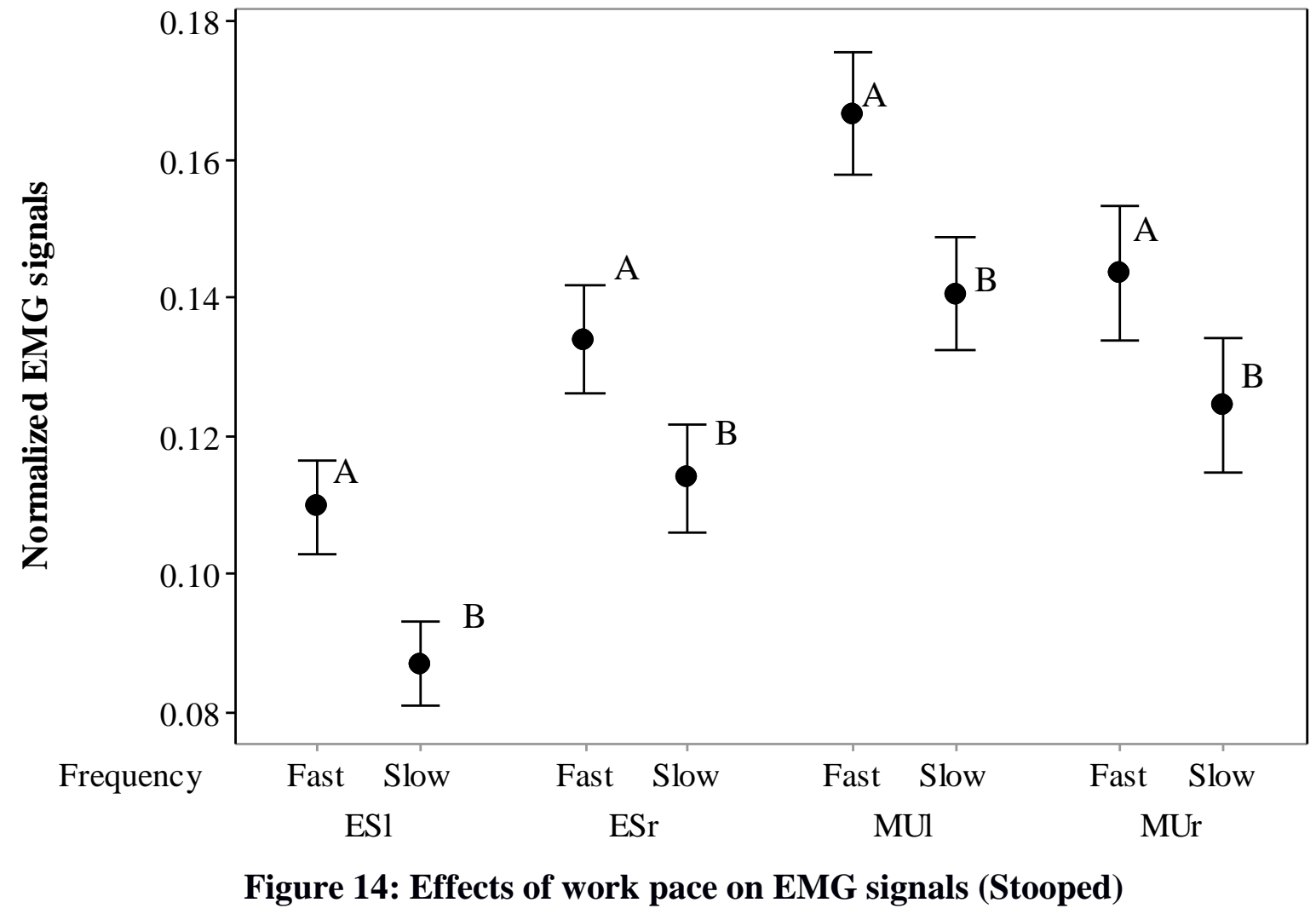

b) Trunk flexion angle: Statistical analysis shows that work pace has no significant effects on flexion angle captured by Vicon. For slow and fast cycles, the participants employed the exact same posture and procedures, which would only result in a negligible difference in movement. 


\subsection{Kneeling Postures}

Table 5: The mean (SD) values of dependent variables at different independent variable levels (ESl, ESr, MUl and MUr refer to left erector spinae, right erector spinae, left multifidus and right multifidus respectively) (Kneeling)

\begin{tabular}{cllllll}
\hline Factors & Conditions & Trunk angle $\left.^{\circ}\right)$ & ESI (\%) & ESr (\%) & MUI (\%) & MUr (\%) \\
\hline \multirow{3}{*}{ Slope Angle } & $0^{\circ}$ & $37.87(15.86)$ & $10.36(5.7)$ & $16.25(6.94)$ & $10.61(4.05)$ & $9.93(5.93)$ \\
\cline { 2 - 7 } & $15^{\circ}$ & $25.42(11.71)$ & $11.24(4.87)$ & $16.56(6.53)$ & $11.38(2.78)$ & $10.06(3.33)$ \\
\cline { 2 - 7 } & $30^{\circ}$ & $23.61(9.31)$ & $12.47(5.25)$ & $17.72(6.45)$ & $13.60(1.56)$ & $10.88(2.83)$ \\
\hline \multirow{2}{*}{ Frequency } & fast & $28.34(13.33)$ & $11.40(5.26)$ & $16.97(6.61)$ & $12.51(2.84)$ & $11.15(4.02)$ \\
\cline { 2 - 7 } & slow & $29.60(14.75)$ & $11.31(5.41)$ & $16.72(6.69)$ & $11.22(3.45)$ & $9.43(4.32)$ \\
\hline
\end{tabular}

For kneeling postures, the facing direction was assumed to be only uphill as only uphill was observed in roofing shingle installation. Besides, the preliminary trials of kneeling towards sideways on the slope have found that a significant amount of effort is needed to maintain balance. There, facing sideways was excluded from the experiment design for kneeling postures. The effects of the slope angles and work pace are discussed as follows. Table 5 summarizes the effects of the slope angles and work pace on all the dependent variables for kneeling postures. Significant effects of slope and frequency were found according to the results of MANOVA for kneeling postures (Table 3). The follow-up univariate ANOVAs revealed the interactions and effects of the independent variables on each dependent variable.

\subsubsection{Influence of slope angles}

The kneeling observations were divided into three groups according to the slope angles and $95 \%$ confidence interval was plotted for each slope group. The response of Vicon showed the trend that the flexion angle decreases as the slope rises, which indicates a less severe bending, 
as shown in Figure 15. The Tukey's test was performed, and it determined that $0^{\circ}$ slope was grouped as Group A, whereas $30^{\circ}$ and $15^{\circ}$ were grouped as Group B. The result means that mean of trunk flexion in Group A is significantly different from that in Group B. But within the group, the slope groups have no significant difference.

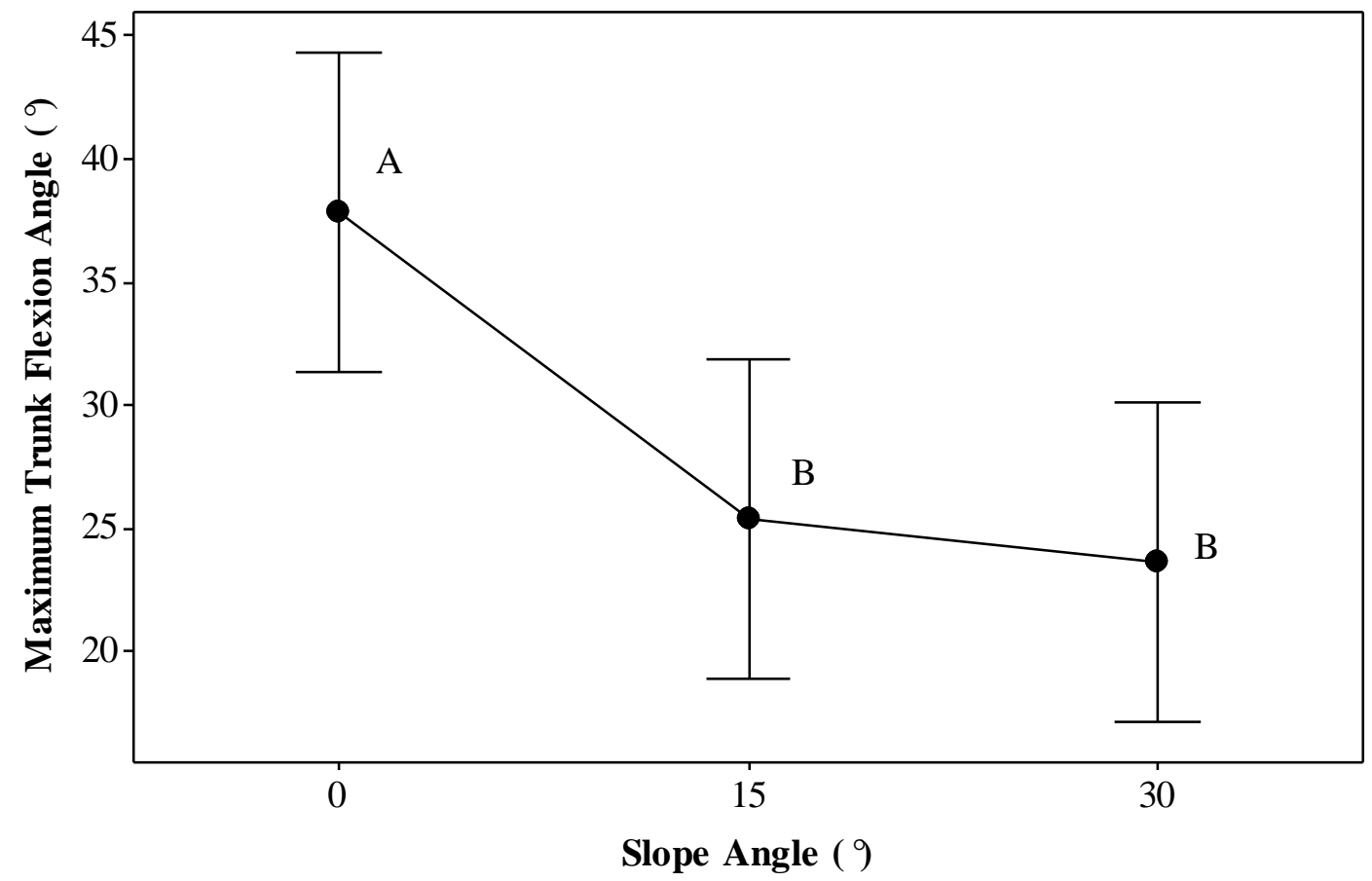

Figure 15: Effects of slope angle on maximum trunk flexion angle (Kneeling)

The effects of slope angles on EMG signals are demonstrated in Figure 16. It indicates a trend that ESl, ESr, MUl and MUr signals grow as slope angles increases. A significant higher MU muscle activation (both sides) was found in the $30^{\circ}$ (marked as Group B) than $0^{\circ}$ and $15^{\circ}$ (Group A). 


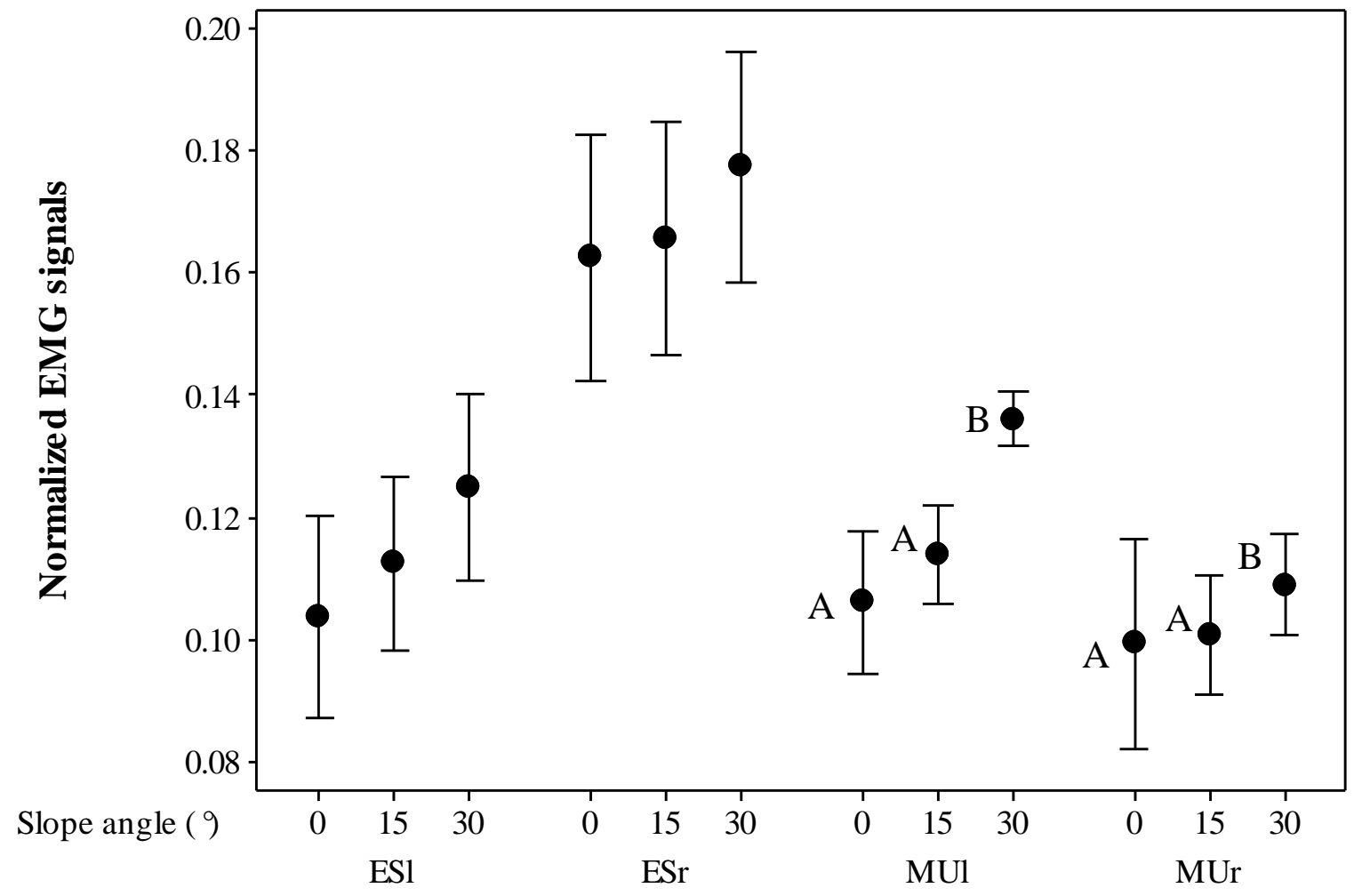

Figure 16: Effects of slope angles on EMG signals (Kneeling)

\subsubsection{Influence of work pace}

Figure 17 demonstrates that work pace has a significant effect on multifidus EMG signals. It has implications for more active muscle utilization at fast work pace than slow work pace for kneeling postures. The EMG signals of the fast group (denoted as A) are significantly higher that of the slow group (denoted as B). However, for erector spinae, no significant difference was detected between fast and slow trials (Table 3).

The mechanism can be explained as below. Different from stooping, when kneeling, the trunk of the subject is so close to the rooftop that the bending and extending phases are no longer needed, especially for steep slopes. During the whole cycle, the participant's trunk has no 
obvious movement. Instead, the arm and shoulder movement speed is adjusted to adapt the work pace changes. In order to differentiate the muscle activities at fast and slow frequencies, one possible solution is to extend the length of the shingle so that the participant needs to significantly move their trunk to reach the two ends of the shingle. Another possible solution is to maximize the time difference between two frequencies, for example, make the fast frequency even faster (i.e., 4 seconds/shingle).

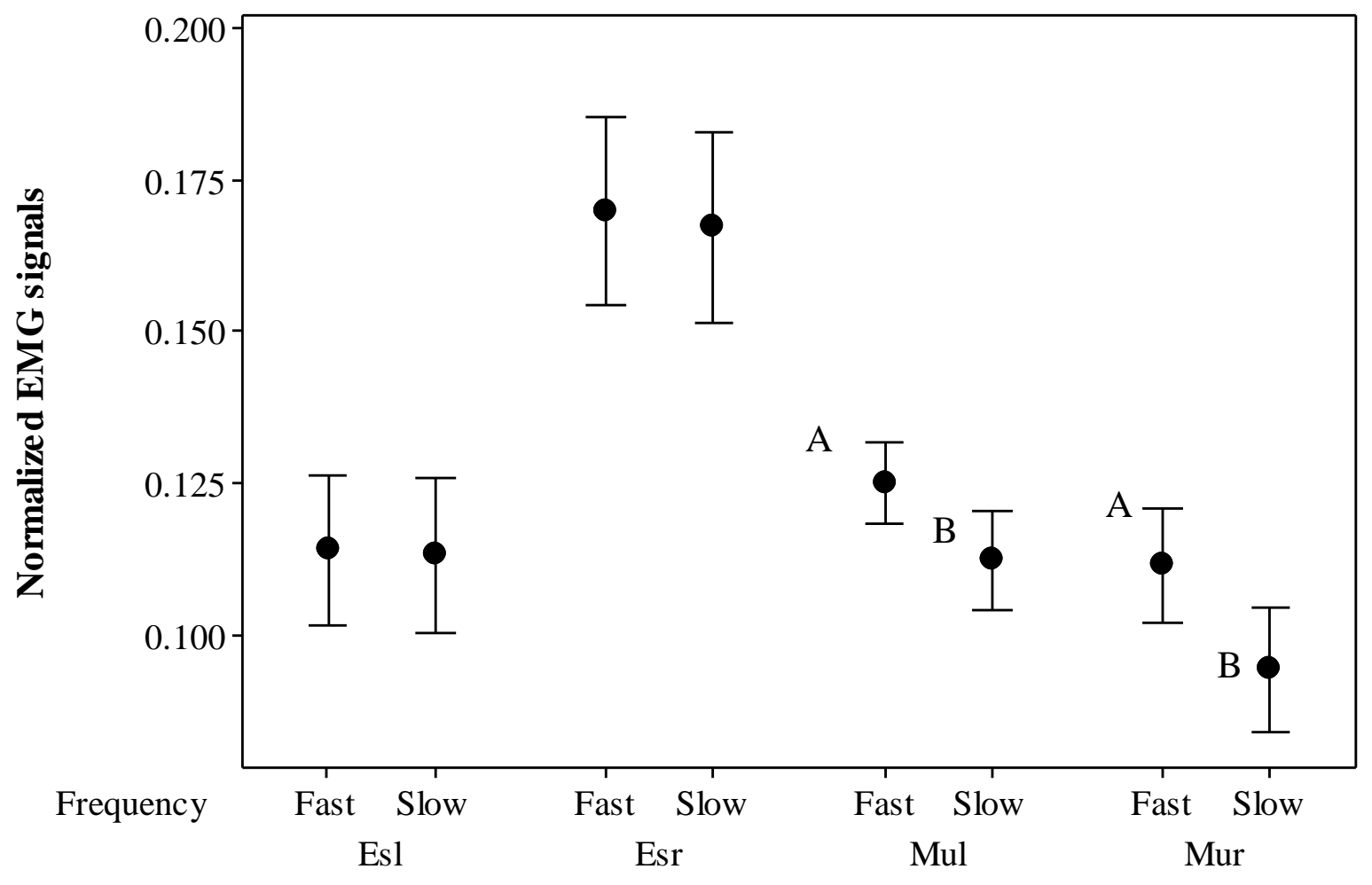

Figure 17: Effects of work pace on EMG signals (Kneeling)

\subsection{Summary of the Findings}

From above, it was revealed that: (1) as the slope angle increases, the maximum trunk flexion angle gradually decreases for both stooped and kneeling postures; (2) facing sideways results in higher maximum trunk flexion angle and slightly higher average trunk flexion angle 
than facing sideways; (3) fast work paces generally generates higher muscle activation and utilization in both stooped and kneeling postures. (4) For stooped trials, there is an interaction effect between facing direction and slope angles on the trunk flexion angle. 


\section{CHAPTER 7}

\section{DISCUSSION}

In this study, two response variables, maximum trunk flexion angle and normalized EMG signals were adopted to implicate the spinal injury risk. The results demonstrated that, all independent variables (the risk factors) have a significant effect on at least one response variable. In the following, the LBD risk associated with a certain working condition and possible interventions are discussed. The kneeling and stooped postures are also compared through video observations.

a) Stooped posture: The Vicon data showed a highly consistent trend among all participants in facing direction and slopes. As the slope increases, the distance of the participants' upper body (i.e., arms, shoulders and trunk) from the nailing spots on the rooftops become closer. Therefore, the participant needs a smaller bending angle to reach the nailing spots. In practice, for roofers working on a low pitch, a higher maximum bending angle is likely to occur. In contrast, a less postural balance and higher fall risk is reported that working on a steep roof (Choi et al. 2008). A similar trend was suggested by EMG data with an insignificant effect. This finding indicates a smaller spinal injury risk on a higher pitch than on a lower pitch or the flat ground.

However, this study only measured the trunk bending angle and back muscle activeness, ignoring the ankle flexion angles and the balance related measures. The survey results showed that 13 out of 15 participants perceived an imbalance and higher ankle stress on steeper slopes. 
Besides, an existing study indicated a reduced balance on the high pitch roof than the low pitch (Choi et al. 2008). In addition, a high ankle flexion angle was observed on higher slopes. Considering the increased ankle flexion and the imbalance which increases fall or slip risk, the steep slope may be considered unfavorable. This information is important for the development of LBD interventions in that the ankle bearing should be maintained at a reasonable level. One possible intervention could be, to install a wooden platform on steep rooftops to form a flat surface for the roofers to step on. This way, it is possible to not only reduce LBD risk as it needs less severe bending to reach the rooftop according to the finding of 6.2 .1 , but also reduce the ankle flexion and ease the discomfort.

In terms of the facing directions, the Vicon data showed that, in facing sideways trials, the participants reached the maximum bending angle at the leftmost nailing spot (the bottom one), where a twisting in the trunk was also perceived. Both a significantly higher maximum angle and a slightly higher average trunk flexion angle were found in facing sideways conditions, which is unfavorable in practices. For the EMG data, the activity of the left-sided muscles was found to be different from the right-sided ones. For example, the left-sided multifidus has a relatively higher EMG signal than the right-sided. This can be due to a severe tension in the left at lower nailing spots. However, in this study, the twisting of the trunk was not studied. Hu et al. (2013) reported that bending on uneven slope can cause asymmetric trunk motion, and the ipsilateral lumbar muscles cease activity earlier than the contralateral lumbar muscles.

In the stooped postures, EMG signals significantly differentiate fast and slow frequencies in both nailing process and in-place flexion-extension trials. The EMG signals showed stronger muscle activeness in fast trials. 
b) Kneeling posture: In kneeling trials, the slope angle was found to have a significant effect on the trunk flexion angle with a lower trunk flexion angle on higher slopes, which is similar to stooped postures. However, EMG signals of the multifidus muscles were found to be higher on the $30^{\circ}$ slope. In addition, severe ankle stress and imbalance was reported by several participants on the $30^{\circ}$ slope. The existing study suggests that the increase of multifidus' activities can help elevate spinal stability (Ning et al., 2010). This was validated by video observation results. The lower extremities in kneeling postures, including legs and ankles, were observed to have a higher loading than that of stooped postures. Possible interventions for kneeling postures could be, wearing knee pads or kneeling on the cushion. For one thing, it can reduce the impact on the knee; for another, by increasing the height of the knee, the ankle flexion can be reduced.

For the kneeling postures, the EMG signals indicate that fast trials result in higher muscle activations and higher LBD risk. But the difference between the fast and slow trials is less that of stooped trials, especially EMG signals of erector spinae muscles. This can be due to that the time lengths for fast and slow trials are close to each other. Further study can either speed up the frequency for fast trials or enlarge the shingle size to explore the difference.

c) Stooped vs. Kneeling Postures: The kneeling postures $\left(<50^{\circ}\right.$ in Figure 16) have a significantly less trunk flexion angle than the stooped postures $\left(>70^{\circ}\right.$ in Figure 8$)$, which indicate a smaller spinal loading in kneeling postures. Due to the limit of the research scope, this study only measured the flexion and muscle activities in the lower back. However, the lower extremities can have a negative effect. The survey study was conducted among the participants about the discomfort in the back and other body parts. It was found that the participants perceived an imbalance and high pressure on the ankle while working on steep slopes for two 
postures, especially on the $30^{\circ}$ slope. The observational study was conducted on the postures of the lower extremities, that is, leg and ankles. It was found that the steep slope exposes the participants to a more severe ankle flexion both for stooped and kneeling postures than flat ground. The lower extremities for kneeling postures were found to have high loading impacts than that of the stooped due to severe bending in legs and ankles. In summary, from the perspective of alleviating LBD risk, the kneeling posture is preferred rather than the stooped, but it requires sufficient protective gears for the knee and ankle. It is recommended to wear knee pads or place cushion under the knee while installing shingles using kneeling postures.

d) Limitations: The current study has several limitations: 1) Participants are not actual roofers, but students from the West Virginia University. Their operations might not be professional. In the future, the real site assessment can be achieved, as the development of outdoor ergonomic assessment equipment, such as wireless EMG system. 2) The participants were assumed to have a uniform time distribution for flexion, nailing, and extension phases. However, during the trials, participant could hardly maintain a strictly steady work pace, which might result in either delay or finish ahead of time. The time difference can bring about errors in the data processing. Ideally, in this study, the time distribution for three phases was set to be 1:4:1, which means that $2 / 3$ of the time series was extracted as nailing process. However, assume that the flexion phase was prolonged and the real time distribution was 2:3:1, the nailing process extracted from the ideal distribution (1:4:1) would contain part of flexion and cause errors. In future, a trigger can be used to record the exact starting and ending time points of each phase. 3) Muscle fatigue is not studied in this experiment. The trial period is relatively short and cannot detect fatigue during the simulation. Future work can include prolonged trials and static severe bending on different working conditions. 4) The twisting angle of the trunk is not measured in 
this experiment, which is expected to differentiate side and uphill posture better. In future, more markers can be attached to upper body parts such as shoulders to measure the twisting of the trunk. 5) Only the trunk muscle is studied and used for the risk analysis. However, the ankle, legs and knee are also prone to WMSD risks due to heavy use in two roofing postures. In future, the ankle flexion can included in the analysis, and muscle activity of the legs is expected to be measured. 


\section{CHAPTER 8}

\section{CONCLUSION}

\subsection{Conclusions}

The roofing industry is a highly physical demanding industry and the working environment of roofers exposes them to various LBD hazards. This thesis begins with an introduction to the nature, and severity of LBD in the roofing industry. The harsh working environment of roofers and the LBD risk factors involved are reviewed. Through site visits and video observations, four physical risk factors are summarized to study their effects on LBD incidence. However, the literature review shows that there is a lack of enforced training, practices and promoted prevention programs in the roofing industry. In addition, existing roofing research mostly focused on fatal falls, and a very few studied the effects of risk factors on the non-fatal injury incidence.

In order to identify LBD risk factors among roofers, this thesis designed a factorial experiment. Through statistical analyses, several LBD risk factors were revealed. It is found that, faster working pace resulted in a higher low back muscle activation level. As the roof angle increases from $0^{\circ}$ to $15^{\circ}$, and then $30^{\circ}$, a decrease in trunk flexion angle was detected. The sidefacing work condition posed extra pressure on the lower back due to a more severe bending. However, although a decreased trunk flexion angle was detected on steep slopes, a higher stress on the ankles and decreased perceived stability was experienced and reported by the participants. 
These findings might be helpful to develop specific guidelines and prevention training for tackling the LBD risk among roofers.

The findings will help roofers avoid unfavorable scenarios with severe LBD risks. Also, potential interventions which can relieve spinal loading while posing a small stress on the lower extremities warrant further investigation.

\subsection{Contribution}

This thesis highlights the severity of LBD among roofers, and summarizes the LBD risk factors in the roofing industry. The risk factors are evaluated through a factorial experiment to reveal the ones with significant effects on spinal loadings and LBD risk. The findings of the study are expected to better educate the construction industry about the LBD risks involved in their daily tasks.

In summary, the contribution of this study is to generate knowledge to help better understand the effect of risk factors on LBD development. This knowledge can be used for education and to also serve as a point of departure for the development of LBD guidelines and interventions. 


\section{References}

Aarås, A., Horgen, G., Bjørset, H.-H. Ro, O., and Thoresen, M. (1998). "Musculoskeletal, visual and psychosocial stress in VDU operators before and after multidisciplinary ergonomic interventions." Applied Ergonomics, 29(5), 335-354.

Albers, J., Estill, C. F., and MacDonald, L. (2006). Proceedings of a meeting to explore the use of ergonomics interventions for the mechanical and electrical trades, Department of Health \& Human Services (DHHS), Centers for Disease Control and Prevention, National Institute fo Occupational Safety and Health (NIOSH), DHHS (NIOSH) Publication No. 2006-119, NIOSH-Publications Dissemination.

Albers, J., and Estill, C. F. (2007). Simple Solutions: Ergonomics for Construction Workers, Department of Health \& Human Services (DHHS), Centers for Disease Control and Prevention, National Institute for Occupational Safety and Health (NIOSH), DHHS (NIOSH) Publication No. 2007-122, NIOSH-Publications Dissemination.

Arcury, T. A., Summers, P., Rushing, J., Mills, T., Grzywacz, J. G., Mora, D., Lang, W., Quandt, S. A. 2014. Occupational safety perceptions, personal protective equipment use, and injury experience of Latino roofers. 142nd APHA Annual Meeting and Exposition, Nov. 15-19, New Orleans, LA.

Ariel Performance Analysis System (APAS) (2014). Ariel Dynamics, “http://www.arielnet.com/” (Dec. 13, 2014)

Bernard, B. P. (Ed.). (1997). Musculoskeletal disorders and workplace factors: a critical review of epidemiologic evidence for work-related musculoskeletal disorders of the neck, upper extremity, and low back (No. 97-141). Cincinnati, OH, USA: US 
Department of Health and Human Services, Public Health Service, Centers for Disease Control and Prevention, National Institute for Occupational Safety and Health.

Borg, G. (1970). "Perceived exertion as an indicator of somatic stress." Scandinavian Journal of Rehabilitation Medicine, 2(2), 92-98.

Boschman, J. S., van der Molen, H. F., Sluiter, J. K., and Frings-Dresen, M. H. (2012). "Musculoskeletal disorders among construction workers: a one-year follow-up study." BMC musculoskeletal disorders, 13(1), 196.

Buchholz, B., Paquet, V., Punnett, L., Lee, D., and Moir, S. (1996). "PATH: A work sampling-based approach to ergonomic job analysis for construction and other non-repetitive work." Applied Ergonomics, 27(3), 177-187.

Bureau of Labor Statistics (BLS). (2013a). Nonfatal occupational injuries and illnesses $\begin{array}{lllll}\text { requiring days away from } & 2012 .\end{array}$ <http://www.bls.gov/news.release/pdf/osh2.pdf> (Dec. 30, 2013).

Bureau of Labor Statistics (BLS). (2013b). Musculoskeletal disorders by nature of injury or illness, West $\quad$ Virginia. 〈http://www.bls.gov/iif/oshwc/osh/case/wv2012_nature.pdf〉.

Bureau of Labor Statistics (BLS). (2013c). B-1. Employees on nonfarm payrolls by major $\begin{array}{llll}\text { industry } & \text { sector, } & 1962 & \text { to }\end{array}$ <www.bls.gov/opub/ee/2012/ces/tableb1_201206.pdf >.

Bureau of Labor Statistics (BLS). (2013d). Musculoskeletal disorders by part of body affected, West Virginia. 〈http://www.bls.gov/iif/oshwc/osh/case/wv2012_pob.pdf〉. 
Bureau of Labor Statistics, (2004). Bureau of Labor Statistics Data. $<$ http://www.bls.gov/>\{02/05/2015\}

Bureau of Labor Statistics (BLS). (2015a). Nonfatal Occupational Injuries and Illnesses $\begin{array}{lllll}\text { Requiring } & \text { Days } & \text { Away } & \text { from } & \text { Work, }\end{array}$ $<$ http://www.bls.gov/news.release/archives/osh2_11092011.pdf $>\{$ Feb. 8, 15 $\}$

$\begin{array}{lllll}\text { Bureau of } & \text { Labor } & \text { Statistics } & \text { (BLS). } & \text { (2015b). Roofers. }\end{array}$ http://www.bls.gov/ooh/construction-and-extraction/mobile/roofers.htm

Canadian Centre for Occupational Health and Safety (CCOHS). (2013). Nonfatal occupational injuries and illnesses requiring days away from work. <www.ccohs.ca/oshanswers/diseases/rmirsi.html〉.

Center for Construction Research and Training (CPWR). (2013a). "48c. Rate of back injuries resulting in days away from work, selected industries, 2010 (Private wageand-salary workers)." The Construction Chart Book. 〈http://www.cpwr.com/publications/construction-chart-book〉.

Center for Construction Research and Training (CPWR). (2013b). “47b. Work-related musculoskeletal disorders resulting in days away from work in construction, by body part, 2003-2010." The Construction Chart Book. 〈http://www.cpwr.com/publications/construction-chart-book〉.

Center for Construction Research and Training (CPWR) (2015). "Hazard Analysis Stooped postures". <http://www.cpwrconstructionsolutions.org/hazard/603/stooped-postures.html> $\{2 / 16 / 2015\}$ 
Cheung, Z., Feletto, M., Galante, J., Waters, T., \& Centers for Disease Control and Prevention. (2007). Ergonomic guidelines for manual material handling. In NIOSH Publication (No. 2007-131). NIOSH.

Choi, S. D., \& Fredericks, T. K. (2008). Surface slope effects on shingling frequency and postural balance in a simulated roofing task. Ergonomics, 51(3), 330-344.

Choi, S. D., Yuan, L., \& Borchardt, J. G. (2014, September). Critical Analyses of Workrelated Musculoskeletal Disorders and Practical Solutions in Construction. In Proceedings of the Human Factors and Ergonomics Society Annual Meeting (Vol. 58, No. 1, pp. 1633-1637). SAGE Publications.

Connecticut Department of Public Health (CDPH). (2014). "Construction work and cumulative trauma disorders." Fact Sheet, <http://www.ct.gov/dph/lib/dph/environmental_health/eoha/pdf/construction_ctds _fact_sheet.pdf>.

Dai, B., Jin, S., Ning, X., \& Mirka, G. A. (2010). The effects of horizontal load speed and lifting frequency on lifting technique and biomechanics.Ergonomics, 53(8), 10241032.

Dane, D., M. Feuerstein, G. D. Huang, L. Dimberg, D. Ali and A. Lincoln (2002). "Measurement properties of a self-report index of ergonomic exposures for use in an office work environment." Journal of Occupational and Environmental Medicine 44(1): 73-81.

David, G. C. (2005). "Ergonomic methods for assessing exposure to risk factors for work-related musculoskeletal disorders." Occupational Medicine 55(3): 190-199. 
Devereux, J., I. Vlachonikolis and P. Buckle (2002). "Epidemiological study to investigate potential interaction between physical and psychosocial factors at work that may increase the risk of symptoms of musculoskeletal disorder of the neck and upper limb." Occupational and environmental medicine 59(4): 269-277.

Dic 2015. The free dictionary by farlex. \{http://medicaldictionary.thefreedictionary.com/low+back+pain $\}\{$ Aug. 18, 2015\}

Dong, X. S., Men, Y., Ringen, K. 2010a. Work-related injuries among Hispanic construction workers-Evidence from the Medical Expenditure Panel Survey. American Journal of Industrial Medicine, 53(6): 561-569.

Dong, X. S., Wang, X., Daw, C. 2010b. Fatal and nonfatal injuries among Hispanic construction workers. CPWR Data Brief 2(2):1-19. Retrieved Aug. 16, 2014, from http://www.cpwr.com/pdfs/Hispanic_Data_Brief3.pdf.

Fathallah, F. A., Meyers, J. M., \& Janowitz, I. (2004). Stooped and squatting postures in the workplace. In Proceedings of the symposium for stooped and squatting posture in the workplace (pp. 29-30).

Fredericks, T. K., Abudayyeh, O., Choi, S. D., Wiersma, M., \& Charles, M. (2005). Occupational injuries and fatalities in the roofing contracting industry. J. Constr. Eng. Manage., 131(11), 1233-1240.

Gatchel, R. J., \& Schultz, I. Z. (Eds.). (2012). Handbook of occupational health and wellness. Springer Science \& Business Media.

Gelman, Andrew (February 2005). "Analysis of variance? why it is more important than ever". The Annals of Statistics 33 (1): 1-53. doi:10.1214/009053604000001048 
George G. Roussas (1997) A Course in Mathematical Statistics, 2nd Edition, Academic Press, p397

George Mason University (GMU), 2015. <https://www2.gmu.edu/>. \{08/20/2015\}

Gilkey, David P., et al. "Low back pain among residential carpenters: ergonomic evaluation using OWAS and 2D compression estimation."International Journal of Occupational Safety and Ergonomics 13.3 (2007): 305-321.

Gillen, M., Faucett, J.A., Beaumont, J.J., \& McLoughlin, E. (1997). Injury severity associated with nonfatal construction falls. American Journal of Industrial Medicine, 32, 647- 655 .

Grzywacz, J. G., Quandt, S. A., Mills, T., Marín, A., Summers, P., Lang, W., ... \& Arcury, T. A. (2012). Employer provision of personal protective equipment to Latino workers in North Carolina residential construction. NEW SOLUTIONS: A Journal of Environmental and Occupational Health Policy, 22(2), 175-190.

Hayden, J. A., Van Tulder, M. W., \& Tomlinson, G. (2005). Systematic review: strategies for using exercise therapy to improve outcomes in chronic low back pain. Annals of internal medicine, 142(9), 776-785.

Health and Safety Executive (HSE 2014). Musculoskeletal disorders. <http://www.hse.gov.uk/construction/healthrisks/msd.htm> $\{08 / 02 / 2015\}$.

Hignett, S. and L. McAtamney (2000). "Rapid entire body assessment (REBA)." Applied ergonomics 31(2): 201-205.

Hoe, V., D. M. Urquhart, H. L. Kelsall and M. R. Sim (2012). "Ergonomic design and training for preventing work-related musculoskeletal disorders of the upper limb and neck in adults." 
Hsiao, H. (2014). Fall prevention research and practice: a total worker safety approach. Industrial health, 52(5), 381.

Hu, B., Ning, X., \& Nimbarte, A. D. (2013). The changes of lumbar muscle flexionrelaxation response due to laterally slanted ground surfaces.Ergonomics, 56(8), 1295-1303.

Hu, B., Shan, X., Zhou, J., \& Ning, X. (2014). "The effects of stance width and foot posture on lumbar muscle flexion-relaxation phenomenon. Clinical Biomechanics, 29(3), 311-316.

Hunting, K. L., Murawski, J. A., \& Welch, L. S. (2004). Occupational Injuries among Construction Workers Treated at the George Washington University Emergency Department, 1990-97. The Center to Protect Workers' Rights (CPWR).

Indiana gov (IN) 2008. <http://www.in.gov/core/>\{05/06/2015\}

Infrastructure Health \& Safety Association (IHSA). (2010). MSD hazards and controls, SHEETMETAL. < http://www.ihsa.ca/PDFs/Products/Id/W314.pdf > \{Aug. 8, 2015\} Infrastructure Health \& Safety Association (IHSA). (2013). MSD hazards and controls for low-slope roofers. < http://www.ihsa.ca/PDFs/Products/Id/IHSA024.pdf > Aug. $8,2015\}$

Inyang, N., M. Al-Hussein, M. El-Rich and S. Al-Jibouri (2012). "Ergonomic Analysis and the Need for Its Integration for Planning and Assessing Construction Tasks." Journal of Construction Engineering and Management-Asce 138(12): 1370-1376. 
Jaffar, N., A. H. Abdul-Tharim, I. F. Mohd-Kamar and N. S. Lop (2011). "A Literature Review of Ergonomics Risk Factors in Construction Industry." Procedia Engineering 20(0): 89-97.

Jin, S., McCulloch, R., \& Mirka, G. A. (2009). Biomechanical evaluation of postures assumed when harvesting from bush crops. International journal of industrial ergonomics, 39(2), 347-352.

Jones, T. and S. Kumar (2010). "Comparison of ergonomic risk assessment output in four sawmill jobs."

Kang, Kaffee, and Rob Thallon. Graphic guide to frame construction. Student ed. Upper Saddle River, N.J.: Prentice Hall, 1998. 177. Print.

Kerr, M.S., Frank, J.W., Shannon, H.S., Norman, R.W., Wells, R.P., and Neumann, W.P. (2001). "Biomechanical and psychosocial risk factors for low back pain at work." American Journal of Public Health, 91(7): 1069-1075.

Killough, M.K., and Crumpton, L. L. (1996). "An investigation of cumulative trauma disorders in the construction industry." International Journal of Industrial Ergonomics, 18(5), 399-405.

Kim, S., and Nussbaum, M. A. (2013). "Performance evaluation of a wearable inertial motion capture system for capturing physical exposures during manual material handling tasks." Ergonomics, 56(2), 314-326.

Kingma, I., de Looze, M. P., Toussaint, H. M., Klijnsma, H. G., and Bruijnen, T. (1996). "Validation of a full body 3-D dynamic linked segment model." Human Movement Science, 15(6), 833-860. 
Kroemer, K. H., and Sheridan, T. B. (1988). Ergonomic models of anthropometry, human biomechanics, and operator-equipment interfaces: proceedings of a workshop, National Academies Press.

Kucera, K. L., Loomis, D., Lipscomb, H. J., Marshall, S. W., Mirka, G. A., and Daniels, J. L. (2009). "Ergonomic risk factors for low back pain in North Carolina crab pot and gill net commercial fishermen." American journal of industrial medicine, 52(4), 311-321.

Kuorinka, I., Jonsson, B., Kilbom, A., Vinterberg, H., Biering-Sørensen, F., Andersson, G., and Jørgensen, K. (1987). "Standardised Nordic questionnaires for the analysis of musculoskeletal symptoms." Applied ergonomics, 18(3), 233-237.

Leigh, J. (2011). "Economic burden of occupational injury and illness in the United States." Milbank Quarterly, 89(4), 728-772.

Li, G., and Buckle, P. (1999). "Current techniques for assessing physical exposure to work-related musculoskeletal risks, with emphasis on posture-based methods." Ergonomics, 42(5), 674-695.

Li, K. W., and Yu, R. (2011). "Assessment of grip force and subjective hand force exertion under handedness and postural conditions." Applied ergonomics, 42(6), 929-933.

Lloyd, D. G., and Besier, T. F. (2003). "An EMG-driven musculoskeletal model to estimate muscle forces and knee joint moments in vivo." Journal of biomechanics, 36(6), 765-776.

Lowry, Richard. "One Way ANOVA - Independent Samples". Vassar.edu. Retrieved December 4, 2008. 
Lynch Ryan (2015). "Highway regulators calling for better truck safety" $<$ http://www.workerscompinsider.com/safety-health> $\{02 / 16 / 15\}$

Miller Jr, R. G. (1997). Beyond ANOVA: Basics of applied statistics. CRC Press.

Marras, W. S., and Granata, K. P. (1997a). "The development of an EMG-assisted model to assess spine loading during whole-body free-dynamic lifting." Journal of Electromyography and Kinesiology, 7(4), 259-268.

Marras, W. S., and Granata, K. P. (1997b). "Spine loading during trunk lateral bending motions." Journal of Biomechanics, 30(7), 697-703.

McAtamney, L., and Corlett, E. N. (1993). "RULA: a survey method for the investigation of work-related upper limb disorders." Applied ergonomics, 24(2): 91-99.

McGill, S., and Norman, R. (1986). "1986 Volvo award in biomechanics: Partitioning of the L4-L5 dynamic moment into disc, ligamentous, and muscular components during lifting." Spine, 11(7), 666-678.

McGraw-Hill Construction (MHC). (2012). "Construction industry workforce shortages: role of certification, training and green jobs in filling the gaps." SmartMarket Report. 〈http://www.usgbc.org/Docs/Archive/General/Docs18984.pdf >.

Moeslund, T. B., Hilton, A., and Krüger, V. (2006). "A survey of advances in visionbased human motion capture and analysis." Computer vision and image understanding, 104(2), 90-126.

Montgomery, D.C., 2005. Design and Analysis of Experiments, fifth ed. John Wiley \& Sons, New York.

National Bureau of Standards (NBS), 1975. <http://www.nist.gov/nvl/nistnbs_history.cfm > $02 / 06 / 2015\}$ 
National Institute of Health, 2015, Low Back Pain Brochure, <http://www.ninds.nih.gov/disorders/backpain/low-back-pain-brochure.pdf> National Institute of Neurological Disorders and Stroke (NINDS), 2014. Low Back Pain $\begin{array}{lll}\text { Fact Sheet, } & 2014 .\end{array}$ <http://www.ninds.nih.gov/disorders/backpain/detail_backpain.htm>\{Feb.8, 2015\}

$\begin{array}{llll}\text { National } & \text { Contractors, } & \text { INC, } & \text { (NCINC). }\end{array}$

<http://www.nationalcontractors.net/specialty-services-roof-low-slope.html> $\{2 / 16 / 2015\}$

Neumann, W.P., Wells, R.P., Norman, R.W., Andrews, D.M., Frank, J., Shannon, H.S., and Kerr, M.S. (1999). "Comparison of four peak spinal loading exposure measurement methods and their association with low-back pain." Scandinavian Journal of Work, Environment \& Health, 25(5): 404-409.

Nimbarte, A.D., Zreiqat, M., Ning, X., 2014. "Impact of fatigue and shoulder position on the flexion-relaxation response in cervical spine", Clinical Biomechanics 29(3): 277-282.

Ning, X., Haddad, O., Jin, S., \& Mirka, G. A. (2011). Influence of asymmetry on the flexion relaxation response of the low back musculature. Clinical Biomechanics, 26(1), 35-39.

Ning, X., and Guo, G. (2013). "Assessing spinal loading using the kinect depth sensor: a feasibility study." Sensors Journal, IEEE, 13(4), 1139 - 1140.

Ning, X., and Mirka, G.A. (2010). "The effect of sinusoidal rolling ground motion on lifting biomechanics”, Applied Ergonomics 42(1): 131-137. 
Ning, X., Zhou, J., Dai, B., and Jaridi, M. (2014). “The assessment of material handling strategies in dealing with sudden loading: the effects of load handling position on trunk biomechanics", Applied Ergonomics 45(6): 1399-1405.

Norman, R., Wells, R., Neumann, P., Frank, J., Shannon, H., and Kerr, M. (1998). “A comparison of peak vs cumulative physical work exposure risk factors for the reporting of low back pain in the automotive industry." Clinical Biomechanics, 13(8), 561-573.

North Carolina Department of Labor (NCDOL). (2014). Sample program on "construction safety and health policy". 〈www.nclabor.com/osha/consult/sampleprograms/ConstructionS\&HPolicy.pdf〉.

Nunes, I. L. and P. M. Bush (2012) "Work-Related Musculoskeletal Disorders Assessment and Prevention."

Nussbaum, M. A., and Chaffin, D. B. (1996). "Development and evaluation of a scalable and deformable geometric model of the human torso." Clinical Biomechanics, 11(1), 25-34.

Nussbaum, M. A., and Chaffin, D. B. (1998). "Lumbar muscle force estimation using a subject-invariant 5-parameter EMG-based model." Journal of Biomechanics, 31(7), 667-672.

$\begin{array}{lllll}\text { O*Net (2013). } & \text { Summary } & \text { report } & \text { for } & \text { roofers. }\end{array}$ <http://www.onetonline.org/find/descriptor/browse/Work_Context/> $\{2 / 16 / 2015\}$

Occupational Safety and Health Administration (OSHA). (1998). "Occupational safety and health standards, toxic and hazardous substances." Code of federal regulations 29. 
Occupational Safety and Health Administration (OSHA). (2012). White Paper on Injury and Illness Prevention $\quad$ Programs. <www.osha.gov/dsg/topics/safetyhealth/OSHAwhite-paper-january2012sm.pdf〉.

Occupational Safety and Health Administration (OSHA). (2014). Ergonomics. <www.osha.gov/SLTC/ergonomics/> (Oct. 18, 2014).

Occupational Safety and Health Administration (OSHA). (2015). "Reducing Falls During Residential Construction: Re-Roofing". < www.osha.gov/Publications/reducingfalls-during-residential-construction-re-roofing.html> (August. 18, 2015).

Ohio Bureau of Workers' Compensation (OBWC). (2014). "Ergonomics Best Practices for the Construction Industry." Ergonomic Industry Guidelines, $<$ http://www.ohiobwc.com/downloads/brochureware/publications/ConstSafeGrant. pdf>.

Pan, C. S., Gardner, L. I., Landsittel, D. P., Hendricks, S. A., Chiou, S. S., \& Punnett, L. (1999). Ergonomic exposure assessment: an application of the PATH systematic observation method to retail workers. International journal of occupational and environmental health, 5(2), 79-87.

Parekh, S., \& Phatak, N. R. (2014). A COMPARATIVE STUDY BETWEEN ERGONOMIC ADVICES VERSUS ERGONOMIC PLUS PHYSIOTHERAPY INTERVENTION IN LOW BACK PAIN AMONG FARMERS. Int J Physiother Res, 2(5), 719-24.

Pennsylvania Health Care Cost Containment Council (PHC4), 2015. Back pain: a costly ache http://www.phc4.org/reports/fyi/docs/phc4fyi24.pdf 
Putz-Anderson, V., Bernard, B. P., Burt, S. E., Cole, L. L., Fairfield-Estill, C., Fine, L. J., ... \& Tanaka, S. (1997). Musculoskeletal disorders and workplace factors. National Institute for Occupational Safety and Health (NIOSH).

Richards, J. G. (1999). "The measurement of human motion: A comparison of commercially available systems." Human Movement Science 18(5): 589-602.

Reaz, M. B. I., Hussain, M. S., \& Mohd-Yasin, F. (2006). Techniques of EMG signal analysis: detection, processing, classification and applications. Biological procedures online, $8(1), 11-35$.

Reme, S. E., Dennerlein, J. T., Hashimoto, D., and Sorensen, G. (2012). "Musculoskeletal pain and psychological distress in hospital patient care workers." Journal of occupational rehabilitation, 22(4), 503-510.

Richards, J. G. (1999). "The measurement of human motion: A comparison of commercially available systems." Human Movement Science, 18(5), 589-602.

Schultz, A. B., and Andersson, G. B. (1981). "Analysis of loads on the lumbar spine." Spine, 6(1), 76-82.

Silverstein, B. A. (1985). The Prevalence of Upper Extremity Cumulative Trauma Disorders in Industry. Ph.D. , University of Michigan.

Simeonov, P., \& Hsiao, H. (2001). Height, surface firmness, and visual reference effects on balance control. Injury Prevention, 7(suppl 1), i50-i53.

Simonton, K. (2007). "Ergonomics Best Practices for the Residential Construction Framing Contractor." 10th Annual Applied Ergonomics Conference, March 12-15, Dallas, Texas. 
Solomonow, M., Baratta, R. V., Banks, A., Freudenberger, C., and Zhou, B. H. (2003). "Flexion-relaxation response to static lumbar flexion in males and females." Clinical Biomechanics, 18(4), 273-279.

Sousa, A. S., and Tavares, J. M. R. (2012). Surface electromyographic amplitude normalization methods: a review. Electromyography: New Developments, Procedures and Applications.

Spielholz, P., Silverstein, B., Morgan, M., Checkoway, H., and Kaufman, J. (2001). "Comparison of self-report, video observation and direct measurement methods for upper extremity musculoskeletal disorder physical risk factors." Ergonomics, 44(6), $588-613$.

Theodore Oslay (1992). Cumulative Trauma Injury. Dynamic Chiropractic - April 24, 1992, Vol. 10, Issue 09

UMass Lowell Hardhat Ergonomics (UMLHE). (2000). "Ergonomics awareness training for construction workers." Powerpoint Slides, A workshop for workers and supervisors in identifying and solving ergonomic problems on construction sites, <http://www.uml.edu/Images/HHE_2hr_slides_v1-2_tcm18-1375.ppt>.

University of Western Ontario (UWO). (2011). MSD Prevention Standard Workbook, <http://www.uwo.ca/hr/form_doc/health_safety/doc/ergo/msd_prevention_standar d_workbook.pdf>.

University of Wyoming 2015, Risk Management \& Safety, What is Ergonomics and Why is it Important? <http://www.uwyo.edu/ehs/_files/docs/factsheets/whatisergonomics.pdf> 
Vieira, E. R., Kumar, S., Coury, H. J., and Narayan, Y. (2006). "Low back problems and possible improvements in nursing jobs." Journal of advanced nursing, 55(1), 79-89. Vicon. Vicon Real Time SDK and API. Oxford UK: Vicon. 2002.

Wang, D., Dai, F., and Ning, X.P. (2015a). Risk assessment of work-related musculoskeletal disorders in construction: state of the art review. Journal of construction engineering and management, in press.

Wang, Di, Boyi Hu, Fei Dai, and Xiaopeng Ning (2015b). "Sensor-based factorial experimental study on low back disorder risk factors among roofers."

Warade, S., Aghav, J., Claude, P., and Udayagiri, S. (2012). "Real-time detection and tracking with Kinect.” Intl. Conf. Comp. Info. Tech., Bangkok, 86-89.

Washington State Department of Labor \& Industries (WSDLI). (2003). L\&I issues statement on repeal of rule. <http://lni.wa.gov/news/2003/pr031105a.asp>.

Waters, T.R., Putz-Anderson, V., Garg, A., and Fine, L.J. (1993). "Revised NIOSH equation for the design and evaluation of manual lifting tasks." Ergonomics, 36(7), 749-776.

Waters, T. R., Putz-Anderson, V., \& Garg, A. (1994). Applications manual for the revised NIOSH lifting equation (pp. 94-110). National Institute for Occupational Safety and Health, Cincinnati, Ohio.

Welch, L.S., Haile, E., Boden, L.I., and Hunting, K.L. (2010). "Impact of musculoskeletal and medical conditions on disability retirement-a longitudinal study among construction roofers." American journal of industrial medicine, 53(6): 552560. 
Wikipedia. (2015). "Roof shingle".<http://en.wikipedia.org/wiki/Roof_shingle> $\{2 / 16 / 2015\}$.

Workers Comp Resource Center (WCRC). (2012). "Worker's compensation in the construction industry." <http://reduceyourworkerscomp.com/industryconstruction/> (May 2, 2014).

Zhou, J., Ning, X., Nimbarte, A. D., \& Dai, F. (2015). The assessment of materialhandling strategies in dealing with sudden loading: the effect of uneven ground surface on trunk biomechanical responses. Ergonomics, 58(2). 259-267. 


\section{APPENDIX I: EMG and VICON Data Processing Code (MATLAB R2013a)}

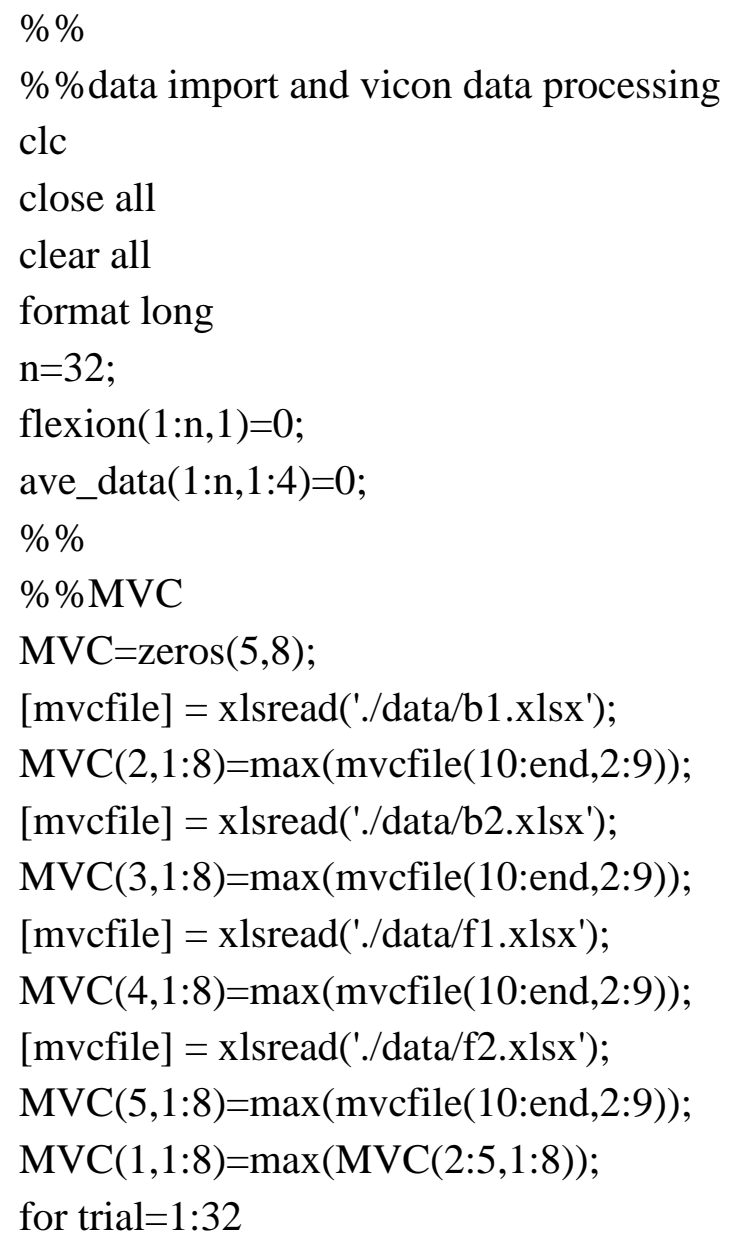


\% lumbar flexion angle

$\mathrm{x}=($ file $(\mathrm{i}, 6)-$ file $(\mathrm{i}, 9)) / \operatorname{sqrt}\left((\text { file }(\mathrm{i}, 5)-\text { file }(\mathrm{i}, 8))^{\wedge} 2+(\text { file }(\mathrm{i}, 4)-\text { file }(\mathrm{i}, 7))^{\wedge} 2\right)$;

angle $(\operatorname{trial}, \mathrm{k})=90-\operatorname{abs}(360 * \operatorname{atan}(\mathrm{x}) /(2 * \mathrm{pi}))$;

$\mathrm{k}=\mathrm{k}+1$;

end

\%disp(sprintf('Angle of file: \%d.xlsx', data))

\%display(angle); \%display one angle every ten data

flexion $($ trial, 1$)=\max ($ angle $($ trial,$:))$;

$\%$ disp(sprintf('\%d max flexion angle: \%d', data,m))

$\% \operatorname{disp}(\operatorname{sprintf}(' \% \mathrm{~d}, \mathrm{~m}))$

$\%$ end

$\% \operatorname{row}(1)+$

$\%$ size(file)

$\% \% \%$ EMG processing

$\% \%$ EMG Processing

[file, text] = xlsread(directory,num2str(sheet),['A9:U',num2str(filesize(1,1)),"]);

aa $=$ size(file);

$\mathrm{EMG}=$ file $($ row $(1)+2:$ end $, 2: 9)$;

$[\mathrm{m}, \mathrm{n}]=\operatorname{size}(\mathrm{EMG})$;

$\% \% \% \% \% \% \% \% \% \% \% \% \% \% \% \% \mathrm{EMG}=\mathrm{abs}(\mathrm{EMG})$

$\%$ Raw EMG data

$\% \quad[\mathrm{~m}, \mathrm{z}]=\operatorname{size}(\mathrm{EMG})$

$\% \quad$ freq $=1000 ; \%$ sampling frequency

$\% \quad \mathrm{n}=$ floor(m/freq); \%n=2; \%duration (sec)

$\% \quad \mathrm{~N}=\mathrm{n} *$ freq $/ 2 ; \%$ number of samples in half of FFT

$\% \mathrm{f}=$ freq $*(0: \mathrm{N}) / 2 / \mathrm{N}$;

$\% \quad \mathrm{ch}=\mathrm{z} ; \%$ number of channels

$\% \mathrm{nn}=\mathrm{n} *$ freq;

$\% \quad \mathrm{EMG}=\mathrm{EMG}(1: \mathrm{nn},:) ; \%$

$\% \% \quad \% \% \% \% \% \% \% \% \% \% \% \% \% \% \% \% \% \% \% \% \% \% \% \% \% \% \% \% \% \% \% \% \% \% \% \% \% \% \% \% \% \%$ \%\%\%test $\% \% \% \% \% \% \% \% \% \% \% \% \% \% \% \% \% \% \% \% \% \% \% \% \% \% \% \% \% \% \% \% \% \% \% \% \% \% \% \%$

Rectified_EMG=abs(EMG);

$\% \%$ subplot

$\%$ Fs $=1024 ; \quad \%$ Sampling frequency

$\% \mathrm{~T}=1 / \mathrm{Fs} ; \quad \%$ Sample time

$\% \mathrm{~L}=\mathrm{m} ; \quad \%$ Length of signal

$\% \mathrm{t}=(0: \mathrm{L}-1) * \mathrm{~T}$; 
$\% \mathrm{y}=\mathrm{t}^{*} \mathrm{EMG}(:, \mathrm{k})$

for $\mathrm{k}=1: 8$

$\mathrm{Fe}=1000 ; \%$ Samling frequenc

$\mathrm{Fc}=2$; \% Cut-off frequency (from $2 \mathrm{~Hz}$ to $6 \mathrm{~Hz}$ depending to the type of your electrod)

$\mathrm{N}=4 ; \%$ Filter Order

$[\mathrm{B}, \mathrm{A}]=$ butter(N,Fc*2/Fe, 'low'); \%filter's parameters

Filter_EMG=Rectified_EMG;

Filter_EMG(:,k)=filtfilt(B, A, Rectified_EMG(:,k));

end

$$
\text { for } \mathrm{i}=1: \mathrm{m}
$$

if Filter_EMG(i,k) $>\operatorname{MVC}(1, \mathrm{k})$

Filter_EMG $(\mathrm{i}, \mathrm{k})=\mathrm{MVC}(1, \mathrm{k}) ; \%$ If there is any EMG larger than MVC, set it as

MVC

$$
\text { end }
$$

end

start_nail=floor $(0.23 * \mathrm{~m})$;

end_nail=floor $(0.67 * \mathrm{~m})$;

for $\mathrm{k}=5: 8$

ave_data(trial,k-4)= mean(Filter_EMG(start_nail:end_nail,k));\%changeable coefficient

Nail_EMG(trial,k-4) = ave_data(trial,k-4)/MVC $(1, \mathrm{k}) ;$ \% print Normalized EMG

$\%$ subplot( $(3,1,1)$; plot(EMG(:,8)), grid on, title('original emg')

$\%$ subplot( $(3,1,2) ; p l o t($ Rectified_EMG(:,8)), grid on, title('rectified emg')

$\%$ subplot(3,1,3);plot(Filter_EMG(:,8)), grid on, title('filtered emg')

end

$\% \% \%$ Filtering using butterworth filter of order 4

$\% \%$ High-pass filter

$\% \quad$ filt $1=$ fdesign.highpass('n,f3db',4,2*10*(1/1024)); \%high-pass filter, cut off frequency at $10 \mathrm{~Hz}$, sampling frequency of $1000 \mathrm{~Hz}$

$\% \quad \mathrm{H} 1=$ design(filt1,'butter');

$\%$ highpass_EMG $=$ filter(H1,EMG(:,k)); \% sampling frequency of $1000 \mathrm{~Hz}$

$\% \%$ Low-pass filter

$\% \quad$ filt2 = fdesign.lowpass ('n,f3db',4,2*500*(1/1024)); \%low-pass filter, cut off frequency at $500 \mathrm{~Hz}$

$\% \quad \mathrm{H} 2=\operatorname{design}($ filt2,'butter');

$\%$ lowpass_EMG $=$ filter(H2,highpass_EMG);

$\% \%$ Notch Filter $(50 \mathrm{~Hz})$

$\% \quad$ filt3 = fdesign.notch $(4,0.05,10) ; \%$ notch filter $(50 \mathrm{~Hz})$ 
$\% \quad \mathrm{H} 3=\operatorname{design}($ filt3);

$\%$ filtered_EMG(:,k) = filter(H3,lowpass_EMG);

$\%$ figure; plot(filtered_EMG(:,k)), grid on, title('filtered EMG') ;

$\%$ ave_data $=$ mean(filtered_EMG(:,k));

$\%$ end

$\% \quad \mathrm{Fe}=1000 ; \%$ Samling frequency in $\mathrm{Hz}$

$\% \mathrm{Fc}=3 ; \%$ Cut-off frequency (from $2 \mathrm{~Hz}$ to $6 \mathrm{~Hz}$ depending to the type of your electrod)

$\% \mathrm{~N}=4 ; \%$ Filter Order

$\%[\mathrm{~B}, \mathrm{~A}]=$ butter(N,Fc*2/Fe, 'low'); \%filter's parameters

$\% \mathrm{EMG}=$ filter(B,A, Rectified_EMG); \%in the case of real-time treatment

$\% \%$ EMG data

export $\quad \% \% \% \% \% \% \% \% \% \% \% \% \% \% \% \% \% \% \% \% \% \% \% \% \% \% \% \% \% \% \% \% \% \% \% \% \% \% \% \%$ $\% \% \% \% \%$ test $\% \% \% \% \% \% \% \% \% \% \% \% \% \% \% \% \% \% \% \% \% \% \% \% \% \% \% \% \% \% \% \% \% \% \% \% \% \% \% \%$ xlswrite('filtered_emg.xlsx',Filter_EMG,num2str(trial),'A1');

xlswrite('intervalangle.xlsx',angle','Angle','A1');

end

xlswrite('nail_emg.xlsx',Nail_EMG,'nail_emg','A1');

xlswrite('maxangle.xlsx',flexion,'Angle','A1');

\%xlswrite('maxemg.xlsx',max_EMG,'EMG','A1'); 


\section{APPENDIX II: Survey Form of LBD Study on Roofing Activities}

Note: 1-20 trials are stooped postures

21-32 trials are crawling postures

For each condition, there are two repetitions, you just need to provide one rating for them Rating from 0-9: 0 means very comfortable, 9 means most risky

\begin{tabular}{|c|c|c|c|c|c|}
\hline Number & Slope angle & Direction & Frequency & $\begin{array}{c}\text { Back } \\
\text { Rating(0-9) }\end{array}$ & $\begin{array}{l}\text { Other body parts } \\
\text { Rating }(0-9)\end{array}$ \\
\hline 1 & 0 & Uphill & Slow & & \\
\hline 2 & 0 & Uphill & Slow & & \\
\hline 3 & 0 & Uphill & Fast & & \\
\hline 4 & 0 & Uphill & Fast & & \\
\hline 5 & 15 & Uphill & Slow & & \\
\hline 6 & 15 & Uphill & Slow & & \\
\hline 7 & 15 & Uphill & Fast & & \\
\hline 8 & 15 & Uphill & Fast & & \\
\hline 9 & 15 & Side & Slow & & \\
\hline 10 & 15 & Side & Slow & & \\
\hline 11 & 15 & Side & Fast & & \\
\hline 12 & 15 & Side & Fast & & \\
\hline 13 & 30 & Uphill & Slow & & \\
\hline 14 & 30 & Uphill & Slow & & \\
\hline 15 & 30 & Uphill & Fast & & \\
\hline 16 & 30 & Uphill & Fast & & \\
\hline 17 & 30 & Side & Slow & & \\
\hline 18 & 30 & Side & Slow & & \\
\hline 19 & 30 & Side & Fast & & \\
\hline 20 & 30 & Side & Fast & & \\
\hline 21 & 30 & Unhill & Slow & & \\
\hline 22 & 30 & Uphill & Slow & & \\
\hline 23 & 30 & Uphill & Fast & & \\
\hline 24 & 30 & Uphill & Fast & & \\
\hline 25 & 15 & Uphill & Slow & & \\
\hline 26 & 15 & Uphill & Slow & & \\
\hline 27 & 15 & Uphill & Fast & & \\
\hline 28 & 15 & Uphill & Fast & & \\
\hline 29 & 0 & Uphill & Slow & & \\
\hline 30 & 0 & Uphill & Slow & & \\
\hline 31 & 0 & Uphill & Fast & & \\
\hline 32 & 0 & Uphill & Fast & & \\
\hline
\end{tabular}


APPENDIX III: Trunk Flexion Angle and Normalized EMG data (15 Subjects)

- Stooped trials

\begin{tabular}{|c|c|c|c|c|c|c|c|c|c|}
\hline Subject & Number & $\begin{array}{l}\text { Tilt } \\
\text { angle }\end{array}$ & Direction & Frequency & Flexion & Esl & Esr & Mul & Mur \\
\hline 1 & 1 & 0 & Uphill & Slow & 74.019 & 0.13004 & 0.19541 & 0.11814 & 0.16148 \\
\hline 1 & 2 & 0 & Uphill & Slow & 71.8817 & 0.12521 & 0.17726 & 0.11505 & 0.12405 \\
\hline 1 & 3 & 0 & Uphill & Fast & 75.885 & 0.11327 & 0.16379 & 0.09554 & 0.10962 \\
\hline 1 & 4 & 0 & Uphill & Fast & 76.9389 & 0.11264 & 0.16311 & 0.09564 & 0.10905 \\
\hline 1 & 5 & 15 & Uphill & Slow & 57.4242 & 0.09861 & 0.14782 & 0.07789 & 0.09107 \\
\hline 1 & 6 & 15 & Uphill & Slow & 57.4069 & 0.09789 & 0.14737 & 0.07711 & 0.09416 \\
\hline 1 & 7 & 15 & \begin{tabular}{|l|} 
Uphill \\
\end{tabular} & Fast & 61.9798 & 0.09863 & 0.14705 & 0.07686 & 0.12576 \\
\hline 1 & 8 & 15 & Uphill & Fast & 55.7313 & 0.09851 & 0.14673 & 0.07625 & 0.10392 \\
\hline 1 & 9 & 15 & Side & Slow & 71.5617 & 0.09604 & 0.14384 & 0.07379 & 0.08653 \\
\hline 1 & 10 & 15 & Side & Slow & 67.2295 & 0.096 & 0.14364 & 0.07331 & 0.08646 \\
\hline 1 & 11 & 15 & Side & Fast & 70.7439 & 0.09752 & 0.14362 & 0.07604 & 0.0872 \\
\hline 1 & 12 & 15 & Side & Fast & 70.3363 & 0.09495 & 0.1428 & 0.07262 & 0.0858 \\
\hline 1 & 13 & 30 & Uphill & Slow & 46.9547 & 0.09159 & 0.13885 & 0.06895 & 0.08152 \\
\hline 1 & 14 & 30 & Uphill & Slow & 48.3032 & 0.09106 & 0.13814 & 0.0677 & 0.08059 \\
\hline 1 & 15 & 30 & Uphill & Fast & 47.7797 & 0.09059 & 0.13775 & 0.06776 & 0.08018 \\
\hline 1 & 16 & 30 & Uphill & Fast & 45.2556 & 0.09025 & 0.13801 & 0.06734 & 0.07982 \\
\hline 1 & 17 & 30 & Side & Slow & 67.0608 & 0.08988 & 0.13734 & 0.06694 & 0.07938 \\
\hline 1 & 18 & 30 & Side & Slow & 65.1174 & 0.09029 & 0.13713 & 0.06554 & 0.07884 \\
\hline 1 & 19 & 30 & Side & Fast & 68.7709 & 0.09008 & 0.13723 & 0.06618 & 0.08759 \\
\hline 1 & 20 & 30 & Side & Fast & 65.4084 & 0.08924 & 0.13636 & 0.06498 & 0.07961 \\
\hline 2 & 1 & 0 & Uphill & Slow & 72.9247 & 0.09045 & 0.09348 & 0.08687 & 0.07739 \\
\hline 2 & 2 & 0 & Uphill & Slow & 71.5025 & 0.09181 & 0.09256 & 0.09151 & 0.07587 \\
\hline 2 & 3 & 0 & Uphill & Fast & 73.1322 & 0.08953 & 0.09287 & 0.13662 & 0.07829 \\
\hline 2 & 4 & 0 & Uphill & Fast & 73.1607 & 0.09282 & 0.0921 & 0.11784 & 0.07528 \\
\hline 2 & 5 & 15 & Uphill & Slow & 61.0615 & 0.08226 & 0.08535 & 0.13651 & 0.09698 \\
\hline 2 & 6 & 15 & Uphill & Slow & 63.0663 & 0.08359 & 0.08502 & 0.11484 & 0.08275 \\
\hline 2 & 7 & 15 & Uphill & Fast & 62.9447 & 0.07852 & 0.08372 & 0.29884 & 0.14783 \\
\hline 2 & 8 & 15 & Uphill & Fast & 64 & 0.07924 & 0.08104 & 0.26269 & 0.16473 \\
\hline 2 & 9 & 15 & Side & Slow & 74.3976 & 0.08645 & 0.08268 & 0.2259 & 0.07922 \\
\hline 2 & 10 & 15 & Side & Slow & 74.5507 & 0.09352 & 0.08223 & 0.2358 & 0.0834 \\
\hline 2 & 11 & 15 & Side & Fast & 72.5554 & 0.08231 & 0.08171 & 0.43879 & 0.13392 \\
\hline 2 & 12 & 15 & Side & Fast & 72.3181 & 0.07195 & 0.07873 & 0.2741 & 0.09549 \\
\hline 2 & 13 & 30 & Uphill & Slow & 48.8025 & 0.08918 & 0.0762 & 0.12911 & 0.09995 \\
\hline
\end{tabular}




\begin{tabular}{|c|c|c|c|c|c|c|c|c|c|}
\hline 2 & 14 & 30 & Uphill & Slow & 47.0155 & 0.08705 & 0.07803 & 0.10981 & 0.09721 \\
\hline 2 & 15 & 30 & Uphill & Fast & 47.9082 & 0.08727 & 0.07811 & 0.09691 & 0.07273 \\
\hline 2 & 16 & 30 & Uphill & Fast & 47.2088 & 0.08523 & 0.07809 & 0.15707 & 0.12467 \\
\hline 2 & 17 & 30 & Side & Slow & 71.3006 & 0.08621 & \begin{tabular}{|l|}
0.07968 \\
\end{tabular} & \begin{tabular}{|l|}
0.24871 \\
\end{tabular} & 0.10938 \\
\hline 2 & 18 & 30 & Side & Slow & 67.5492 & 0.08299 & 0.07666 & 0.21342 & 0.089 \\
\hline 2 & 19 & 30 & Side & Fast & 66.2309 & 0.08109 & 0.07931 & 0.25937 & 0.1093 \\
\hline 2 & 20 & 30 & Side & Fast & 68.378 & 0.0916 & 0.07774 & 0.20266 & 0.08974 \\
\hline 3 & 1 & 0 & Uphill & Slow & 66.4519 & 0.3075 & 0.33839 & 0.15374 & 0.14698 \\
\hline 3 & 2 & 0 & Uphill & Slow & \begin{tabular}{|l|}
67.2491 \\
\end{tabular} & 0.30602 & 0.3372 & \begin{tabular}{|l|}
0.15174 \\
\end{tabular} & 0.14653 \\
\hline 3 & 3 & 0 & Uphill & Fast & 69.7719 & 0.30539 & 0.33525 & 0.15146 & 0.14869 \\
\hline 3 & 4 & 0 & Uphill & Fast & 68.1967 & 0.30387 & 0.33524 & 0.15032 & 0.1453 \\
\hline 3 & 5 & 15 & Uphill & Slow & 60.6838 & 0.29979 & 0.33112 & 0.14722 & 0.14307 \\
\hline 3 & 6 & 15 & Uphill & Slow & \begin{tabular}{|l|}
57.0544 \\
\end{tabular} & \begin{tabular}{|l|}
0.29904 \\
\end{tabular} & \begin{tabular}{|l|}
0.33044 \\
\end{tabular} & \begin{tabular}{|l|}
0.14645 \\
\end{tabular} & 0.14215 \\
\hline 3 & 7 & 15 & Uphill & Fast & 57.3167 & 0.29896 & 0.33071 & 0.14806 & 0.14344 \\
\hline 3 & 8 & 15 & Uphill & Fast & 54.096 & 0.29802 & 0.32959 & 0.14604 & 0.14269 \\
\hline 3 & 9 & 15 & Side & Slow & 65.2977 & 0.29792 & 0.32712 & 0.14498 & 0.14029 \\
\hline 3 & 10 & 15 & Side & Slow & 62.9366 & 0.29606 & 0.32604 & 0.14448 & 0.13982 \\
\hline 3 & 11 & 15 & Side & Fast & 62.7898 & 0.30149 & 0.32907 & 0.16423 & 0.15529 \\
\hline 3 & 12 & 15 & Side & Fast & 63.9154 & 0.29749 & 0.32564 & 0.14763 & 0.1435 \\
\hline 3 & 13 & 30 & Uphill & Slow & 43.7205 & 0.29258 & 0.32345 & 0.1437 & 0.14154 \\
\hline 3 & 14 & 30 & Uphill & Slow & 43.8627 & 0.29124 & 0.32289 & 0.14171 & 0.14825 \\
\hline 3 & 15 & 30 & Uphill & Fast & 48.7404 & 0.29133 & 0.32277 & 0.14217 & 0.13798 \\
\hline 3 & 16 & 30 & Uphill & Fast & 45.8118 & 0.29202 & 0.32305 & 0.14166 & 0.13791 \\
\hline 3 & 17 & 30 & Side & Slow & 58.6115 & 0.28993 & 0.32085 & 0.14082 & 0.13706 \\
\hline 3 & 18 & 30 & Side & Slow & \begin{tabular}{|l|}
57.2655 \\
\end{tabular} & \begin{tabular}{|l|}
0.29202 \\
\end{tabular} & 0.32116 & \begin{tabular}{|l|}
0.14549 \\
\end{tabular} & 0.14123 \\
\hline 3 & 19 & 30 & Side & Fast & 59.6538 & 0.2892 & 0.32014 & 0.14052 & 0.13689 \\
\hline 3 & 20 & 30 & Side & Fast & 60.5769 & 0.29137 & 0.32015 & 0.14052 & 0.13639 \\
\hline 4 & 1 & 0 & Uphill & Slow & 76.28 & 0.10303 & 0.27592 & 0.17767 & 0.20017 \\
\hline 4 & 2 & 0 & Uphill & Slow & 76.753 & 0.10366 & 0.27173 & 0.18778 & 0.30702 \\
\hline 4 & 3 & 0 & Uphill & Fast & \begin{tabular}{|l|}
75.1153 \\
\end{tabular} & \begin{tabular}{|l|}
0.10393 \\
\end{tabular} & \begin{tabular}{|l|}
0.27046 \\
\end{tabular} & \begin{tabular}{|l|}
0.17324 \\
\end{tabular} & 0.30705 \\
\hline 4 & 4 & 0 & Uphill & Fast & 68.9795 & 0.09837 & 0.265 & 0.17586 & 0.17222 \\
\hline 4 & 5 & 15 & Uphill & Slow & 62.9858 & 0.0967 & 0.25755 & 0.16356 & 0.14757 \\
\hline 4 & 6 & 15 & Uphill & Slow & 63.8999 & 0.09902 & 0.25603 & 0.15918 & 0.13857 \\
\hline 4 & 7 & 15 & Uphill & Fast & 63.549 & 0.09524 & 0.25516 & 0.15874 & 0.15092 \\
\hline 4 & 8 & 15 & Uphill & Fast & 64.0593 & 0.0938 & \begin{tabular}{|l|}
0.25429 \\
\end{tabular} & \begin{tabular}{|l|}
0.15652 \\
\end{tabular} & 0.13909 \\
\hline 4 & 9 & 15 & Side & Slow & 71.5642 & 0.0992 & 0.2519 & \begin{tabular}{|l|}
0.15405 \\
\end{tabular} & 0.13317 \\
\hline 4 & 10 & 15 & Side & Slow & 70.3485 & 0.09502 & 0.25126 & 0.15483 & 0.13612 \\
\hline 4 & 11 & 15 & Side & Fast & 66.4571 & 0.09444 & 0.25271 & 0.16123 & 0.149 \\
\hline 4 & 12 & 15 & Side & Fast & 66.5151 & 0.0962 & 0.25289 & 0.17142 & 0.15423 \\
\hline
\end{tabular}




\begin{tabular}{|c|c|c|c|c|c|c|c|c|c|}
\hline 4 & 13 & 30 & Uphill & Slow & 51.479 & 0.09055 & 0.24782 & 0.16126 & 0.15747 \\
\hline 4 & 14 & 30 & Uphill & Slow & 52.6718 & 0.09077 & 0.24628 & 0.14877 & 0.12897 \\
\hline 4 & 15 & 30 & Uphill & Fast & 50.7548 & 0.09047 & 0.24605 & 0.1532 & 0.13623 \\
\hline 4 & 16 & 30 & Uphill & Fast & 48.9671 & 0.08886 & 0.24537 & 0.15447 & 0.15219 \\
\hline 4 & 17 & 30 & Side & Slow & 71.7307 & 0.09485 & 0.26142 & 0.17299 & 0.16217 \\
\hline 4 & 18 & 30 & Side & Slow & 72.1501 & 0.09315 & 0.24684 & 0.14993 & 0.14035 \\
\hline 4 & 19 & 30 & Side & Fast & 70.6639 & 0.09747 & 0.24469 & 0.14745 & 0.1331 \\
\hline 4 & 20 & 30 & Side & Fast & 66.743 & 0.09694 & 0.25441 & 0.17895 & 0.16387 \\
\hline 5 & 1 & 0 & Uphill & Slow & 58.9294 & 0.19406 & 0.20414 & 0.12546 & 0.06828 \\
\hline 5 & 2 & 0 & Uphill & Slow & 66.4327 & 0.198 & 0.20598 & 0.12512 & 0.0686 \\
\hline 5 & 3 & 0 & Uphill & Fast & 69.9702 & 0.22827 & 0.20872 & 0.12963 & 0.06984 \\
\hline 5 & 4 & 0 & Uphill & Fast & 67.5823 & 0.22726 & 0.20801 & 0.12878 & 0.07119 \\
\hline 5 & 5 & 15 & Uphill & Slow & 46.516 & 0.20031 & 0.20931 & 0.13063 & 0.07142 \\
\hline 5 & 6 & 15 & Uphill & Slow & 43.7075 & 0.20053 & 0.20908 & 0.12975 & 0.07102 \\
\hline 5 & 7 & 15 & Uphill & Fast & 45.1659 & 0.20939 & 0.20839 & 0.12995 & 0.07111 \\
\hline 5 & 8 & 15 & Uphill & Fast & 45.8712 & 0.21218 & 0.20865 & 0.13139 & 0.07115 \\
\hline 5 & 9 & 15 & Side & Slow & 60.4713 & 0.19962 & 0.20776 & 0.12825 & 0.07046 \\
\hline 5 & 10 & 15 & Side & Slow & 65.9534 & 0.20193 & 0.20768 & 0.12853 & 0.07026 \\
\hline 5 & 11 & 15 & Side & Fast & 61.1466 & 0.20259 & 0.20671 & 0.12834 & 0.07035 \\
\hline 5 & 12 & 15 & Side & Fast & 62.8639 & 0.2118 & 0.20727 & 0.1283 & 0.07012 \\
\hline 5 & 13 & 30 & Uphill & Slow & 49.0948 & 0.22983 & 0.2258 & 0.1479 & 0.08005 \\
\hline 5 & 14 & 30 & Uphill & Slow & 43.8529 & 0.21864 & 0.22416 & 0.1453 & 0.0786 \\
\hline 5 & 15 & 30 & Uphill & Fast & 45.4863 & 0.2195 & 0.22353 & 0.14473 & 0.07842 \\
\hline 5 & 16 & 30 & Uphill & Fast & 44.0711 & 0.21559 & 0.22296 & 0.14356 & 0.07825 \\
\hline 5 & 17 & 30 & Side & Slow & 66.1438 & 0.21332 & 0.22005 & 0.14191 & 0.07696 \\
\hline 5 & 18 & 30 & Side & Slow & 68.9926 & 0.21139 & 0.21897 & 0.1406 & 0.07636 \\
\hline 5 & 19 & 30 & Side & Fast & 63.288 & 0.21468 & 0.21879 & 0.14029 & 0.07622 \\
\hline 5 & 20 & 30 & Side & Fast & 62.7129 & 0.21398 & 0.21784 & 0.13975 & 0.07569 \\
\hline 6 & 1 & 0 & Uphill & Slow & 60.8017 & 0.36348 & 0.49053 & 0.31335 & 0.38133 \\
\hline 6 & 2 & 0 & Uphill & Slow & 60.8357 & 0.36278 & 0.48924 & 0.31158 & 0.38043 \\
\hline 6 & 3 & 0 & Uphill & Fast & 60.6464 & 0.36114 & 0.48712 & 0.3144 & 0.37938 \\
\hline 6 & 4 & 0 & Uphill & Fast & 61.6385 & 0.35955 & 0.48669 & 0.31218 & 0.3767 \\
\hline 6 & 5 & 15 & Uphill & Slow & 52.2205 & 0.34278 & 0.46109 & 0.30536 & 0.36352 \\
\hline 6 & 6 & 15 & Uphill & Slow & 50.7886 & 0.33754 & 0.45771 & 0.29139 & 0.35599 \\
\hline 6 & 7 & 15 & Uphill & Fast & 41.7886 & 0.33795 & 0.45626 & 0.30781 & 0.3615 \\
\hline 6 & 8 & 15 & Uphill & Fast & 45.7488 & 0.336 & 0.45573 & 0.297 & 0.3486 \\
\hline 6 & 9 & 15 & Side & Slow & 60.4758 & 0.33403 & 0.45364 & 0.28733 & 0.36027 \\
\hline 6 & 10 & 15 & Side & Slow & 60.3331 & 0.33264 & 0.45204 & 0.28761 & 0.36693 \\
\hline 6 & 11 & 15 & Side & Fast & 55.5317 & 0.33186 & 0.45083 & 0.28836 & 0.35125 \\
\hline
\end{tabular}




\begin{tabular}{|c|c|c|c|c|c|c|c|c|c|}
\hline 6 & 12 & 15 & Side & Fast & 55.402 & 0.33765 & 0.44976 & 0.31243 & 0.375 \\
\hline 6 & 13 & 30 & Uphill & Slow & 50.0347 & 0.33128 & 0.4451 & 0.30654 & 0.34303 \\
\hline 6 & 14 & 30 & Uphill & Slow & 45.6695 & 0.32762 & 0.44263 & 0.30648 & 0.35657 \\
\hline 6 & 15 & 30 & Uphill & Fast & 32.0615 & 0.3296 & 0.44158 & \begin{tabular}{|l|}
0.30984 \\
\end{tabular} & 0.3403 \\
\hline 6 & 16 & 30 & Uphill & Fast & 29.4275 & 0.32525 & 0.44157 & 0.28923 & 0.34747 \\
\hline 6 & 17 & 30 & Side & Slow & 46.3134 & 0.32389 & 0.43945 & 0.2927 & 0.35665 \\
\hline 6 & 18 & 30 & Side & Slow & 44.4034 & 0.32163 & 0.43814 & 0.28818 & 0.34746 \\
\hline 6 & 19 & 30 & Side & Fast & 46.9491 & 0.32176 & 0.4376 & 0.28916 & 0.35028 \\
\hline 6 & 20 & 30 & Side & Fast & 49.6187 & 0.32625 & \begin{tabular}{|l|}
0.43671 \\
\end{tabular} & \begin{tabular}{|l|}
0.29822 \\
\end{tabular} & 0.35419 \\
\hline 7 & 1 & 0 & Uphill & Slow & 92.7864 & 0.11272 & 0.11693 & 0.13236 & 0.11911 \\
\hline 7 & 2 & 0 & Uphill & Slow & 94.2338 & 0.11135 & 0.1238 & 0.13455 & 0.10984 \\
\hline 7 & 3 & 0 & Uphill & Fast & 92.1396 & 0.82211 & 0.64261 & 0.10484 & 0.06499 \\
\hline 7 & 4 & 0 & Uphill & Fast & 94.8238 & 0.71054 & 0.49445 & 0.10488 & 0.0642 \\
\hline 7 & 5 & 15 & Uphill & Slow & 84.5226 & 0.11193 & 0.11992 & 0.13365 & 0.10802 \\
\hline 7 & 6 & 15 & Uphill & Slow & 85.3022 & 0.11282 & 0.11461 & 0.13477 & 0.1091 \\
\hline 7 & 7 & 15 & Uphill & Fast & 83.7794 & 0.13188 & 0.12555 & 0.14494 & 0.10914 \\
\hline 7 & 8 & 15 & Uphill & Fast & 84.4354 & 0.11664 & 0.12463 & 0.13545 & 0.1107 \\
\hline 7 & 9 & 15 & Side & Slow & 92.0476 & 0.11122 & 0.12093 & 0.13325 & 0.10718 \\
\hline 7 & 10 & 15 & Side & Slow & 94.2177 & 0.10276 & 0.1125 & 0.13226 & 0.10674 \\
\hline 7 & 11 & 15 & Side & Fast & 91.6664 & 0.10212 & 0.11373 & 0.13238 & 0.10941 \\
\hline 7 & 12 & 15 & Side & Fast & 91.6664 & 0.10212 & 0.11373 & 0.13238 & 0.10941 \\
\hline 7 & 13 & 30 & Uphill & Slow & 69.7008 & 0.11474 & 0.13426 & 0.13206 & 0.10664 \\
\hline 7 & 14 & 30 & Uphill & Slow & 76.3196 & 0.10765 & 0.11671 & 0.13137 & 0.10639 \\
\hline 7 & 15 & 30 & Uphill & Fast & 71.4388 & 0.10254 & 0.11264 & 0.13122 & 0.1056 \\
\hline 7 & 16 & 30 & Uphill & Fast & 71.616 & \begin{tabular}{|l|}
0.10409 \\
\end{tabular} & 0.11665 & 0.1309 & 0.10599 \\
\hline 7 & 17 & 30 & Side & Slow & 92.6252 & 0.10278 & 0.11173 & 0.13115 & 0.10815 \\
\hline 7 & 18 & 30 & Side & Slow & 92.4904 & 0.10147 & 0.11548 & 0.13123 & 0.11699 \\
\hline 7 & 19 & 30 & Side & Fast & 93.5966 & 0.10764 & 0.11967 & 0.1331 & 0.1251 \\
\hline 7 & 20 & 30 & Side & Fast & 92.524 & 0.10351 & 0.11107 & 0.1341 & 0.12463 \\
\hline 8 & 1 & 0 & Uphill & Slow & 89.845 & 0.05405 & 0.05865 & 0.06412 & 0.06435 \\
\hline 8 & 2 & 0 & Uphill & Slow & 91.0925 & 0.05185 & 0.05641 & 0.06073 & 0.06135 \\
\hline 8 & 3 & 0 & Uphill & Fast & 87.1457 & 0.04871 & 0.0537 & 0.05691 & 0.05815 \\
\hline 8 & 4 & 0 & Uphill & Fast & 86.9677 & 0.04808 & 0.05253 & 0.05535 & 0.05677 \\
\hline 8 & 5 & 15 & Uphill & Slow & 78.0048 & 0.31387 & 0.537 & 0.04404 & 0.06067 \\
\hline 8 & 6 & 15 & Uphill & Slow & \begin{tabular}{|l|}
74.4209 \\
\end{tabular} & 0.04187 & 0.04648 & \begin{tabular}{|l|}
0.04579 \\
\end{tabular} & 0.04913 \\
\hline 8 & 7 & 15 & Uphill & Fast & \begin{tabular}{|l|}
75.1998 \\
\end{tabular} & \begin{tabular}{|l|}
0.04069 \\
\end{tabular} & 0.0456 & \begin{tabular}{|l|}
0.04492 \\
\end{tabular} & 0.04806 \\
\hline 8 & 8 & 15 & Uphill & Fast & 76.7265 & 0.04006 & 0.0449 & 0.04381 & 0.04731 \\
\hline 8 & 9 & 15 & Side & Slow & 91.8805 & 0.03932 & 0.04226 & 0.04067 & 0.04389 \\
\hline 8 & 10 & 15 & Side & Slow & 91.5441 & 0.03831 & 0.04154 & 0.03895 & 0.04278 \\
\hline
\end{tabular}




\begin{tabular}{|c|c|c|c|c|c|c|c|c|c|}
\hline 8 & 11 & 15 & Side & Fast & 91.0885 & 0.03879 & 0.0408 & 0.03793 & 0.04186 \\
\hline 8 & 12 & 15 & Side & Fast & 91.2596 & 0.03929 & 0.04038 & 0.03842 & 0.04145 \\
\hline 8 & 13 & 30 & Uphill & Slow & 66.8546 & 0.04021 & 0.03755 & 0.03563 & 0.03635 \\
\hline 8 & 14 & 30 & Uphill & Slow & 68.0612 & 0.03389 & 0.03625 & 0.03134 & 0.03527 \\
\hline 8 & 15 & 30 & Uphill & Fast & 64.6233 & 0.03567 & 0.03538 & 0.03225 & 0.03447 \\
\hline 8 & 16 & 30 & Uphill & Fast & 62.5131 & 0.0354 & 0.03499 & 0.03198 & 0.03377 \\
\hline 8 & 17 & 30 & Side & Slow & 89.4686 & 0.0447 & 0.03355 & 0.03546 & 0.03187 \\
\hline 8 & 18 & 30 & Side & Slow & 87.4945 & 0.04205 & 0.03261 & 0.0322 & 0.03095 \\
\hline 8 & 19 & 30 & Side & Fast & 86.9358 & 0.04065 & 0.03071 & 0.03555 & 0.02849 \\
\hline 8 & 20 & 30 & Side & Fast & 88.9155 & 0.03486 & 0.03034 & 0.03016 & 0.0277 \\
\hline 9 & 1 & 0 & Uphill & Slow & 93.8334 & 0.08659 & 0.14097 & 0.08283 & 0.09662 \\
\hline 9 & 2 & 0 & Uphill & Slow & 94.522 & 0.08587 & 0.1227 & 0.19291 & 0.09309 \\
\hline 9 & 3 & 0 & Uphill & Fast & 95.0177 & 0.07237 & 0.10944 & 0.07292 & 0.08898 \\
\hline 9 & 4 & 0 & Uphill & Fast & 94.4017 & 0.07719 & 0.1105 & 0.16329 & 0.08695 \\
\hline 9 & 5 & 15 & Uphill & Slow & 87.1203 & 0.07055 & 0.09689 & 0.13974 & 0.07514 \\
\hline 9 & 6 & 15 & Uphill & Slow & 91.2497 & 0.06101 & 0.09177 & 0.12463 & 0.06351 \\
\hline 9 & 7 & 15 & Uphill & Fast & 87.1363 & 0.0718 & 0.0941 & 0.17126 & 0.07594 \\
\hline 9 & 8 & 15 & Uphill & Fast & 86.2851 & 0.05733 & 0.08772 & 0.15556 & 0.05945 \\
\hline 9 & 9 & 15 & Side & Slow & 100.163 & 0.05704 & 0.09164 & 0.35494 & 0.07463 \\
\hline 9 & 10 & 15 & Side & Slow & 96.2571 & 0.05946 & 0.0866 & 0.1372 & 0.05979 \\
\hline 9 & 11 & 15 & Side & Fast & 96.5198 & 0.05892 & 0.09486 & 0.1371 & 0.07741 \\
\hline 9 & 12 & 15 & Side & Fast & 99.1793 & 0.05715 & 0.08583 & 0.12767 & 0.05945 \\
\hline 9 & 13 & 30 & Uphill & Slow & 76.1898 & 0.07942 & 0.08702 & 0.13057 & 0.08309 \\
\hline 9 & 14 & 30 & Uphill & Slow & 75.5204 & 0.05282 & 0.07523 & 0.17746 & 0.04907 \\
\hline 9 & 15 & 30 & Uphill & Fast & 73.6273 & 0.05357 & 0.08331 & 0.18992 & 0.04999 \\
\hline 9 & 16 & 30 & Uphill & Fast & 73.9116 & 0.05982 & 0.08795 & 0.20274 & 0.05129 \\
\hline 9 & 17 & 30 & Side & Slow & 99.1964 & 0.001 & 0.00155 & 0.0319 & 0.06365 \\
\hline 9 & 18 & 30 & Side & Slow & 99.5923 & 0.04882 & 0.07278 & 0.19268 & 0.04565 \\
\hline 9 & 19 & 30 & Side & Fast & 98.8366 & 0.05193 & 0.07794 & 0.23295 & 0.05998 \\
\hline 9 & 20 & 30 & Side & Fast & 100.904 & 0.0472 & 0.08323 & 0.22854 & 0.0529 \\
\hline 10 & 1 & 0 & Uphill & Slow & 74.019 & 0.13004 & 0.19541 & 0.11814 & 0.16148 \\
\hline 10 & 2 & 0 & Uphill & Slow & 71.8817 & 0.12521 & 0.17726 & 0.11505 & 0.12405 \\
\hline 10 & 3 & 0 & Uphill & Fast & 75.885 & 0.11327 & 0.16379 & 0.09554 & 0.10962 \\
\hline 10 & 4 & 0 & Uphill & Fast & 76.9389 & 0.11264 & 0.16311 & 0.09564 & 0.10905 \\
\hline 10 & 5 & 15 & Uphill & Slow & 57.4242 & 0.09861 & 0.14782 & 0.07789 & 0.09107 \\
\hline 10 & 6 & 15 & Uphill & Slow & 57.4069 & 0.09789 & 0.14737 & 0.07711 & 0.09416 \\
\hline 10 & 7 & 15 & Uphill & Fast & 61.9798 & 0.09863 & 0.14705 & 0.07686 & 0.12576 \\
\hline 10 & 8 & 15 & Uphill & Fast & 55.7313 & 0.09851 & 0.14673 & 0.07625 & 0.10392 \\
\hline 10 & 9 & 15 & Side & Slow & 71.5617 & 0.09604 & 0.14384 & 0.07379 & 0.08653 \\
\hline
\end{tabular}




\begin{tabular}{|c|c|c|c|c|c|c|c|c|c|}
\hline 10 & 10 & 15 & Side & Slow & 67.2295 & 0.096 & 0.14364 & 0.07331 & 0.08646 \\
\hline 10 & 11 & 15 & Side & Fast & 70.7439 & 0.09752 & 0.14362 & 0.07604 & 0.0872 \\
\hline 10 & 12 & 15 & Side & Fast & 70.3363 & 0.09495 & 0.1428 & 0.07262 & 0.0858 \\
\hline 10 & 13 & 30 & Uphill & Slow & 46.9547 & 0.09159 & 0.13885 & 0.06895 & 0.08152 \\
\hline 10 & 14 & 30 & Uphill & Slow & 48.3032 & 0.09106 & 0.13814 & 0.0677 & 0.08059 \\
\hline 10 & 15 & 30 & Uphill & Fast & 47.7797 & 0.09059 & 0.13775 & 0.06776 & 0.08018 \\
\hline 10 & 16 & 30 & Uphill & Fast & 45.2556 & 0.09025 & 0.13801 & 0.06734 & 0.07982 \\
\hline 10 & 17 & 30 & Side & Slow & 67.0608 & 0.08988 & 0.13734 & 0.06694 & 0.07938 \\
\hline 10 & 18 & 30 & Side & Slow & 65.1174 & 0.09029 & 0.13713 & 0.06554 & 0.07884 \\
\hline 10 & 19 & 30 & Side & Fast & 68.7709 & 0.09008 & 0.13723 & 0.06618 & 0.08759 \\
\hline 10 & 20 & 30 & Side & Fast & 65.4084 & 0.08924 & 0.13636 & 0.06498 & 0.07961 \\
\hline 11 & 1 & 0 & Uphill & Slow & 74.019 & 0.13004 & 0.19541 & 0.11814 & 0.16148 \\
\hline 11 & 2 & 0 & Uphill & Slow & 71.8817 & 0.12521 & 0.17726 & 0.11505 & 0.12405 \\
\hline 11 & 3 & 0 & Uphill & Fast & 75.885 & 0.11327 & 0.16379 & 0.09554 & 0.10962 \\
\hline 11 & 4 & 0 & Uphill & Fast & 76.9389 & 0.11264 & 0.16311 & 0.09564 & 0.10905 \\
\hline 11 & 5 & 15 & Uphill & Slow & 57.4242 & 0.09861 & 0.14782 & 0.07789 & 0.09107 \\
\hline 11 & 6 & 15 & Uphill & Slow & 57.4069 & 0.09789 & 0.14737 & 0.07711 & 0.09416 \\
\hline 11 & 7 & 15 & Uphill & Fast & 61.9798 & 0.09863 & 0.14705 & 0.07686 & 0.12576 \\
\hline 11 & 8 & 15 & Uphill & Fast & 55.7313 & 0.09851 & 0.14673 & 0.07625 & 0.10392 \\
\hline 11 & 9 & 15 & Side & Slow & 71.5617 & 0.09604 & 0.14384 & 0.07379 & 0.08653 \\
\hline 11 & 10 & 15 & Side & Slow & 67.2295 & 0.096 & 0.14364 & 0.07331 & 0.08646 \\
\hline 11 & 11 & 15 & Side & Fast & 70.7439 & 0.09752 & 0.14362 & 0.07604 & 0.0872 \\
\hline 11 & 12 & 15 & Side & Fast & 70.3363 & 0.09495 & 0.1428 & 0.07262 & 0.0858 \\
\hline 11 & 13 & 30 & Uphill & Slow & 46.9547 & 0.09159 & 0.13885 & 0.06895 & 0.08152 \\
\hline 11 & 14 & 30 & Uphill & Slow & 48.3032 & 0.09106 & 0.13814 & 0.0677 & 0.08059 \\
\hline 11 & 15 & 30 & Uphill & Fast & 47.7797 & 0.09059 & 0.13775 & 0.06776 & 0.08018 \\
\hline 11 & 16 & 30 & Uphill & Fast & 45.2556 & 0.09025 & 0.13801 & 0.06734 & 0.07982 \\
\hline 11 & 17 & 30 & Side & Slow & 67.0608 & 0.08988 & 0.13734 & 0.06694 & 0.07938 \\
\hline 11 & 18 & 30 & Side & Slow & 65.1174 & 0.09029 & 0.13713 & 0.06554 & 0.07884 \\
\hline 11 & 19 & 30 & Side & Fast & 68.7709 & 0.09008 & 0.13723 & 0.06618 & 0.08759 \\
\hline 11 & 20 & 30 & Side & Fast & 65.4084 & 0.08924 & 0.13636 & 0.06498 & 0.07961 \\
\hline 12 & 1 & 0 & Uphill & Slow & 72.9247 & 0.09045 & 0.09348 & 0.08687 & 0.07739 \\
\hline 12 & 2 & 0 & Uphill & Slow & 71.5025 & 0.09181 & 0.09256 & 0.09151 & 0.07587 \\
\hline 12 & 3 & 0 & Uphill & Fast & 73.1322 & 0.08953 & 0.09287 & 0.13662 & 0.07829 \\
\hline 12 & 4 & 0 & Uphill & Fast & 73.1607 & 0.09282 & 0.0921 & 0.11784 & 0.07528 \\
\hline 12 & 5 & 15 & Uphill & Slow & 61.0615 & 0.08226 & 0.08535 & 0.13651 & 0.09698 \\
\hline 12 & 6 & 15 & Uphill & Slow & 63.0663 & 0.08359 & 0.08502 & 0.11484 & 0.08275 \\
\hline 12 & 7 & 15 & Uphill & Fast & 62.9447 & 0.07852 & 0.08372 & 0.29884 & 0.14783 \\
\hline 12 & 8 & 15 & Uphill & Fast & 64 & 0.07924 & 0.08104 & 0.26269 & 0.16473 \\
\hline
\end{tabular}




\begin{tabular}{|c|c|c|c|c|c|c|c|c|c|}
\hline 12 & 9 & 15 & Side & Slow & 74.3976 & 0.08645 & 0.08268 & 0.2259 & 0.07922 \\
\hline 12 & 10 & 15 & Side & Slow & 74.5507 & 0.09352 & 0.08223 & 0.2358 & 0.0834 \\
\hline 12 & 11 & 15 & Side & Fast & 72.5554 & 0.08231 & 0.08171 & \begin{tabular}{|l|}
0.43879 \\
\end{tabular} & 0.13392 \\
\hline 12 & 12 & 15 & Side & Fast & 72.3181 & 0.07195 & 0.07873 & 0.2741 & 0.09549 \\
\hline 12 & 13 & 30 & Uphill & Slow & 48.8025 & 0.08918 & 0.0762 & 0.12911 & 0.09995 \\
\hline 12 & 14 & 30 & Uphill & Slow & 47.0155 & 0.08705 & 0.07803 & 0.10981 & 0.09721 \\
\hline 12 & 15 & 30 & Uphill & Fast & 47.9082 & 0.08727 & 0.07811 & 0.09691 & 0.07273 \\
\hline 12 & 16 & 30 & Uphill & Fast & 47.2088 & 0.08523 & 0.07809 & 0.15707 & 0.12467 \\
\hline 12 & 17 & 30 & Side & Slow & 71.3006 & 0.08621 & \begin{tabular}{|l|}
0.07968 \\
\end{tabular} & \begin{tabular}{|l|}
0.24871 \\
\end{tabular} & 0.10938 \\
\hline 12 & 18 & 30 & Side & Slow & 67.5492 & 0.08299 & 0.07666 & 0.21342 & 0.089 \\
\hline 12 & 19 & 30 & Side & Fast & 66.2309 & 0.08109 & 0.07931 & 0.25937 & 0.1093 \\
\hline 12 & 20 & 30 & Side & Fast & 68.378 & 0.0916 & 0.07774 & 0.20266 & 0.08974 \\
\hline 14 & 1 & 0 & Uphill & Slow & 74.019 & 0.13004 & 0.19541 & 0.11814 & 0.16148 \\
\hline 14 & 2 & 0 & Uphill & Slow & 71.8817 & 0.12521 & 0.17726 & 0.11505 & 0.12405 \\
\hline 14 & 3 & 0 & Uphill & Fast & 75.885 & 0.11327 & 0.16379 & 0.09554 & 0.10962 \\
\hline 14 & 4 & 0 & Uphill & Fast & 76.9389 & 0.11264 & 0.16311 & 0.09564 & 0.10905 \\
\hline 14 & 5 & 15 & Uphill & Slow & 57.4242 & 0.09861 & 0.14782 & 0.07789 & 0.09107 \\
\hline 14 & 6 & 15 & Uphill & Slow & 57.4069 & 0.09789 & 0.14737 & 0.07711 & 0.09416 \\
\hline 14 & 7 & 15 & Uphill & Fast & 61.9798 & 0.09863 & 0.14705 & 0.07686 & 0.12576 \\
\hline 14 & 8 & 15 & Uphill & Fast & 55.7313 & 0.09851 & 0.14673 & 0.07625 & 0.10392 \\
\hline 14 & 9 & 15 & Side & Slow & 71.5617 & 0.09604 & 0.14384 & 0.07379 & 0.08653 \\
\hline 14 & 10 & 15 & Side & Slow & 67.2295 & 0.096 & 0.14364 & 0.07331 & 0.08646 \\
\hline 14 & 11 & 15 & Side & Fast & \begin{tabular}{|l|}
70.7439 \\
\end{tabular} & \begin{tabular}{|l|}
0.09752 \\
\end{tabular} & 0.14362 & \begin{tabular}{|l|}
0.07604 \\
\end{tabular} & 0.0872 \\
\hline 14 & 12 & 15 & Side & Fast & 70.3363 & 0.09495 & 0.1428 & 0.07262 & 0.0858 \\
\hline 14 & 13 & 30 & Uphill & Slow & \begin{tabular}{|l}
46.9547 \\
\end{tabular} & \begin{tabular}{|l|}
0.09159 \\
\end{tabular} & 0.13885 & \begin{tabular}{|l|}
0.06895 \\
\end{tabular} & 0.08152 \\
\hline 14 & 14 & 30 & Uphill & Slow & 48.3032 & 0.09106 & 0.13814 & 0.0677 & 0.08059 \\
\hline 14 & 15 & 30 & Uphill & Fast & 47.7797 & 0.09059 & 0.13775 & 0.06776 & 0.08018 \\
\hline 14 & 16 & 30 & Uphill & Fast & 45.2556 & 0.09025 & 0.13801 & 0.06734 & 0.07982 \\
\hline 14 & 17 & 30 & Side & Slow & 67.0608 & 0.08988 & 0.13734 & 0.06694 & 0.07938 \\
\hline 14 & 18 & 30 & Side & Slow & 65.1174 & 0.09029 & 0.13713 & 0.06554 & 0.07884 \\
\hline 14 & 19 & 30 & Side & Fast & 68.7709 & 0.09008 & 0.13723 & 0.06618 & 0.08759 \\
\hline 14 & 20 & 30 & Side & Fast & 65.4084 & 0.08924 & 0.13636 & 0.06498 & 0.07961 \\
\hline 15 & 1 & 0 & Uphill & Slow & 72.9247 & 0.09045 & 0.09348 & 0.08687 & 0.07739 \\
\hline 15 & 2 & 0 & Uphill & Slow & 71.5025 & 0.09181 & 0.09256 & 0.09151 & 0.07587 \\
\hline 15 & 3 & 0 & Uphill & Fast & \begin{tabular}{|l|}
73.1322 \\
\end{tabular} & 0.08953 & 0.09287 & \begin{tabular}{|l|}
0.13662 \\
\end{tabular} & 0.07829 \\
\hline 15 & 4 & 0 & Uphill & Fast & 73.1607 & 0.09282 & 0.0921 & \begin{tabular}{|l|}
0.11784 \\
\end{tabular} & 0.07528 \\
\hline 15 & 5 & 15 & Uphill & Slow & 61.0615 & 0.08226 & 0.08535 & 0.13651 & 0.09698 \\
\hline 15 & 6 & 15 & Uphill & Slow & 63.0663 & 0.08359 & 0.08502 & 0.11484 & 0.08275 \\
\hline 15 & 7 & 15 & Uphill & Fast & 62.9447 & 0.07852 & 0.08372 & 0.29884 & 0.14783 \\
\hline
\end{tabular}




\begin{tabular}{|r|r|r|l|l|r|r|r|r|r|}
\hline 15 & 8 & 15 & Uphill & Fast & 64 & 0.07924 & 0.08104 & 0.26269 & 0.16473 \\
\hline 15 & 9 & 15 & Side & Slow & 74.3976 & 0.08645 & 0.08268 & 0.2259 & 0.07922 \\
\hline 15 & 10 & 15 & Side & Slow & 74.5507 & 0.09352 & 0.08223 & 0.2358 & 0.0834 \\
\hline 15 & 11 & 15 & Side & Fast & 72.5554 & 0.08231 & 0.08171 & 0.43879 & 0.13392 \\
\hline 15 & 12 & 15 & Side & Fast & 72.3181 & 0.07195 & 0.07873 & 0.2741 & 0.09549 \\
\hline 15 & 13 & 30 & Uphill & Slow & 48.8025 & 0.08918 & 0.0762 & 0.12911 & 0.09995 \\
\hline 15 & 14 & 30 & Uphill & Slow & 47.0155 & 0.08705 & 0.07803 & 0.10981 & 0.09721 \\
\hline 15 & 15 & 30 & Uphill & Fast & 47.9082 & 0.08727 & 0.07811 & 0.09691 & 0.07273 \\
\hline 15 & 16 & 30 & Uphill & Fast & 47.2088 & 0.08523 & 0.07809 & 0.15707 & 0.12467 \\
\hline 15 & 17 & 30 & Side & Slow & 71.3006 & 0.08621 & 0.07968 & 0.24871 & 0.10938 \\
\hline 15 & 18 & 30 & Side & Slow & 67.5492 & 0.08299 & 0.07666 & 0.21342 & 0.089 \\
\hline 15 & 19 & 30 & Side & Fast & 66.2309 & 0.08109 & 0.07931 & 0.25937 & 0.1093 \\
\hline 15 & 20 & 30 & Side & Fast & 68.378 & 0.0916 & 0.07774 & 0.20266 & 0.08974 \\
\hline
\end{tabular}


- Kneeling trials

\begin{tabular}{|c|c|c|c|c|c|c|c|c|c|}
\hline Subject & Number & $\begin{array}{l}\text { Tilt } \\
\text { angle }\end{array}$ & Direction & Frequency & Flexion & Esl & Esr & Mul & Mur \\
\hline 1 & 21 & 30 & Uphill & Slow & 22.3857 & 0.13004 & 0.19541 & 0.11814 & 0.16148 \\
\hline 1 & 22 & 30 & Uphill & Slow & 27.258 & 0.12521 & 0.17726 & 0.11505 & 0.12405 \\
\hline 1 & 23 & 30 & Uphill & Fast & 27.7391 & 0.11327 & 0.16379 & 0.09554 & 0.10962 \\
\hline 1 & 24 & 30 & Uphill & Fast & 26.4186 & 0.11264 & 0.16311 & 0.09564 & 0.10905 \\
\hline 1 & 25 & 15 & Uphill & Slow & 23.1277 & 0.09861 & 0.14782 & 0.07789 & 0.09107 \\
\hline 1 & 26 & 15 & Uphill & Slow & 27.1796 & 0.09789 & 0.14737 & 0.07711 & 0.09416 \\
\hline 1 & 27 & 15 & Uphill & Fast & 25.2745 & 0.09863 & 0.14705 & 0.07686 & 0.12576 \\
\hline 1 & 28 & 15 & Uphill & Fast & 27.4052 & 0.09851 & 0.14673 & 0.07625 & 0.10392 \\
\hline 1 & 29 & 0 & Uphill & Slow & 33.792 & 0.09604 & 0.14384 & 0.07379 & 0.08653 \\
\hline 1 & 30 & 0 & Uphill & Slow & 27.0399 & 0.096 & 0.14364 & 0.07331 & 0.08646 \\
\hline 1 & 31 & 0 & Uphill & Fast & 28.1782 & 0.09752 & 0.14362 & 0.07604 & 0.0872 \\
\hline 1 & 32 & 0 & Uphill & Fast & 27.5436 & 0.09495 & 0.1428 & 0.07262 & 0.0858 \\
\hline 2 & 21 & 30 & Uphill & Slow & 18.4513 & 0.08525 & 0.24007 & 0.1458 & 0.1345 \\
\hline 2 & 22 & 30 & Uphill & Slow & 18.2797 & 0.08489 & 0.23837 & 0.14276 & 0.1235 \\
\hline 2 & 23 & 30 & Uphill & Fast & 16.0599 & 0.08485 & 0.23782 & 0.14103 & 0.12383 \\
\hline 2 & 24 & 30 & Uphill & Fast & 17.1726 & 0.08493 & 0.23745 & 0.1435 & 0.124 \\
\hline 2 & 25 & 15 & Uphill & Slow & 12.7225 & 0.08215 & 0.23554 & 0.13942 & 0.13273 \\
\hline 2 & 26 & 15 & Uphill & Slow & 13.1847 & 0.08279 & 0.23644 & 0.13871 & 0.14389 \\
\hline 2 & 27 & 15 & Uphill & Fast & 12.0729 & 0.08387 & 0.23492 & 0.14004 & 0.13488 \\
\hline 2 & 28 & 15 & Uphill & Fast & 11.9017 & 0.08326 & 0.23513 & 0.13841 & 0.13743 \\
\hline 2 & 29 & 0 & Uphill & Slow & 26.7952 & 0.08745 & 0.23707 & 0.14941 & 0.1724 \\
\hline 2 & 30 & 0 & Uphill & Slow & 26.973 & 0.09121 & 0.23907 & 0.14934 & 0.18958 \\
\hline 2 & 31 & 0 & Uphill & Fast & 24.9121 & 0.08639 & 0.24013 & 0.14166 & 0.20258 \\
\hline 2 & 32 & 0 & Uphill & Fast & 26.4071 & 0.08527 & 0.23383 & 0.14581 & 0.17608 \\
\hline 3 & 21 & 30 & Uphill & Slow & 14.8601 & 0.21057 & 0.21434 & 0.13539 & 0.07473 \\
\hline 3 & 22 & 30 & Uphill & Slow & 14.8601 & 0.20737 & 0.21392 & 0.13509 & 0.07457 \\
\hline 3 & 23 & 30 & Uphill & Fast & 12.9374 & 0.21032 & 0.21397 & 0.13447 & 0.07453 \\
\hline 3 & 24 & 30 & Uphill & Fast & 12.034 & 0.21403 & 0.2134 & 0.13413 & 0.0815 \\
\hline 3 & 25 & 15 & Uphill & Slow & 19.0521 & 0.19491 & 0.20484 & 0.12528 & 0.06944 \\
\hline 3 & 26 & 15 & Uphill & Slow & 21.0823 & 0.19435 & 0.2044 & 0.12477 & 0.06867 \\
\hline 3 & 27 & 15 & Uphill & Fast & 20.0634 & 0.19377 & 0.20378 & 0.12484 & 0.07049 \\
\hline 3 & 28 & 15 & Uphill & Fast & 19.723 & 0.19437 & 0.20387 & 0.12483 & 0.06875 \\
\hline 3 & 29 & 0 & Uphill & Slow & 29.9237 & 0.19386 & 0.20315 & 0.12333 & 0.06757 \\
\hline 3 & 30 & 0 & Uphill & Slow & 29.9237 & 0.19294 & 0.20249 & 0.12387 & 0.06724 \\
\hline 3 & 31 & 0 & Uphill & Fast & 33.0644 & 0.19319 & 0.20253 & 0.12324 & 0.06712 \\
\hline 3 & 32 & 0 & Uphill & Fast & 33.0644 & 0.19316 & 0.20217 & 0.12315 & 0.06693 \\
\hline
\end{tabular}




\begin{tabular}{|c|c|c|c|c|c|c|c|c|c|}
\hline 4 & 21 & 30 & Uphill & Slow & 38.0473 & 0.07813 & 0.07577 & 0.15296 & 0.07521 \\
\hline 4 & 22 & 30 & Uphill & Slow & 38.6825 & 0.08326 & 0.06979 & 0.13161 & 0.06177 \\
\hline 4 & 23 & 30 & Uphill & Fast & 35.0386 & 0.08099 & 0.07041 & 0.12166 & 0.08433 \\
\hline 4 & 24 & 30 & Uphill & Fast & 37.6111 & 0.08938 & 0.07137 & 0.11401 & 0.08483 \\
\hline 4 & 25 & 15 & Uphill & Slow & 47.7891 & 0.06699 & 0.06393 & 0.08533 & 0.04875 \\
\hline 4 & 26 & 15 & Uphill & Slow & 43.7004 & 0.06748 & 0.06458 & 0.08022 & 0.061 \\
\hline 4 & 27 & 15 & Uphill & Fast & 43.2067 & 0.07949 & 0.06649 & 0.08071 & 0.06899 \\
\hline 4 & 28 & 15 & Uphill & Fast & 39.2914 & 0.08078 & 0.0672 & 0.09038 & 0.06906 \\
\hline 4 & 29 & 0 & Uphill & Slow & 68.8994 & 0.03387 & 0.05666 & 0.03846 & 0.02765 \\
\hline 4 & 30 & 0 & Uphill & Slow & 66.3993 & 0.0345 & 0.05667 & 0.03646 & 0.02676 \\
\hline 4 & 31 & 0 & Uphill & Fast & 61.5049 & 0.04061 & 0.05653 & 0.05816 & 0.02954 \\
\hline 4 & 32 & 0 & Uphill & Fast & 61.5214 & 0.04079 & 0.05576 & 0.06849 & 0.02972 \\
\hline 5 & 21 & 30 & Uphill & Slow & 22.3857 & 0.13004 & 0.19541 & 0.11814 & 0.16148 \\
\hline 5 & 22 & 30 & Uphill & Slow & 27.258 & 0.12521 & 0.17726 & 0.11505 & 0.12405 \\
\hline 5 & 23 & 30 & Uphill & Fast & 27.7391 & 0.11327 & 0.16379 & 0.09554 & 0.10962 \\
\hline 5 & 24 & 30 & Uphill & Fast & 26.4186 & 0.11264 & 0.16311 & 0.09564 & 0.10905 \\
\hline 5 & 25 & 15 & Uphill & Slow & 23.1277 & 0.09861 & 0.14782 & 0.07789 & 0.09107 \\
\hline 5 & 26 & 15 & Uphill & Slow & 27.1796 & 0.09789 & 0.14737 & 0.07711 & 0.09416 \\
\hline 5 & 27 & 15 & Uphill & Fast & 25.2745 & 0.09863 & 0.14705 & 0.07686 & 0.12576 \\
\hline 5 & 28 & 15 & Uphill & Fast & 27.4052 & 0.09851 & 0.14673 & 0.07625 & 0.10392 \\
\hline 5 & 29 & 0 & Uphill & Slow & 33.792 & 0.09604 & 0.14384 & 0.07379 & 0.08653 \\
\hline 5 & 30 & 0 & Uphill & Slow & 27.0399 & 0.096 & 0.14364 & 0.07331 & 0.08646 \\
\hline 5 & 31 & 0 & Uphill & Fast & 28.1782 & 0.09752 & 0.14362 & 0.07604 & 0.0872 \\
\hline 5 & 32 & 0 & Uphill & Fast & 27.5436 & 0.09495 & 0.1428 & 0.07262 & 0.0858 \\
\hline 6 & 21 & 30 & Uphill & Slow & 18.4513 & 0.08525 & 0.24007 & 0.1458 & 0.1345 \\
\hline 6 & 22 & 30 & Uphill & Slow & 18.2797 & 0.08489 & 0.23837 & 0.14276 & 0.1235 \\
\hline 6 & 23 & 30 & Uphill & Fast & 16.0599 & 0.08485 & 0.23782 & 0.14103 & 0.12383 \\
\hline 6 & 24 & 30 & Uphill & Fast & 17.1726 & 0.08493 & 0.23745 & 0.1435 & 0.124 \\
\hline 6 & 25 & 15 & Uphill & Slow & 12.7225 & 0.08215 & 0.23554 & 0.13942 & 0.13273 \\
\hline 6 & 26 & 15 & Uphill & Slow & 13.1847 & 0.08279 & 0.23644 & 0.13871 & 0.14389 \\
\hline 6 & 27 & 15 & Uphill & Fast & 12.0729 & 0.08387 & 0.23492 & 0.14004 & 0.13488 \\
\hline 6 & 28 & 15 & Uphill & Fast & 11.9017 & 0.08326 & 0.23513 & 0.13841 & 0.13743 \\
\hline 6 & 29 & 0 & Uphill & Slow & 26.7952 & 0.08745 & 0.23707 & 0.14941 & 0.1724 \\
\hline 6 & 30 & 0 & Uphill & Slow & 26.973 & 0.09121 & 0.23907 & 0.14934 & 0.18958 \\
\hline 6 & 31 & 0 & Uphill & Fast & 24.9121 & 0.08639 & 0.24013 & 0.14166 & 0.20258 \\
\hline 6 & 32 & 0 & Uphill & Fast & 26.4071 & 0.08527 & 0.23383 & 0.14581 & 0.17608 \\
\hline 6 & 21 & 30 & Uphill & Slow & 14.8601 & 0.21057 & 0.21434 & 0.13539 & 0.07473 \\
\hline 6 & 22 & 30 & Uphill & Slow & 14.8601 & 0.20737 & 0.21392 & 0.13509 & 0.07457 \\
\hline 6 & 23 & 30 & Uphill & Fast & 12.9374 & 0.21032 & 0.21397 & 0.13447 & 0.07453 \\
\hline
\end{tabular}




\begin{tabular}{|c|c|c|c|c|c|c|c|c|c|}
\hline 6 & 24 & 30 & Uphill & Fast & 12.034 & 0.21403 & 0.2134 & 0.13413 & 0.0815 \\
\hline 6 & 25 & 15 & Uphill & Slow & 19.0521 & 0.19491 & 0.20484 & 0.12528 & 0.06944 \\
\hline 6 & 26 & 15 & Uphill & Slow & 21.0823 & 0.19435 & 0.2044 & 0.12477 & 0.06867 \\
\hline 6 & 27 & 15 & Uphill & Fast & 20.0634 & 0.19377 & 0.20378 & 0.12484 & 0.07049 \\
\hline 6 & 28 & 15 & Uphill & Fast & 19.723 & 0.19437 & 0.20387 & 0.12483 & 0.06875 \\
\hline 6 & 29 & 0 & Uphill & Slow & 29.9237 & 0.19386 & 0.20315 & 0.12333 & 0.06757 \\
\hline 6 & 30 & 0 & Uphill & Slow & 29.9237 & 0.19294 & 0.20249 & 0.12387 & 0.06724 \\
\hline 6 & 31 & 0 & Uphill & Fast & 33.0644 & 0.19319 & 0.20253 & 0.12324 & 0.06712 \\
\hline 6 & 32 & 0 & Uphill & Fast & 33.0644 & 0.19316 & 0.20217 & 0.12315 & 0.06693 \\
\hline 8 & 21 & 30 & Uphill & Slow & 38.0473 & 0.07813 & 0.07577 & 0.15296 & 0.07521 \\
\hline 8 & 22 & 30 & Uphill & Slow & 38.6825 & 0.08326 & 0.06979 & 0.13161 & 0.06177 \\
\hline 8 & 23 & 30 & Uphill & Fast & 35.0386 & 0.08099 & 0.07041 & 0.12166 & 0.08433 \\
\hline 8 & 24 & 30 & Uphill & Fast & 37.6111 & 0.08938 & 0.07137 & 0.11401 & 0.08483 \\
\hline 8 & 25 & 15 & Uphill & Slow & 47.7891 & 0.06699 & 0.06393 & 0.08533 & 0.04875 \\
\hline 8 & 26 & 15 & Uphill & Slow & 43.7004 & 0.06748 & 0.06458 & 0.08022 & 0.061 \\
\hline 8 & 27 & 15 & Uphill & Fast & 43.2067 & 0.07949 & 0.06649 & 0.08071 & 0.06899 \\
\hline 8 & 28 & 15 & Uphill & Fast & 39.2914 & 0.08078 & 0.0672 & 0.09038 & 0.06906 \\
\hline 8 & 29 & 0 & Uphill & Slow & 68.8994 & 0.03387 & 0.05666 & 0.03846 & 0.02765 \\
\hline 8 & 30 & 0 & Uphill & Slow & 66.3993 & 0.0345 & 0.05667 & 0.03646 & 0.02676 \\
\hline 8 & 31 & 0 & Uphill & Fast & 61.5049 & 0.04061 & 0.05653 & 0.05816 & 0.02954 \\
\hline 8 & 32 & 0 & Uphill & Fast & 61.5214 & 0.04079 & 0.05576 & 0.06849 & 0.02972 \\
\hline 9 & 21 & 30 & Uphill & Slow & 22.3857 & 0.13004 & 0.19541 & 0.11814 & 0.16148 \\
\hline 9 & 22 & 30 & Uphill & Slow & 27.258 & 0.12521 & 0.17726 & 0.11505 & 0.12405 \\
\hline 9 & 23 & 30 & Uphill & Fast & 27.7391 & 0.11327 & 0.16379 & 0.09554 & 0.10962 \\
\hline 9 & 24 & 30 & Uphill & Fast & 26.4186 & 0.11264 & 0.16311 & 0.09564 & 0.10905 \\
\hline 9 & 25 & 15 & Uphill & Slow & 23.1277 & 0.09861 & 0.14782 & 0.07789 & 0.09107 \\
\hline 9 & 26 & 15 & Uphill & Slow & 27.1796 & 0.09789 & 0.14737 & 0.07711 & 0.09416 \\
\hline 9 & 27 & 15 & Uphill & Fast & 25.2745 & 0.09863 & 0.14705 & 0.07686 & 0.12576 \\
\hline 9 & 28 & 15 & Uphill & Fast & 27.4052 & 0.09851 & 0.14673 & 0.07625 & 0.10392 \\
\hline 9 & 29 & 0 & Uphill & Slow & 33.792 & 0.09604 & 0.14384 & 0.07379 & 0.08653 \\
\hline 9 & 30 & 0 & Uphill & Slow & 27.0399 & 0.096 & 0.14364 & 0.07331 & 0.08646 \\
\hline 9 & 31 & 0 & Uphill & Fast & 28.1782 & 0.09752 & 0.14362 & 0.07604 & 0.0872 \\
\hline 9 & 32 & 0 & Uphill & Fast & 27.5436 & 0.09495 & 0.1428 & 0.07262 & 0.0858 \\
\hline 10 & 21 & 30 & Uphill & Slow & 18.4513 & 0.08525 & 0.24007 & 0.1458 & 0.1345 \\
\hline 10 & 22 & 30 & Uphill & Slow & 18.2797 & 0.08489 & 0.23837 & 0.14276 & 0.1235 \\
\hline 10 & 23 & 30 & Uphill & Fast & 16.0599 & 0.08485 & 0.23782 & 0.14103 & 0.12383 \\
\hline 10 & 24 & 30 & Uphill & Fast & 17.1726 & 0.08493 & 0.23745 & 0.1435 & 0.124 \\
\hline 10 & 25 & 15 & Uphill & Slow & 12.7225 & 0.08215 & 0.23554 & 0.13942 & 0.13273 \\
\hline 10 & 26 & 15 & Uphill & Slow & 13.1847 & 0.08279 & 0.23644 & 0.13871 & 0.14389 \\
\hline
\end{tabular}




\begin{tabular}{|c|c|c|c|c|c|c|c|c|c|}
\hline 10 & 27 & 15 & Uphill & Fast & 12.0729 & 0.08387 & 0.23492 & 0.14004 & 0.13488 \\
\hline 10 & 28 & 15 & Uphill & Fast & 11.9017 & 0.08326 & 0.23513 & 0.13841 & 0.13743 \\
\hline 10 & 29 & 0 & Uphill & Slow & 26.7952 & 0.08745 & 0.23707 & 0.14941 & 0.1724 \\
\hline 10 & 30 & 0 & Uphill & Slow & 26.973 & 0.09121 & 0.23907 & 0.14934 & 0.18958 \\
\hline 10 & 31 & 0 & Uphill & Fast & 24.9121 & 0.08639 & 0.24013 & 0.14166 & 0.20258 \\
\hline 10 & 32 & 0 & Uphill & Fast & 26.4071 & 0.08527 & 0.23383 & 0.14581 & 0.17608 \\
\hline 11 & 21 & 30 & Uphill & Slow & 14.8601 & 0.21057 & 0.21434 & 0.13539 & 0.07473 \\
\hline 11 & 22 & 30 & Uphill & Slow & 14.8601 & 0.20737 & 0.21392 & 0.13509 & 0.07457 \\
\hline 11 & 23 & 30 & Uphill & Fast & 12.9374 & 0.21032 & 0.21397 & 0.13447 & 0.07453 \\
\hline 11 & 24 & 30 & Uphill & Fast & 12.034 & 0.21403 & 0.2134 & 0.13413 & 0.0815 \\
\hline 11 & 25 & 15 & Uphill & Slow & 19.0521 & 0.19491 & 0.20484 & 0.12528 & 0.06944 \\
\hline 11 & 26 & 15 & Uphill & Slow & 21.0823 & 0.19435 & 0.2044 & 0.12477 & 0.06867 \\
\hline 11 & 27 & 15 & Uphill & Fast & 20.0634 & 0.19377 & 0.20378 & 0.12484 & 0.07049 \\
\hline 11 & 28 & 15 & Uphill & Fast & 19.723 & 0.19437 & 0.20387 & 0.12483 & 0.06875 \\
\hline 11 & 29 & 0 & Uphill & Slow & 29.9237 & 0.19386 & 0.20315 & 0.12333 & 0.06757 \\
\hline 11 & 30 & 0 & Uphill & Slow & 29.9237 & 0.19294 & 0.20249 & 0.12387 & 0.06724 \\
\hline 11 & 31 & 0 & Uphill & Fast & 33.0644 & 0.19319 & 0.20253 & 0.12324 & 0.06712 \\
\hline 11 & 32 & 0 & Uphill & Fast & 33.0644 & 0.19316 & 0.20217 & 0.12315 & 0.06693 \\
\hline 12 & 21 & 30 & Uphill & Slow & 38.0473 & 0.07813 & 0.07577 & 0.15296 & 0.07521 \\
\hline 12 & 22 & 30 & Uphill & Slow & 38.6825 & 0.08326 & 0.06979 & 0.13161 & 0.06177 \\
\hline 12 & 23 & 30 & Uphill & Fast & 35.0386 & 0.08099 & 0.07041 & 0.12166 & 0.08433 \\
\hline 12 & 24 & 30 & Uphill & Fast & 37.6111 & 0.08938 & 0.07137 & 0.11401 & 0.08483 \\
\hline 12 & 25 & 15 & Uphill & Slow & 47.7891 & 0.06699 & 0.06393 & 0.08533 & 0.04875 \\
\hline 12 & 26 & 15 & Uphill & Slow & 43.7004 & 0.06748 & 0.06458 & 0.08022 & 0.061 \\
\hline 12 & 27 & 15 & Uphill & Fast & 43.2067 & 0.07949 & 0.06649 & 0.08071 & 0.06899 \\
\hline 12 & 28 & 15 & Uphill & Fast & 39.2914 & 0.08078 & 0.0672 & 0.09038 & 0.06906 \\
\hline 12 & 29 & 0 & Uphill & Slow & 68.8994 & 0.03387 & 0.05666 & 0.03846 & 0.02765 \\
\hline 12 & 30 & 0 & Uphill & Slow & 66.3993 & 0.0345 & 0.05667 & 0.03646 & 0.02676 \\
\hline 12 & 31 & 0 & Uphill & Fast & 61.5049 & 0.04061 & 0.05653 & 0.05816 & 0.02954 \\
\hline 12 & 32 & 0 & Uphill & Fast & 61.5214 & 0.04079 & 0.05576 & 0.06849 & 0.02972 \\
\hline 13 & 21 & 30 & Uphill & Slow & 22.3857 & 0.13004 & 0.19541 & 0.11814 & 0.16148 \\
\hline 13 & 22 & 30 & Uphill & Slow & 27.258 & 0.12521 & 0.17726 & 0.11505 & 0.12405 \\
\hline 13 & 23 & 30 & Uphill & Fast & 27.7391 & 0.11327 & 0.16379 & 0.09554 & 0.10962 \\
\hline 13 & 24 & 30 & Uphill & Fast & 26.4186 & 0.11264 & 0.16311 & 0.09564 & 0.10905 \\
\hline 13 & 25 & 15 & Uphill & Slow & 23.1277 & 0.09861 & 0.14782 & 0.07789 & 0.09107 \\
\hline 13 & 26 & 15 & Uphill & Slow & 27.1796 & 0.09789 & 0.14737 & 0.07711 & 0.09416 \\
\hline 13 & 27 & 15 & Uphill & Fast & 25.2745 & 0.09863 & 0.14705 & 0.07686 & 0.12576 \\
\hline 13 & 28 & 15 & Uphill & Fast & 27.4052 & 0.09851 & 0.14673 & 0.07625 & 0.10392 \\
\hline 13 & 29 & 0 & Uphill & Slow & 33.792 & 0.09604 & 0.14384 & 0.07379 & 0.08653 \\
\hline
\end{tabular}




\begin{tabular}{|c|c|c|c|c|c|c|c|c|c|}
\hline 13 & 30 & 0 & Uphill & Slow & 27.0399 & 0.096 & 0.14364 & 0.07331 & 0.08646 \\
\hline 13 & 31 & 0 & Uphill & Fast & 28.1782 & 0.09752 & 0.14362 & 0.07604 & 0.0872 \\
\hline 13 & 32 & 0 & Uphill & Fast & 27.5436 & 0.09495 & 0.1428 & 0.07262 & 0.0858 \\
\hline 14 & 21 & 30 & Uphill & Slow & 18.4513 & 0.08525 & 0.24007 & 0.1458 & 0.1345 \\
\hline 14 & 22 & 30 & Uphill & Slow & 18.2797 & 0.08489 & 0.23837 & 0.14276 & 0.1235 \\
\hline 14 & 23 & 30 & Uphill & Fast & 16.0599 & 0.08485 & 0.23782 & 0.14103 & 0.12383 \\
\hline 14 & 24 & 30 & Uphill & Fast & 17.1726 & 0.08493 & 0.23745 & 0.1435 & 0.124 \\
\hline 14 & 25 & 15 & Uphill & Slow & 12.7225 & 0.08215 & 0.23554 & 0.13942 & 0.13273 \\
\hline 14 & 26 & 15 & Uphill & Slow & 13.1847 & 0.08279 & 0.23644 & 0.13871 & 0.14389 \\
\hline 14 & 27 & 15 & Uphill & Fast & 12.0729 & 0.08387 & 0.23492 & 0.14004 & 0.13488 \\
\hline 14 & 28 & 15 & Uphill & Fast & 11.9017 & 0.08326 & 0.23513 & 0.13841 & 0.13743 \\
\hline 14 & 29 & 0 & Uphill & Slow & 26.7952 & 0.08745 & 0.23707 & 0.14941 & 0.1724 \\
\hline 14 & 30 & 0 & Uphill & Slow & 26.973 & 0.09121 & 0.23907 & 0.14934 & 0.18958 \\
\hline 14 & 31 & 0 & Uphill & Fast & 24.9121 & 0.08639 & 0.24013 & 0.14166 & 0.20258 \\
\hline 14 & 32 & 0 & Uphill & Fast & 26.4071 & 0.08527 & 0.23383 & 0.14581 & 0.17608 \\
\hline 15 & 21 & 30 & Uphill & Slow & 14.8601 & 0.21057 & 0.21434 & 0.13539 & 0.07473 \\
\hline 15 & 22 & 30 & Uphill & Slow & 14.8601 & 0.20737 & 0.21392 & 0.13509 & 0.07457 \\
\hline 15 & 23 & 30 & Uphill & Fast & 12.9374 & 0.21032 & 0.21397 & 0.13447 & 0.07453 \\
\hline 15 & 24 & 30 & Uphill & Fast & 12.034 & 0.21403 & 0.2134 & 0.13413 & 0.0815 \\
\hline 15 & 25 & 15 & Uphill & Slow & 19.0521 & 0.19491 & 0.20484 & 0.12528 & 0.06944 \\
\hline 15 & 26 & 15 & Uphill & Slow & 21.0823 & 0.19435 & 0.2044 & 0.12477 & 0.06867 \\
\hline 15 & 27 & 15 & Uphill & Fast & 20.0634 & 0.19377 & 0.20378 & 0.12484 & 0.07049 \\
\hline 15 & 28 & 15 & Uphill & Fast & 19.723 & 0.19437 & 0.20387 & 0.12483 & 0.06875 \\
\hline 15 & 29 & 0 & Uphill & Slow & 29.9237 & 0.19386 & 0.20315 & 0.12333 & 0.06757 \\
\hline 15 & 30 & 0 & Uphill & Slow & 29.9237 & 0.19294 & 0.20249 & 0.12387 & 0.06724 \\
\hline 15 & 31 & 0 & Uphill & Fast & 33.0644 & 0.19319 & 0.20253 & 0.12324 & 0.06712 \\
\hline 15 & 32 & 0 & Uphill & Fast & 33.0644 & 0.19316 & 0.20217 & 0.12315 & 0.06693 \\
\hline
\end{tabular}

